\title{
Control of Degradation of Spent LWR Fuel During Dry Storage in an Inert Atmosphere
}

October 1987

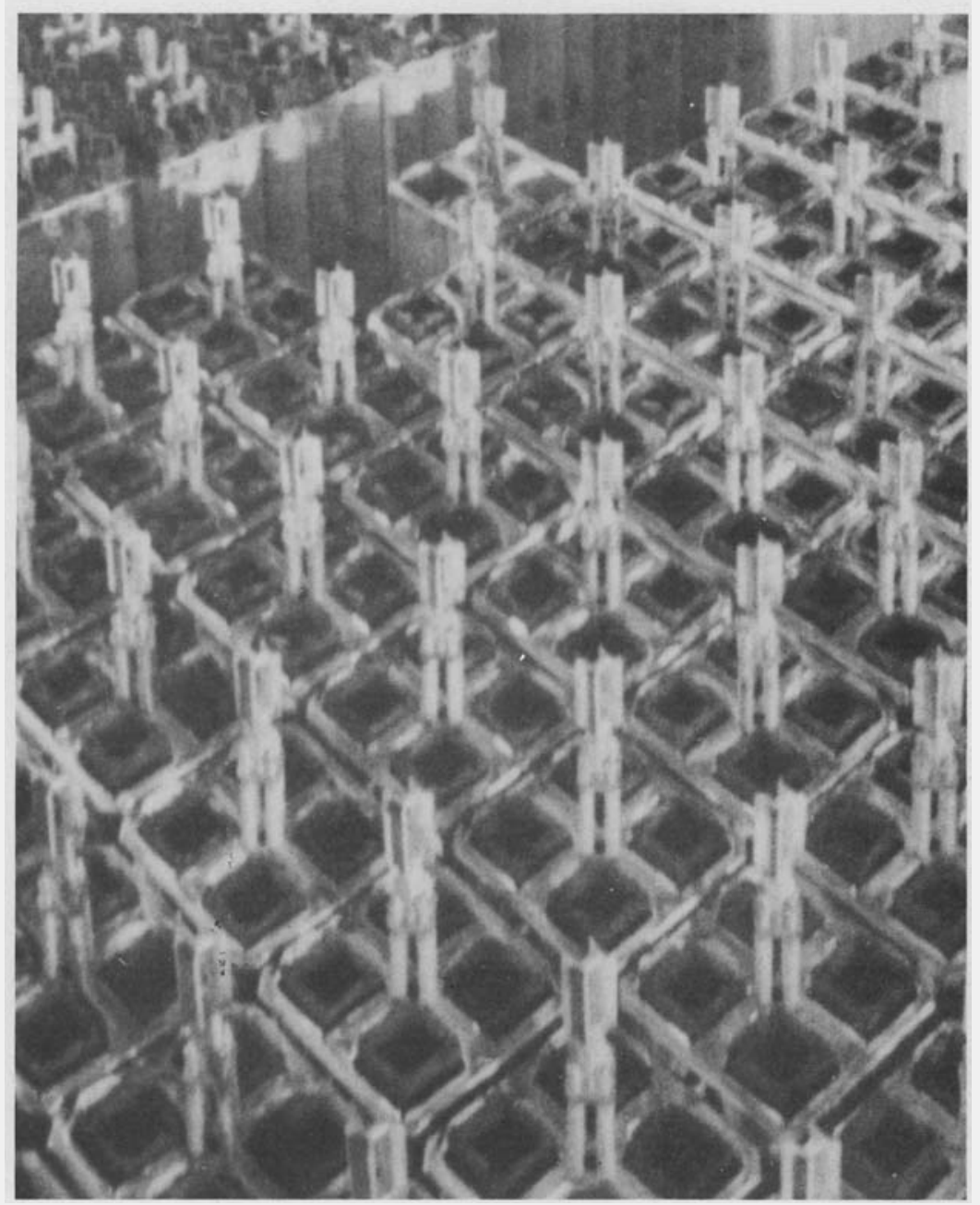

Prepared for the U.S. Department of Energy under Contract DE-AC06-76RLO 1830

Pacific Northwest Laboratory Operated for the U.S. Department of Energy by Battelle Memorial Institute 


\section{DISCLAIMER}

This report was prepared as an account of work sponsored by an agency of the United States Government. Neither the United States Government nor any agency thereof, nor Battelle Memorial Institute, nor any of their employees, makes any warranty, expressed or implied, or assumes any legal liability or responsibility for the accuracy, completeness, or usefulness of any information, apparatus, product, or process disclosed, or represents that its use would not infringe privately owned rights. Reference herein to any specific commercial product, process, or serviceby trade name, trademark, manufacturer, or otherwise, does not necessarily constitute or imply its endorsement, recommendation, or favoring by the United States Government of any agency thereof, or Battelle Memorial Institute. The views and opinions of authors expressed herein do not necessarlystate or reflect those of the United States Governmentor any agency thereof, or Battelle Memorial Institute.

\section{PACIFIC NORTHWEST LABORATORY operated by \\ BATTELLEMEMORIAL INSTITUTE \\ for the \\ UNITED STATES DEPARTMENT OF ENERGY \\ under Contract DE-AC06-76RLO 1830}

\begin{tabular}{|c|c|}
\hline \multicolumn{2}{|c|}{$\begin{array}{l}\text { Printed in the United States of America } \\
\text { Available from } \\
\text { National Technical Information Service } \\
\text { United States Department of Commerce } \\
5285 \text { Port Royal Road } \\
\text { Springfield, Virginia } 22161\end{array}$} \\
\hline \multicolumn{2}{|c|}{$\begin{array}{l}\text { NTIS Price Codes } \\
\text { Microfiche A01 }\end{array}$} \\
\hline \multicolumn{2}{|c|}{ Printed Copy } \\
\hline Pages & $\begin{array}{l}\text { Price } \\
\text { Codes }\end{array}$ \\
\hline $001-025$ & $\mathrm{~A} 02$ \\
\hline $026-050$ & $\mathrm{~A} 03$ \\
\hline $051-075$ & $\mathrm{~A} 04$ \\
\hline $076-100$ & A05 \\
\hline $101-125$ & A06 \\
\hline $126-150$ & $\mathrm{~A} 07$ \\
\hline $151-175$ & $\mathrm{~A} 08$ \\
\hline $176-200$ & A09 \\
\hline $201-225$ & $\mathrm{~A} 010$ \\
\hline $226-250$ & $\mathrm{~A} 011$ \\
\hline $251-275$ & $\mathrm{~A} 012$ \\
\hline $276-300$ & $\mathrm{~A} 013$ \\
\hline
\end{tabular}


CONTROL OF DEGRADATION OF SPENT IWR FUEL DURING DRY STORAGE IN AN INERT ATMOSPHERE

\author{
M. E. Cunningham \\ E. P. Simonen \\ R. T. Allemann \\ I. S. Levy \\ R. F. Hazelton \\ E. R. Gilbert, Project Manager
}

October 1987

Prepared for the U.S. Department of Energy under Contract DE-AC06-76RLO 1830

Pacific Northwest Laboratory Richland, Washington 99352 


\section{SUMARY}

Dry storage of Zircaloy-clad spent fuel in inert gas (referred to as inerted dry storage or IDS) is being developed as an alternative to water pool storage of spent fuel. Regulatory requirements state that during IDS the Zircaloy cladding needs to be protected against degradation and gross rupture; i.e., the irradiated $\mathrm{UO}_{2}$ is to remain confined to prevent significant releases of radioactive materials that could cause safety and handling difficulties.

The Commercial Spent Fuel Management Program at Pacific Northwest Laboratory has performed work in support of establishing acceptable conditions for IDS. The objectives of the activities described in this report are to identify potential Zircaloy degradation mechanisms and evaluate their applicability to cladding breach during IDS, develop models of the dominant Zircaloy degradation mechanisms, and recommend cladding temperature limits during IDS to control Zircaloy degradation.

The principal potential Zircaloy cladding breach mechanisms during IDS have been identified as creep rupture, stress corrosion cracking (SCC), and delayed hydride cracking (DHC). Creep rupture is concluded to be the primary cladding breach mechanism during IDS. Cladding breach due to $S O C$ and DHC is not expected because the threshold stress intensity levels for these mechanisms are greater than those expected for spent fuel.

Deformation and fracture maps based on creep rupture were developed for Zircaloy. These maps were then used as the basis for developing spent fuel cladding temperature limits that would prevent cladding breach during a 40-year IDS period. The probability of cladding breach for spent fuel stored at the temperature limit is less than $0.5 \%$ per spent fuel rod. 


\section{ACKNOWFDGMENTS}

This work was supported by the U.S. Department of Energy (DOE) Office of Civilian Radioactive Waste Management through the Commercial Spent Fuel Management Division of the DOE Richland Operations Office. The project was managed by the PNL Commercial Spent Fuel Management Program. Special recognition is given to G E Lucas and J. A Nevshemal for peer reviews and to $S$. $K$ Edler for technical editing. 


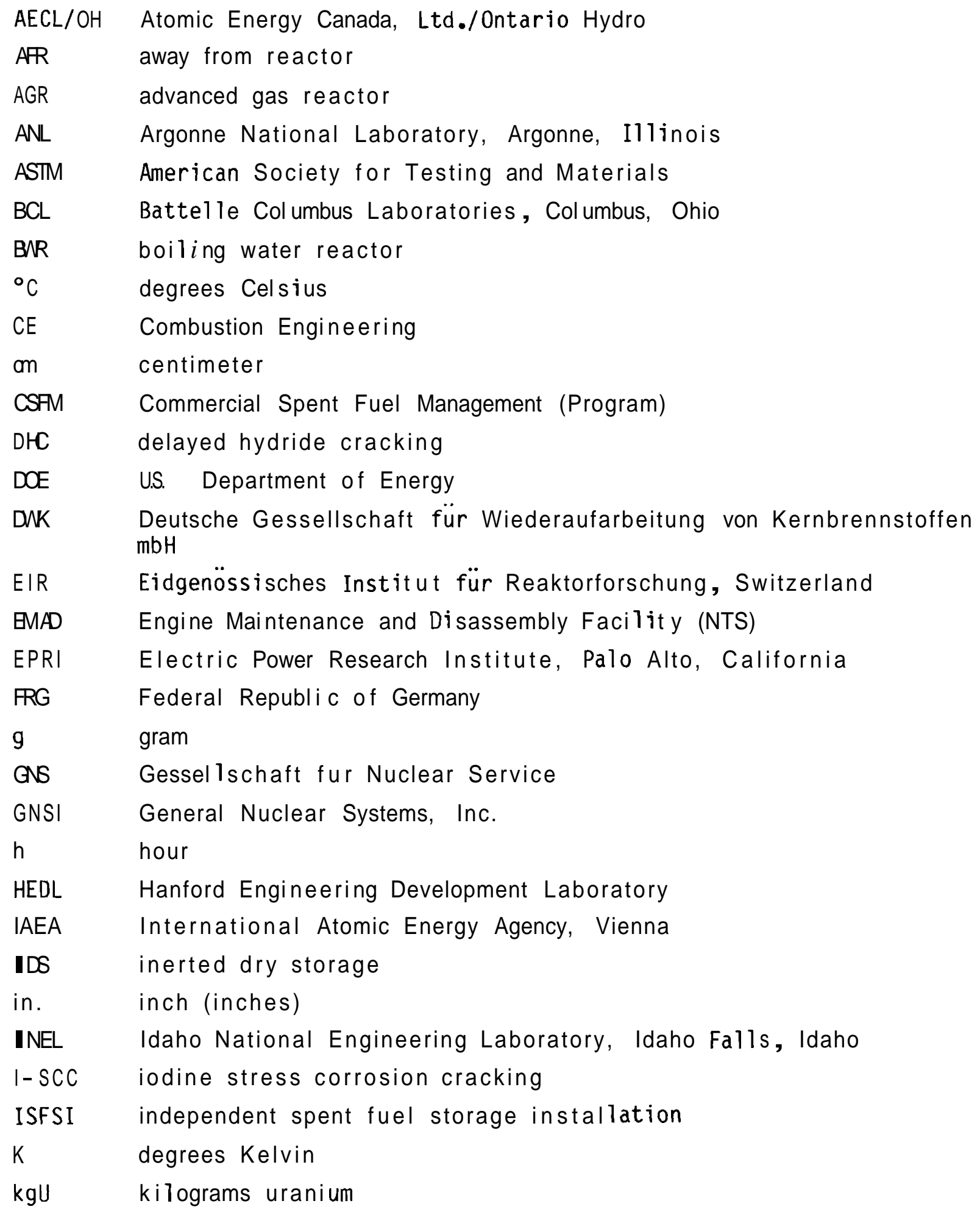




$\begin{array}{ll}\text { KKS } & \text { Kernkraftwerk Stade, RG } \\ \text { KWO } & \text { Kernkraftwerk Obrigheim, RR } \\ \text { KWU } & \text { Kraftwerk Union Aktiengesellschaft } \\ \text { KWW } & \text { Kernkraftwerk wügassen, RG } \\ \text { LWR } & \text { light-water reactor } \\ \text { m } & \text { meter } \\ \text { MPa } & \text { mega-Pascal } \\ \text { MRS } & \text { monitored retrievable storage } \\ \text { MWd } & \text { megawatt day } \\ \text { NAC } & \text { Nuclear Assurance Corporation } \\ \text { NRC } & \text { US. Nuclear Regulatory Commission } \\ \text { NTS } & \text { Nevada Test Site } \\ \text { NUHOMS } & \text { NUTECH Horizontal Modular Storage } \\ \text { PNL } & \text { Pacific Northwest Laboratory, Richland, Washington } \\ \text { psi } & \text { pounds per square inch } \\ \text { PWR } & \text { pressurized water reactor } \\ \text { REA } & \text { Ridihalgh, Eggers \& Associates } \\ \text { S } & \text { second } \\ \text { SOC } & \text { stress corrosion cracking } \\ \text { TN } & \text { Transnuclear, Inc. } \\ \text { TSAR } & \text { topical safety analysis report } \\ \text { TSS } & \text { terminal solid solubility } \\ \text { TVA } & \text { Tennessee Valley Authority } \\ \text { WNRE } & \text { Whiteshell Nuclear Research Establishrnent, Canada } \\ \text { Zry } & \text { Zircaloy } \\ & \end{array}$


CONTENTS

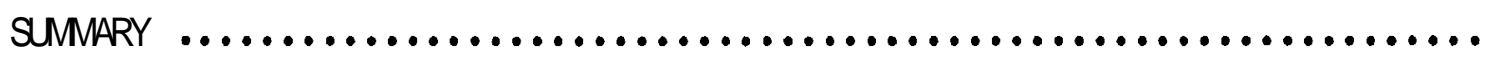

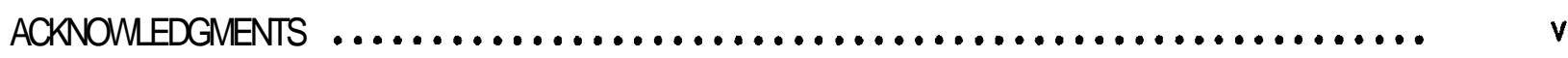

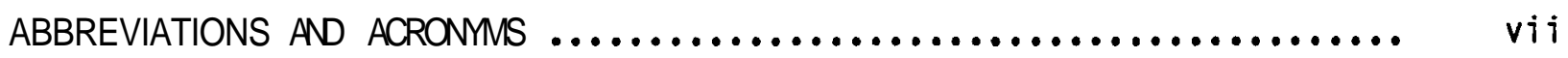

$1.0 \quad$ INTRODUCTION ............................................. 1.1

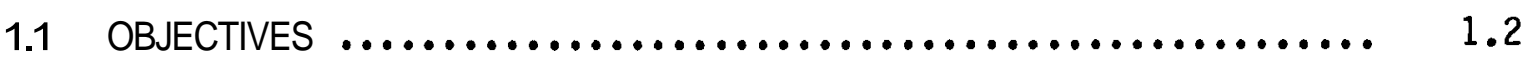

1.2 REPORT OVERVIEW ...................................... 1.2

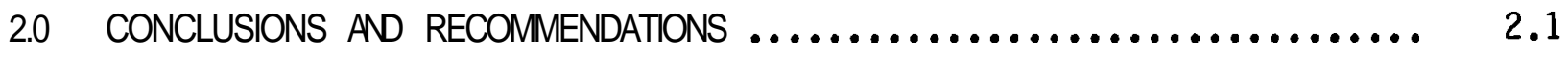

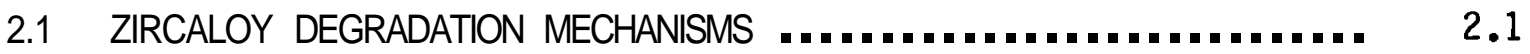

2.2 CLADDING TEMPERATURE LIMITS DURING INERTED

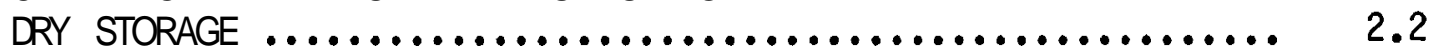

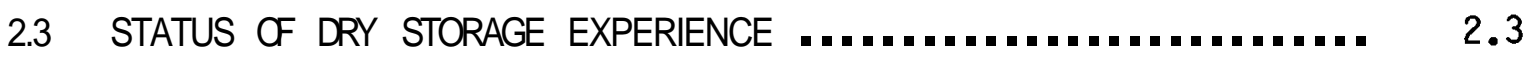

2.4 RECOMMENDATIONS FOR INERTED DRY STORAGE $\ldots \ldots \ldots \ldots \ldots \ldots \ldots \ldots . . \ldots$

3.0 ZIRCALOY DEGRADATION MECHANISMS AND MODELING ................... 3.1

3.1 CREEP RUPTURE ............................................ 3.2

3.1.1 Creep Deformation and Rupture Mechanisms ............ 3.3

3.1.2 Creep Rupture Modeling ........................... 3.4

3.2 STRESS CORROSION CRACKING ........................... 3.9

3.2.1 Threshold lodine Concentration ..................... $\quad 3.10$

3.2.2 Threshold Cladding Stress $\ldots \ldots \ldots \ldots \ldots \ldots \ldots \ldots \ldots \ldots . \quad 3.11$

3.3 ZIRCALOY DEGRADATION BY HYDROGEN ........................ 3.12

3.3.1 Delayed Hydride Cracking ........................ 3.12

3.3.2 Hydride Reorientation .......................... 3.13

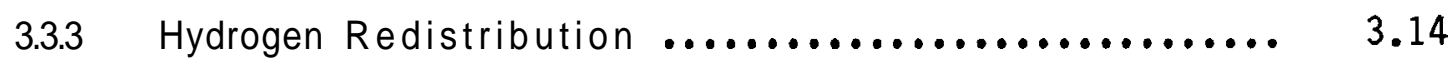

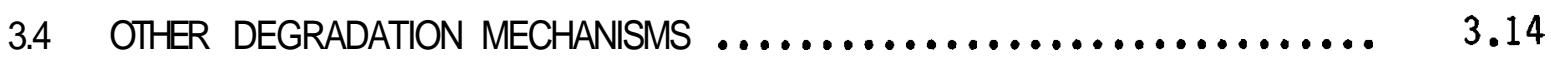




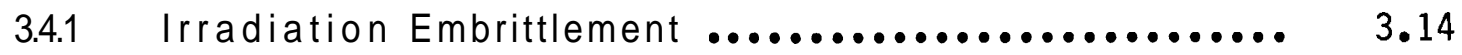

3.4. Cladding Oxidation ................................. 3.15

3.4.3 Fuel Oxidation ...................................... 3.15

3.4. Strain Rate Embrittlement ........................... 3.16

3.5 SUMMARY $\sigma$ DEGRADATION MECHANISMS AND MODELING $\ldots \ldots \ldots \ldots \ldots . . . . .16$

4.0 CLADDING TEMPERATURE LIMITS FOR INERTED DRY STORAGE

OF ZIRCALOY-CLAD SPENT FUEL

4.1 RECOMMENDED INERTED DRY STORAGE TEMPERATURE LIMITS ......... 4.2

4.1.1 Generic Inerted Dry Storage Cladding

Temperature Model ................................. 4.3

4.1.2 Inerted Dry Storage Cladding Temperature

Limits for Specific Spent Fuel .................... 4.7

4.1.3 Factors Affecting Spent Fuel Gas Pressure

During Dry Storage ................................. 4.10

4.2 MODELING of INERTED DRY STORAGE CLADDING TEMPERATURES $\ldots . . . .4 .13$

4.3 CLADDING TEMPERATURES DURING CASK DRYING OPERATIONS ........ 4.16

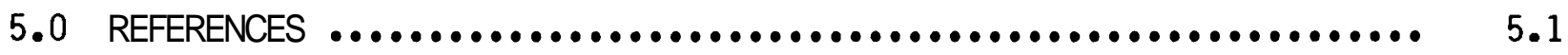

$\begin{aligned} \text { APPENDIX A } & \text { ZIRCALOY DEGRADATION MECHANISMS: STRESS } \\ & \text { CORROSION CRACKING AND HDROGEN } \ldots \ldots \ldots \ldots \ldots \ldots \ldots \ldots \ldots \ldots \text { A.1 }\end{aligned}$

APPENDIX B - THEORETICAL DISCUSSION ON DELAYED HYDRIDE CRACKING ...... B.1

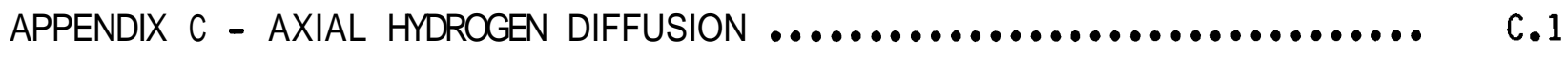

APPENDIX D - CREEP RUPTURE MODELING ........................... D.1

APPENDIX E - STATUS OF INERTED DRY STORAGE TECHNOLOGY .............. E.1 
FIGURES

3.1 Comparison of Predicted and Measured Creep Rates at $400^{\circ} \mathrm{C} \ldots \ldots \ldots . .6$

3.2 Comparison of Predicted and Measured Creep Time to Fracture

at $400^{\circ} \mathrm{C}$.......................................................

4.1 IDS Cladding Temperature Limits for Spent Fuel Aged 5 Years ...... 4.4

4.2 Comparison of IDS Cladding Temperature Limit Curves for Spent Fuel of Varying Ages

4.3 Graphical Determination of Specific IDS Cladding Temperature Limit for Example Spent Fuel

4.4 ORIGEN2-Predicted Helium Production from Actinide Decay ......... 4.13

4.5 Predicted Helium Production from Actinide Decay for

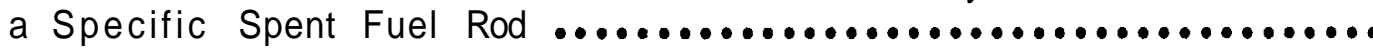

A.1 Relationship Between Stress Intensity and Crack Growth Rate for Zircaloy at $350^{\circ} \mathrm{C}$

A.2 Crack Growth Rates Extrapolated to a Stress Intensity of $1.6 \mathrm{MPa} \cdot \sqrt{\mathrm{m}}$ for Zircaloy at $350^{\circ} \mathrm{C}$.

A.3 Stress Corrosion Crack Depth for Zircaloy as a Function of Time for an IDS Temperature History

A.4 Initial Cladding Stress Intensity for Various Crack Depths in Zircaloy Spent Fuel Cladding...............................

A.5 Crack Growth Rates in Zircaloy-2 Due to I-SCC and DHC

B.1 Schematic of Crack Geometry

B.2 Hydrostatic Stress as a Function of Distance from Crack Tip ...... B.4

B.3 Schematic of Relationship Between Crack Growth Rate and Stress Intensity

B.4 Crack Geometry with Definition of Plastic Zone ................. B.8

B.5 Hydrostatic Stress as a Function of Position ................... B.8

B.6 Hydrogen Concentration as a Function of Position ................ B.99

B.7 Schematic of Criteria for Hydride Nucleation ................... B.10 
B.8 Time Evolution of Hydrogen Redistribution During Hydride Nucleation and Growth ..............................................

B.9 Hydrogen Redistribution During Heating or Cooling ............... B.13

B.10 Hydrogen Redistribution During Cooling ......................... B.14

C.1 Axial Temperature Profile ...................................... C.4

C.2 Maximum Cladding Temperature as a Function of Decay Heat ......... C.6

C.3 Maximum Cladding Temperature as a Function of Time After

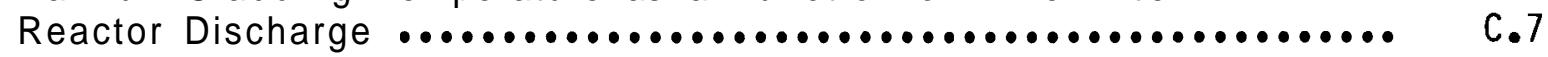

C.4 Semi-Log Plot of Maximum Cladding Temperature as a Function of Time After Reactor Discharge ................................. C.9

C.5 Fuel Rod and Hydride Deposits ............................... C.10

C.6 Axial Hydrogen Distribution Observed in Fuel Rod Zircaloy Cladding from the Turkey Point Unit 3 Reactor

D.1 Deformation Map for Zircaloy with Constant Stress and Strain Rate Contours

D.2

D.2 Fracture Map for Zircaloy Generated Using Strain Rates from Deformation Map ...........................................

D.5

D.3 Predicted Strain Rate Contours at $350^{\circ} \mathrm{C}$ Compared with Experimental Data D.6

D.4 Predicted Time to Fracture at $350^{\circ} \mathrm{C}$ Compared with Experimental Data

D.5 Time and Temperature Dependence of Recovery Factor in Zircaloy

D.6 Comparison of Predicted Strain Rates with $\mathrm{PG}$ Experimental Data ...............................................

D.7 Comparison of Predicted Fracture Times with FGR Experimental Data

E.1 Projected Number of Spent Fuel Assemblies in Excess of Available Onsite Storage Capacity

E.2 Distribution of Stored Spent Fuel as a Function of Assembly-Average Burnup 


\section{TABLES}

3.1 Summary of Zircaloy Cladding Degradation Mechanisms During IDS.. . . $\quad 3.17$

B.1 Time to Constant Crack Growth Rate as a Function of

Temperature ....................................... B.15

C.1 Decay Heat for BAR Spent Fuel as Determined from ORIGEN2

Predictions $\ldots \ldots \ldots \ldots \ldots \ldots \ldots \ldots \ldots \ldots \ldots \ldots \ldots \ldots \ldots \ldots \ldots \ldots \ldots \ldots \ldots . \ldots \ldots$

C.2 Constants Used in Hydrogen Redistribution Calculations ......... C.10

0.1 Strain Rate Data from the Federal Republic of Germany ........... D.11

E.1 Laboratory/Hot Cell Tests Involving Zircaloy-Clad

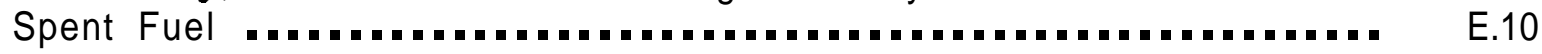

E.2 Dry Storage Demonstrations Involving Zircaloy-Clad Spent Fuel ......................................... E.II

E.3 Dry Storage Cask Demonstrations in the United States .......... E.14 


\section{$1.0 \quad$ INTRODUCTION}

The commercial light-water reactor (LWR) power industry primarily uses fuel composed of $\mathrm{UO}_{2}$ clad with Zircaloy. At the end of its useful irradiation period, the fuel is removed from the reactor and placed in water storage for cooling and radiation shielding. This "spent" fuel (Zircaloy-clad $\mathrm{UO}_{2}$ fuel that has concluded its useful in-reactor life) is expected to remain in water storage until it is sent offsite for final disposition. However, the amount of spent fuel now exceeds, or is projected to exceed, the wet storage capacity at many reactor sites.(a) Therefore, alternatives to wet storage of spent fuel are becoming important to the commercial nuclear power industry. The current primary alternative to wet storage of spent fuel is dry storage using an inert cover gas (referred to as inerted dry storage or IDS). Inerted dry storage is proving to be a practical storage method and is currently being licensed for use in the United States and abroad.

In 1980, the U.S. Nuclear Regulatory Commission (NRC) specified in 10CFR72, Licensing Requirements for the Storage of Spent Fuel in an Independent Spent Fuel Storage Installation (ISFSI), that during dry storage [part 72.72(h)(1)]: "The fuel cladding shall be protected against degradation and gross ruptures." A modification to this regulation has been proposed(b) (approval anticipated for fall 1987) that more clearly defines cladding degradation. This modified regulation 10CFR72.92(h)(1) wi11 read: "The spent fuel cladding must be protected against degradation that leads to gross ruptures or the fuel must be otherwise confined during storage such that degradation of the fuel during storage will not pose operational safety problems with respect to its removal from storage. This may be accomplished by canning of consolidated fuel rods or unconsolidated assemblies or other means as appropriate." Meeting this NRC regulatory requirement, if canisters are not used, means that the Zircaloy cladding must maintain sufficient integrity during IDS

(a) Reracking, transshipment, and consolidation are considered to be aspects of wet storage.

(b) Published in the Federal Register, May 27, 1986, Vol. 51, No. 101, pp. 19106-19132. 
to provide adequate confinement of the irradiated $\mathrm{UO}_{2}$ to prevent significant releases of radioactive particles during IDS and associated handling operations.

The Dry Storage Licensing Support Project of the Commercial Spent Fuel Management (CSFM) Program (a) has the broad objective of supporting licensing activities for IDS through experimental programs and analyses. One element of the work has been to recommend cladding temperature limits for IDS (Levy et al. 1987) such that the Zircaloy cladding will be acceptably protected against breach and gross ruptures due to creep and will continue to confine the irradiated $\mathrm{UO}_{2}$. Cladding temperature limits, rather than cladding stress, strain, or corrosion limits, are specified because temperature is a parameter that affects each of the other possible types of limits and can be monitored and controlled during IDS.

\subsection{OBJECTIVES}

The objectives of the activities described in this report were to 1) identify possible Zircaloy degradation mechanisms and evaluate their applicability to potential cladding breach during IDS, 2) develop predictive deformation 1 fracture models of the cladding based on the dominant Zircaloy degradation mechanisms, and 3) recommend cladding temperature limits to control Zircaloy degradation during IDS.

It is anticipated that the information provided in this report together with the creep-derived cladding temperature limits recommended by Levy et al. (1987) will serve as the technical background for licensing activities related to IDS.

\subsection{REPORT OVERVIEW}

Preventing gross rupture of the cladding is specified in 10CFR72.92(h)(1) to prevent the release of significant quantities of irradiated $\mathrm{UO}_{2}$ (including

(a) The CSFM Program is managed by Pacific Northwest Laboratory (PNL), which is operated for the U.S. Department of Energy (DOE) by Battelle Memorial Institute under Contract DE-AC06-76RLO 1830. 
fission products) to the storage environment. The definition of gross rupture is based on the potential consequences of the released material on spent fuel handling operations: if additional filtration, confinement, or handling equipment would be required because of the material released via the rupture, then the rupture may be considered excessive (gross). The objective of confining the radioactive material is to prevent unnecessary radiation exposure to workers during spent fuel handling subsequent to IDS. Thus, a small breach of the cladding (e.g., a pinhole or hairline crack) that would release fission gas but not irradiated $\mathrm{UO}_{2}$ particles would not be considered a gross rupture. (a) A large rupture (e.g., cracked and split cladding) that could release significant amounts of radioactive material and thus affect handling requirements would be considered a gross rupture.

To meet regulatory requirements, technical criteria are commonly specified. For example, to ensure that the cladding is adequately protected, possible criteria might include an inert cover gas to prevent Zircaloy and $\mathrm{UO}_{2}$ oxidation, a cladding strain limit to limit deformation, and/or a failure rate 1imit. No quantitative criteria for cladding strains or failure rates have yet been specified for IDS, although operating temperature limits have been specified. The creep-derived cladding temperature limits recommended by Levy et al. (1987) result in limited cladding diametral strain $(<1 \%)$ and limited cladding breach probability $(<0.5 \%$ per spent fuel rod).

To assure that cladding degradation and gross rupture do not occur, four steps were undertaken. First, possible Zircaloy degradation mechanisms were identified. Second, the degradation mechanisms were evaluated as to their applicability during IDS. Some of the possible mechanisms are precluded by the specifications of IDS (i.e., Zircaloy and $\mathrm{UO}_{2}$ oxidation cannot occur with an inert cover gas). Third, degradation mechanisms of principal concern were

(a) In MacDonald (1984), the NC stated that in regards to transportation of spent fuel "known or suspected failed fuel assemblies (rods) and fuel with cladding defects greater than pinholes and hairline cracks are not authorized." Therefore, the NRC does not consider pinholes or hairline cracks to be gross spent fuel ruptures. 
modeled for analysis and prediction. And fourth, a methodology was developed to predict allowable cladding temperatures for IDS assuming a 40 -year storage period.

The identification, evaluation, and modeling of Zircaloy degradation mechanisms are summarized in Section 3 Additional detailed discussions on Zircaloy degradation may be found in Appendices A, B, and C. Appendix A presents an overview of crack growth behavior, stress corrosion cracking (SCC), and delayed hydride cracking (DHC); Appendix $B$ describes a qualitative model for QHC; and Appendix $C$ describes a hydrogen diffusion model.

It $w$ ill be demonstrated in Section 3.1 that creep rupture is the primary mechani sm that could cause a through-wall cladding crack (breach). The behavior of creep deformation and failure has been modeled, and this model is summarized in Section 3.2; supporting details are presented in Appendix D.

The creep rupture model forms the basis for a methodology that defines the allowable maximum cladding temperatures during IDS. The predictive methodology and recommended temperature limits, developed as part of the CSFM Program and reported by Levy et al. (1987), are summarized in Section 4.1. Supporting the temperature limit methodology is modeling of spent fuel cladding temperatures during IDS. Computer codes are currently capable of predicting cladding temperatures to within $\pm 30^{\circ} \mathrm{C}$ of the temperatures measured during metal cask demonstration tests (Section 4.2).

Inerted dry storage is now being licensed for use in the United States and abroad. A number of IDS systems are being offered and evaluated for future use. An overview of the current status of IDS technology is presented in Appendix $E$. 


\subsection{CONCLUSIONS AND RECOMMENDATIONS}

In this section, specific conclusions are presented regarding Zircaloy degradation mechanisms and cladding temperature limits during IDS. The current status of dry storage experience is discussed, and recommendations are made regarding IDS.

\subsection{ZIRCALOY DEGRADATION MECHANISMS}

Degradation of Zircaloy during IDS may lead to cladding breaches in spent fuel. The driving force for the principal degradation mechanisms is cladding stress, which is a function of the gas pressure differential across the cladding. Once the cladding has been breached (usually a pinhole or hairline crack), (a) the pressure differential and resulting cladding stress are relieved. With the stress relieved, there is no driving force to enlarge the breach and therefore no gross rupture.

The principal Zircaloy cladding degradation mechanisms are creep rupture, SCC, and DHC. Creep rupture is the most likely type of cladding breach for the IDS cladding temperature and stress regimes. Creep deformation and fracture maps that define the temperature/stress regimes of various creep deformation and fracture mechanisms have been developed and validated by comparison with experimental data.

Specific conclusions related to Zircaloy degradation mechanisms include the following:

- The most likely Zircaloy cladding breach mechanism is creep rupture.

- The critical stress intensity levels for SCC and DHC are 3 and $12 \mathrm{MPa} \cdot \sqrt{\mathrm{m}}$, respectively. Spent fuel cladding stress intensities during $\operatorname{IDS}^{(b)}$ will be lower than these critical levels. Therefore, $S O C$ and DHC are not expected to be Zircaloy cladding breach mechanisms during IDS.

(a) Cubicciotti, Jones, and Syrett 1980; Mattas, Neimark, and Yaggee 1980.

(b) It is assumed that reasonably maximum IDS cladding conditions are stress equal to $70 \mathrm{MPa}$ and stress intensity equal to $1.6 \mathrm{MPa} \cdot \sqrt{\mathrm{m}}$. 
- The critical iodine concentration level for $\operatorname{SCC}$ is $5 \times 10^{-6} \mathrm{~g} / \mathrm{cm}^{2}$. Spent fuel free iodine concentrations are below this critical concentration. Therefore, SCC is not expected to be a cladding breach mechanism during IDS.

- Radial reorientation of hydrides requires a stress level of at least $100 \mathrm{MPa}$. Spent fuel cladding stress levels during $\operatorname{IDS}^{(\mathrm{a})}$ will be below this stress level; therefore, radial reorientation of hydrides is not expected to be a cladding degradation mechanism during IDS.

- Predicted hydrogen redistribution within the spent fuel cladding is not significant and is therefore not expected to be a cladding degradation mechanism during IDS.

- A spent fuel cladding breach due to radiation embrittlement requires a stress intensity of $>40 \mathrm{MPa} \cdot \sqrt{\mathrm{m}}$. Spent fuel cladding stress intensities during IDS(a) will be lower than this critical level. Therefore, irradiation embrittlement is not considered to be a significant cladding degradation mechanism during IDS.

- Zircaloy and $\mathrm{UO}_{2}$ oxidation are precluded by the inert gas atmosphere and are therefore not credible cladding degradation mechanisms during IDS (as long as no oxygen is allowed into the storage cask).

- Cladding stress levels during IDS(a) are insufficient to promote cladding strain rate embrittlement; a stress level of $>150 \mathrm{MPa}$ is required.

\subsection{CLADDING TEMPERATURE LIMITS DURING INERTED DRY STORAGE}

Based on 1) the creep deformation and fracture maps for Zircaloy and 2) a conservative decay heat/cladding temperature history for IDS, a model was developed that defines the maximum allowable cladding temperature as a function of cladding stress (Levy et al. 1987). This model accounts for fuel design,

(a) It is assumed that reasonably maximum IDS cladding conditions are stress equal to $70 \mathrm{MPa}$ and stress intensity equal to $1.6 \mathrm{MPa} \cdot \sqrt{\mathrm{m}}$. 
burnup level, and length of cooling period and thus provides specific cladding temperature limits rather than a single generic limit.

Specific conclusions related to cladding temperature limits and other temperature issues include the following:

- The probability for cladding breach, using the cladding temperature methodology, is $<0.5 \%$ for a spent fuel rod stored at the cladding temperature $1 \mathrm{imit}$.

- Computer codes for predicting cladding temperatures within IDS systems are currently within $\pm 30^{\circ} \mathrm{C}$ of experimentally measured cladding temperatures.

- Decay heat levels for spent fuel can be predicted within $10 \%$ of experimentally measured levels for periods of up to 10 years. The codes generally overpredict decay heat levels and are thus conservative for providing decay heat values for temperature prediction codes.

- Spent fuel gas pressure increases during IDS as a result of helium production from actinide decay will be negligible. Fission gas release during IDS will also be a negligible contributor to spent fuel internal gas pressure.

- Spent fuel cladding temperatures during cask drying operations are not expected to exceed the recomniended temperature levels. However, should short periods in excess of the recommended temperature levels occur, they should not be detrimental.

\subsection{STATUS OF DRY STORAGE EXPERIENCE}

Two IDS facilities were licensed at commercial nuclear power reactor sites in the United States during 1986: one at the Surry power reactor, using CASTOR-V/21 metal casks, and the other at the $H$ B. Robinson site, using the NHOMS concrete module system. Several other manufacturers have submitted topical reports to the NRC for either metal casks or other dry storage systems for evaluation and approval. 
Experience with dry storage of Zircaloy-clad spent fuel has ranged from single-rod hot cell tests, to multiassembly storage system characterization tests, to licensed dry storage facilities. More than 30,000 Zircaloy-clad spent fuel rods have been subjected to dry storage conditions, of which more than 18,000 were irradiated in LWRs. Only two Zircaloy-clad spent fuel rods have been reported as developing breached cladding during dry storage. One of the rod breaches occurred during a test using air as the cover gas; the other cladding breach occurred during storage in helium. The causes of the cladding breaches have not been determined, and no examinations are planned.

\section{RECOMMENDATIONS FOR INERTED DRY STORAGE}

It is recommended that the CSFM IDS cladding temperature model, based on cladding creep during IDS and reported by Levy et al. (1987), be used for spent fuel IDS licensing. This model accounts for specific spent fuel characteristics, limits the probability of cladding breach (pinholes or hairline cracks) for a limiting spent fuel rod to $<0.5 \%$ over a 40 -year period, and is associated with cladding strain levels of $-1 \%$. Other cladding degradation/breach mechanisms such as SCC and DHC require cladding stress levels in excess of those associated with the CSFM IDS model and are therefore not considered credible cladding degradation/breach mechanisms.

Cask drying operations may possibly expose spent fuel cladding to temperatures in excess of the CSFM IDS temperature limits. If this should occur, it is recommended that cladding strain from creep be limited to $0.1 \%$ during the cask drying operation. A strain of $0.1 \%$ may result from a temperature of $450^{\circ} \mathrm{C}$ for $8 \mathrm{~h}$. 


\subsection{ZIRCALOY DEGRADATION MECHANISMS AND MODELING}

Degradation of Zircaloy during IDS may lead to breaching of the fuel rod cladding. This section identifies several Zircaloy degradation mechanisms, evaluates the applicability of those mechanisms to IDS, and presents appropriate degradation models.

Possible cladding breach mechanisms for spent fuel during IDS are creep rupture, SCC, and hydrogen-re1ated failure mechanisms. Creep rupture (Section 3.1) is the most likely mechanism that could cause a cladding breach and is the principal basis for the IDS temperature limits presented in Section 4.1. A methodology for predicting the degree of creep rupture (cumulative damage) is presented in Section 3.1.2. The temperature and stress limits established to prevent cladding breach by creep rupture are also shown to prevent cladding breach caused by SOC (Section 3.2) and hydrogen-re1ated mechanisms (Section 3.3).

Additional mechanisms known to degrade Zircaloy cladding are presented in Section 3.4 and are shown to not be significant during IDS. These additional mechanisms include Zircaloy irradiation embrittlement, Zircaloy oxidation, $\mathrm{UO}_{2}$ oxidation, and Zircaloy strain rate embrittlement.

Cladding breach by a crack growth mechanism requires the pre-existence of a crack. These pre-existing cracks (incipient defects) may result from manufacturing defects and/or irradiation. Tasooji, Einziger, and Miller (1984) have determined that $1 \%$ of spent fuel rods would have a defect greater than $0.13 \mathrm{~mm}$ deep. Therefore, for this report, a maximum pre-IDS defect depth of $0.13 \mathrm{~mm}$ ( $-20 \%$ of the cladding thickness) has been assumed for the evaluation of crack growth mechanisms.

The cladding degradation mechanisms to be presented in this section commonly have a threshold cladding stress, or stress intensity, for the mechanism to be operative. To compare these degradation thresholds to expected condi-

tions for spent fuel in IDS, a maximum cladding hoop stress of $70 \mathrm{MPa}$ (cladding 
stress intensity of $1.6 \mathrm{MPa} \cdot \sqrt{\mathrm{m}})(\mathrm{a})$ is assumed for spent fuel in IDS. To illus trate that this is a likely maximum spent fuel cladding stress, a pressurized water reactor (PWR) spent fuel rod with a gas pressure of $6 \mathrm{MPa}$ at $25^{\circ} \mathrm{C}$ (approximately double the preirradiation value and signifying a very large amount of fission gas release during irradiation) would have a hoop stress of $53 \mathrm{MPa}$ at $400^{\circ} \mathrm{C}$. This value is $76 \%$ of the assumed maximum cladding hoop stress of $70 \mathrm{MPa}$ used in the following analyses.

An important point to consider in the following discussions is that once a crack breaches the cladding the driving force to continue propagating the crack is removed. The driving force for crack propagation in spent fuel is the stress caused by the pressure differential between the fill gas of the spent fuel $^{(b)}$ and the cover gas. Once the cladding is breached, the pressure differential is relieved and the stress on the cladding is removed. Therefore, the identified degradation/cladding breach mechanisms should result in pinhole or hairline crack cladding breaches that release gas but not in gross ruptures that could release spent fuel particles (Cubicciotti, Jones, and Syrett 1980; Mattas, Neimark, and Yaggee 1980).

\subsection{CREEP RUPTURE}

Failure of the Zircaloy cladding by creep rupture is caused by the formation of microscopic cracks/cavities within the material. These cracks and cavities result in a reduced cross-sectional area of the cladding and subsequent failure of the cladding to bear the imposed pressure load. Cladding failures of this type are generally material failures and are not dependent on outside influences such as cover gas or reactive materials (e.g., iodine or

(a) Stress intensity may be related to cladding hoop stress and crack size by the following equation:

$$
k_{i}=1.12 \sigma \sqrt{\pi a}
$$

where $k_{j}$ i.s the stress intensity, $o$ is the stress, and a is the crack length (Rolfe and Barsom 1977).

(b) The fill gas of the spent fuel is a mixture of the initial fill gas and fission gas released from the $\mathrm{UO}_{2}$ matrix to the free void volume during irradiation. The pressure of the fill gas depends on the volume of the fill gas, the temperature of the fill gas, and the free void volume. 
hydrogen) within the cladding. The presence of incipient defects affects creep rupture by increasing local stresses through a reduced cross-sectional area.

Experimental measurement of the creep rupture lifetime of Zircaloy cladding is the most desired basis to determine expected creep rupture lifetimes during IDS. Direct experimental measurements, however, are not practical for two reasons: test periods are too long and too many tests are required, Long testing periods are required to experimentally measure material behavior over the anticipated licensing period of 40 years. Many dry storage temperature and stress histories would need to be studied for the different types of spent fuel and types of storage cask designs. Specific temperature/stress histories must be evaluated because the creep degradation kinetics decrease with increasing time as the temperature and stress levels decay with time. The decreasing kinetics significantly affect the expected creep rates and rupture lifetimes.

Calculated cumulative creep damage for decaying temperature and stress histories has been used as a basis to develop initial temperature and stress limits for IDS of spent fuel. These limits are described in Section 4.1 and specify the maximum initial IDS temperatures at which fuel can be stored for a given cladding stress without being breached by creep rupture. The creep rupture model provides a reasonable prediction of creep rupture lifetime for the following reasons: 1) it properly accounts for IDS thermal and stress histories; 2) it includes mechanism-based temperature and stress dependencies for creep behavior; and 3) it is consistent with experimentally measured creep strains, rupture times, and failure strains.

\subsubsection{Creep Deformation and Rupture Mechanisms}

According to Chin, Khan, and Tarn (1986), the creep rate/mechanism of Zircaloy varies with temperature and stress. At high temperatures and high stresses, creep is dominated by high-temperature dislocation climb with the climb rate controlled by lattice diffusion. For low temperatures and low stresses, creep is dominated by grain boundary sliding, which is controlled by grain boundary diffusion, The transition temperature between mechanisms is about $300^{\circ} \mathrm{C}$ at $100 \mathrm{MPa}, 400^{\circ} \mathrm{C}$ at $50 \mathrm{MPa}$, and $500^{\circ} \mathrm{C}$ at $20 \mathrm{MPa}$. A transition in creep mechanism has also been reported by Keusseyan (1985) at $400^{\circ} \mathrm{C}$ and $120 \mathrm{MPa}$ 
for Zircaloy-2. This transition was also interpreted as a shift to grain boundary sliding at lower temperatures.

The interpretations of the temperature and stress dependencies of creep rupture times are more complicated than for creep rate (Chin, Khan, and Tarn 1986). The rupture time depends on both the creep rate and the grain boundary fracture resistance. Intergranular fracture mechanisms dominate creep rupture times at temperatures of interest for IDS. At stresses above $-150 \mathrm{MPa}$, fracture occurs by triple-point cracking. At stresses below -150 MPa, fracture occurs by grain boundary cavitation. Rupture time is more strongly affected by stress during high-stress triple-point cracking than during low-stress cavitation fracture for a given strain rate.

Microstructural studies have revealed evidence for the grain separation processes proposed in the creep rupture models, but quantitative validation of the mechanisms for rupture are not practical for the required spent fuel lifetimes in excess of 40 years. Evidence for triple-point cracking has been reported by Kubo et al. (1985) for zirconium strained at $4.4 \times 10^{-5} \mathrm{~s}^{-1}$ and at $350^{\circ} \mathrm{C}$. Evidence for cavitation damage has been characterized by Keusseyan (1985) for Zircaloy-2 at temperatures from 350 to $400^{\circ} \mathrm{C}$ and at stresses near $100 \mathrm{MPa}$.

\subsubsection{Creep Rupture Modeling}

Creep deformation and failure mechanisms in nonirradiated and irradiated Type 316 stainless steel can be predicted using deformation and fracture mechanism maps. These maps simultaneously display several deformation or failure modes in the form of a schematic diagram of temperature/stress space. Such maps enable prediction of the dominant deformation mechanism and failure mode for various temperatures as well as varying irradiation histories. Zircaloy deformation and fracture maps have been developed by Chin, Khan, and Tarn (1986) as part of the CSFM Program and have been used in determining IDS cladding temperature limits.

Deformation and fracture maps are usually constructed with normalized stress on the ordinate and homologous temperature on the abscissa. Two distinct approaches to constructing the maps have been adopted: experiment 
based and model based. For the experiment-based approach, a large number of data points (derived from tests on different specimens) are placed on the map with the deformation or fracture mode associated with each point identified. Lines are then drawn on the map to indicate the approximate boundaries between the different deformation or fracture processes.

To generate model-based fracture maps, theoretical expressions for times to failure are numerically evaluated for possible fracture mechanisms under the assumption that the mechanism with the shortest failure time controls the fracture. Similarly, deformation maps are generated by numerically evaluating different deformation mechanisms and determining which deformation mechanism has the highest deformation rate. In the construction of deformation and fracture maps, the various mechanisms are assumed to operate independently. This concept is an oversimplification of the actual process because mixed modes of fracture occur and because damage introduced by one mechanism can affect another. However, the deformation and fracture maps do allow the prediction of dominant deformation and failure modes over a wide range of temperatures and stresses and represent a reasonable approach in the absence of more detailed information. The details of developing the deformation and failure maps for the CSFM creep model are summarized in Appendix $D$ and were presented in Chan, Khan, and Tarn (1986).

Measured creep rates have been reported for Zircaloy at temperatures and stresses within the temperature and stress regimes expected for IDS. A comparison between CSFM creep model predictions and measured data at $400^{\circ} \mathrm{C}$ is shown in Figure 3.1. The model prediction represents a reasonable fit of the data at stresses relevant to dry storage and is conservative when the data are sorted according to the type of metal or alloy used for the measurement. The creep rate data of Pahutova and Cadek (1973) indicated a higher creep rate than the model prediction; but those data were for zirconium metal, which is less resistant to creep than Zircaloy. The data demonstrating lower creep rates than the model prediction are for typical Zircaloy alloys that are of interest for dry storage predictions. In particular, the data obtained by Peehs and coworkers in the Federal Republic of Germany (FRG) (discussed in Appendix D) indicate that the predicted creep rates are reasonable and conservative. 


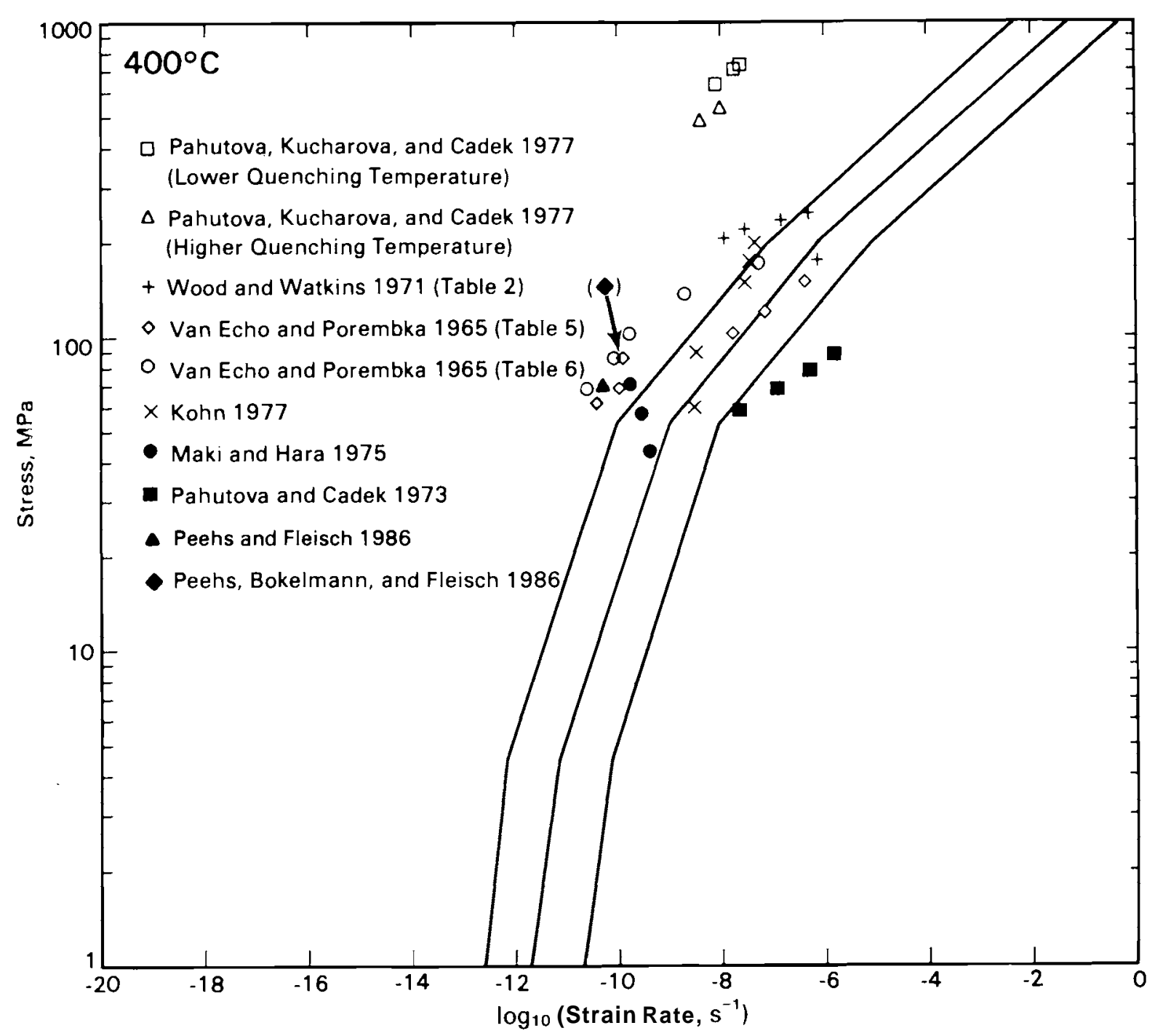

FIGURE 3.1. Comparison of Predicted and Measured Creep Rates at $400^{\circ} \mathrm{C}$. The middle curve is the prediction; the outer curves are order-of-magnitude shifts of the prediction.

The CSFM creep model accounts for the transitions in creep rate and grain boundary fracture processes when extrapolating measured rupture times to lower stresses and lower temperatures for dry storage predictions. The load relaxation tests of Keusseyan (1985) do not quantitatively validate the modeled transition but do verify that lower stress exponents are expected for creep at the lower stresses relevant to dry storage. The CSFM creep model, therefore, accounts for this transition and does not underestimate the creep rate as 
empirical creep models would when based only on high-temperature and highstress creep rate data. Predictions of creep rupture time illustrate the strong stress dependence expected at high stresses and the weak stress dependence expected at low stresses, as shown in Figure 3.2.

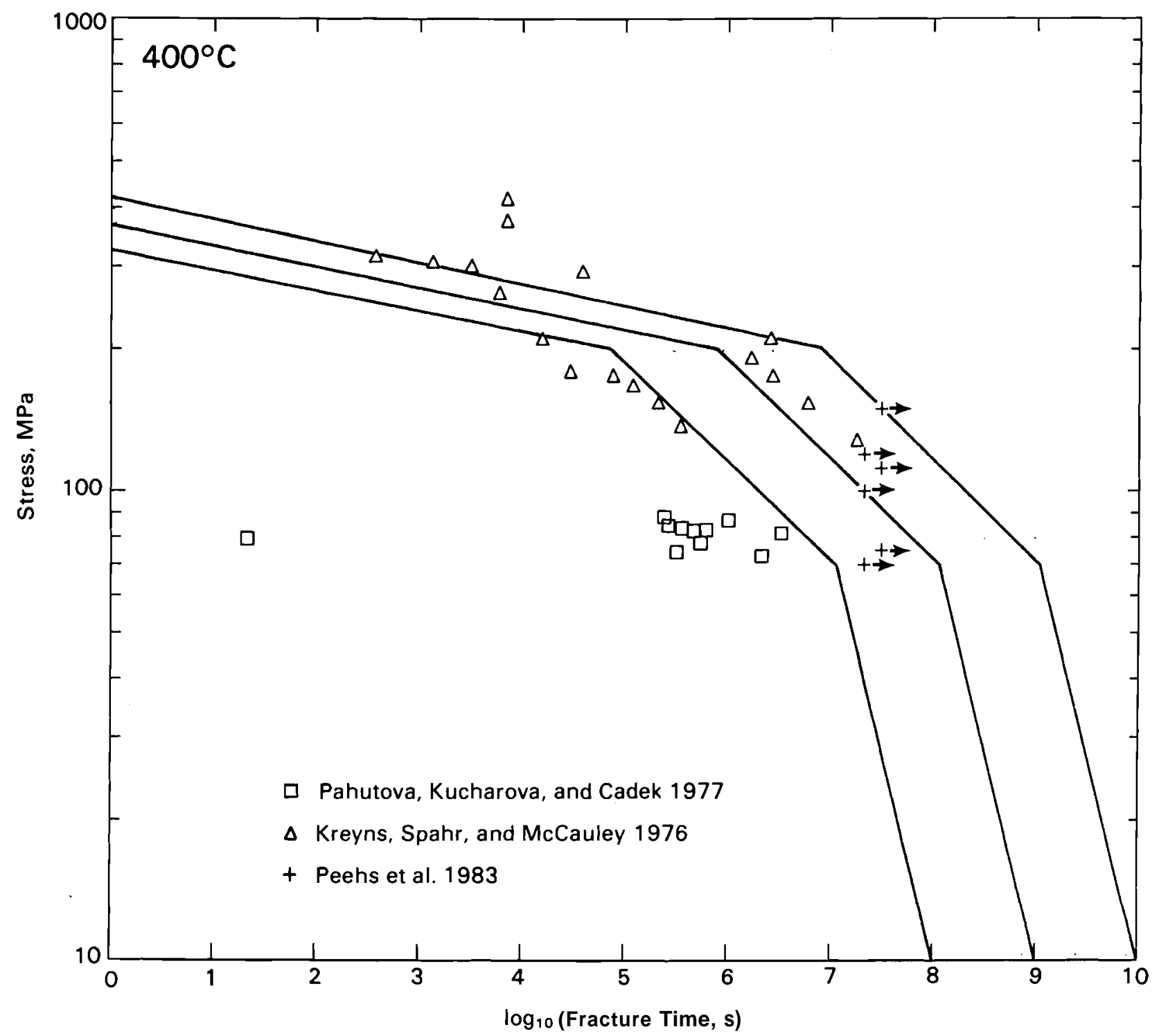

FIGURE 3.2. Comparison of Predicted and Measured Creep Time to Fracture at $400^{\circ} \mathrm{C}$. The middle curve is the prediction; the outer curves are order-of-magnitude shifts of the prediction. Curves given in Figure 16 of Chin, Khan, and Tarn (1986) are in error and have been corrected here. Arrows indicate that fracture did not occur. 
Empirical creep models such as the Larson-Miller parameter approach (Blackburn et al. 1978) overestimate the rupture times for dry storage temperatures and stresses. The empirical models incorrectly assume that behavior evaluated at high temperature and stress levels, with high temperature and stress dependencies, may be adequately extrapolated to low temperature and stress levels. However, the temperature and stress dependencies found at high temperatures and stresses do not exist at low levels; therefore, empirical models underestimate the creep rate at dry storage conditions and overestimate failure times.

The analytical form of the CSFM creep model facilitates computer calculation of creep rates and rupture times for the multiple temperatures, stresses, and mechanisms that exist during dry storage of spent fuel in a given cask. The model predictions reasonably account for the decrease in the temperature and stress sensitivities for creep behavior at low temperatures and stresses. The CSFM creep model also retains the benefit of empirical models in that it uses the data to calibrate predicted creep rates and rupture times for temperatures and stresses at which data are available.

Chin, Khan, and Tarn (1986) made the following primary conclusions regarding creep modeling:

- Fracture and deformation maps provide acceptable methods for extrapolating creep rupture data over large ranges of temperature and stress.

- Experimental data are in agreement with deformation and fracture map predictions. Strain data are best predicted by lower boundary strain rate predictions.

- Flaws in the spent fuel cladding are expected to increase the frequency of cladding breach by creep rupture, with the breach characterized by slow fission gas leakage through a pinhole crack.

- Annealing of irradiation damage during the initial storage period may be advantageous to long-term reliability of Zircaloy cladding during IDS. 
Creep rupture strain is a measure of resistance to fracture that can be used as an alternative failure criterion to a rupture time criterion. Such an alternative is desirable because of the absence of measured creep rupture time data at lower temperatures and stresses of interest for IDS. Calculations reported by Levy et al. (1987) demonstrated that a failure criterion based on a $1 \%$ creep strain resulted in temperature limits not significantly different from those based on cumulative creep damage. Measured failure strains for Zircaloy in the absence of iodine are reported to be greater than $1 \%$ (Porsch, Fleisch, and Heits 1986). Therefore, failure is not expected at the creep model temperature limit (discussed further in Section 4.1) because the Zircaloy strains at that limit $(-1 \%)$ are too low to expect failure.

\subsection{STRESS CORROSION CRACKING}

The susceptibility of Zircaloy to iodine stress corrosion cracking (I-SCC) has been conclusively demonstrated (Cubicciotti and Jones 1978). Therefore, the influence of I-SCC on Zircaloy cladding integrity during IDS is of practical concern. Stress corrosion cracking requires two conditions in addition to material susceptibility: an aggressive chemical environment and adequate stress levels.

A threshold iodine concentration has been determined below which I-SCC has not been observed. Also, a threshold cladding stress has been determined for crack initiation. Once initiated, the stress must be sufficient to propagate the crack at a rate that would cause failure during the 40-year IDS period.

The summary presented below and the analysis in Appendix A demonstrate that I-SCC is not considered a significant degradation/cladding breach mechanism for Zircaloy in IDS because spent fuel iodine concentrations and cladding stresses expected during IDS are too low to promote I-SCC. Cadmium and cesium have also been identified as crack-promoting elements; however, data quantifying their effects on SCC are limited and require further research. 


\subsubsection{Threshold lodine Concentration}

The threshold concentration of free iodine necessary for Zircaloy I-SCC(a) has been experimentally determined to be greater than $5 \times 10^{-6} \mathrm{~g} / \mathrm{cm}^{2}$ (Cubicciotti and Jones 1978). Below this free iodine concentration, Zircaloy cracking due to I-SCC has not been observed.

lodine concentrations in excess of the threshold concentration for I-SCC are not expected in spent fuel during IDS. However, definitive data on free iodine concentrations in spent fuel at IDS temperatures are lacking. Several arguments may be made that indicate the free iodine concentration available in spent fuel for I-SCC at IDS temperatures is negligible. Those arguments include the following:

- A lack of evidence for I-SCC during IDS demonstration tests suggests that insufficient free iodine for I-SCC is present in spent fuel during IDS.

- Theoretical considerations indicate that the iodine should form compounds with cesium and zirconium; in addition, iodine has been observed to condense at temperatures $\angle 450^{\circ} \mathrm{C}$ (Genks 1979).

- Release of iodine from $\mathrm{UO}_{2}$ is generally low at in-reactor fuel temperatures $\left(1000\right.$ to $\left.1800^{\circ} \mathrm{C}\right)$ and will be negligible at IDS temperatures $\left(<400^{\circ} \mathrm{C}\right)$. Additionally, there is no radial temperature gradient to act as a driving force for iodine transport from the fuel to the cladding.

- Gamma radiolysis of iodine compounds has been observed for in-reactor fuel. However, in-reactor gamma fluxes are three orders of magnitude greater than IDS gamma fluxes $\left(>1 \times 10^{9} \mathrm{R} / \mathrm{h}\right.$ compared with $\left.<1 \times 10^{6} \mathrm{R} / \mathrm{h}\right)$, suggesting that iodine available from radiolysis will be inconsequential.

(a) That is, the threshold concentration of iodine in the fuel-cladding gap. 
- Thermal decomposition of CSI has been investigated by Hoffman and Spino (1985). Experiments at $700^{\circ} \mathrm{C}$ and theoretical analyses indicate that the quantity of iodine from CSI decomposition at IDS temperatures is negligible.

\subsubsection{Threshold Cladding Stress}

Given some uncertainty in the estimate of iodine concentrations in spent fuel during IDS, stress thresholds for cracking must also be considered. Threshold cladding stress intensities, which are functions of both stress and flaw size, have been measured for cracking of Zircaloy. The possibility of cracking during IDS is related to the likelihood of having a flaw deep enough in the cladding to have a stress intensity greater than the threshold stress intensity.

The threshold stress intensity for SCC has been experimentally measured to be $-3 \mathrm{MPa} \cdot \sqrt{\mathrm{m}}$ (Cubicciotti and Jones 1978). For a $20 \%$ through-wall crack, a stress greater than $130 \mathrm{MPa}$ is required to exceed the threshold stress intensity of $3 \mathrm{MPa} \cdot \sqrt{\mathrm{m}} ; 1 \%$ of the spent fuel in IDS will have cracks penetrating $\geqslant 20 \%$ through the wall (Tasooji, Einziger, and Miller 1984). This magnitude of stress is greater than expected during IDS; therefore, I-SCC is not considered a likely cladding breach mechanism during IDS even if sufficient iodine were avai lable to promote cracking.

Given the unlikely event that I-SCC can be initiated, failure can only occur if the crack grows to a significant depth during IDS. Analyses presented in Appendix A demonstrate that SOC growth kinetics are sufficient to expect through-wall penetration of cracks during IDS if the cracks are able to initiate and if iodine concentration and cladding stress intensity thresholds are exceeded. The temperature limit for preventing growth of a $0.13-\mathrm{mm}$ crack $(-20 \%$ of the wall thickness) through Zircaloy cladding at $70 \mathrm{MPa}$ is $290^{\circ} \mathrm{C}$ or about $100^{\circ} \mathrm{C}$ less than the corresponding creep rupture temperature limit (see Section 4.1). Therefore, preventing I-SCC failures at the creep rupture temperature limit requires maintaining the cladding stress intensity below the threshold for I-SCC cracking. Maintaining the iodine concentration below its respective threshold will also prevent I-SCC; however, iodine concentration is not a controllable variable. 
ZIRCALOY DEGRADATION BY HYDROGEN

Hydrogen is known to affect cracking of Zircaloy. The following three aspects of the effect of hydrogen on Zircaloy were considered:

- DHC is a process that occurs because of hydride precipitation at the tip of a crack and subsequent fracture of the brittle hydride. The cracking is a time-dependent stable crack growth process and can occur at velocities that are comparable to SCC. Similar to the case of SCC, DHC only occurs if the stress intensity is greater than a threshold value.

- Hydride reorientation can occur in Zircaloy and reduce the fracture toughness. This reduction in fracture toughness may cause brittle failure of the Zircaloy under conditions where failure would not otherwise occur.

- Hydrogen redistribution occurs in gradients of temperature, stress, and concentration. This redistribution can cause local accumulations of hydrogen and excessive hydriding. Because axial temperature gradients exist in the cladding during IDS, the possibility of hydrogen redistribution effects on Zircaloy degradation must be considered.

\subsubsection{Delayed Hydride Cracking}

The general DHC process begins with precipitation of a hydride at the crack tip. The stress gradient at the crack tip provides a driving force for preferential hydride precipitation in the tensile stress field in front of the crack tip. If the crack tip stress is greater than the fracture stress of the brittle hydride, the hydride fractures and crack growth occurs. A decreasing temperature history, as occurs in IDS, promotes the repeated precipitation of hydrides at the crack tip as the crack grows. A theoretical DHC model is presented in Appendix B.

There are three basic requirements for DHC: incipient defects or cracks; the presence of hydride at or near the crack tip; and sufficient stress to propagate the crack. Incipient defects and cracks are present as a result of the manufacturing process and irradiation. Hydrogen is present in the cladding 
as a result of alloy impurities and in-reactor corrosion, and cooling of the cladding following irradiation promotes the precipitation of hydrides.

The high stresses required to crack a hydride exist only in front of a deep crack. The critical stress intensity for DHC is $-12 \mathrm{MPa} \cdot \sqrt{\mathrm{m}}$, which is much greater than cladding stress intensities expected during IDS $(<1.6 \mathrm{MPa} \cdot \sqrt{\mathrm{m}})$. Additionally, at the high stress intensities required for DHC, SOC is the dominant crack growth mechani sm

Cladding breach during IDS due to DHC is not expected because cladding stress intensities during IDS are below the DHC critical stress intensity. If cladding stress intensities were above the critical stress intensity, SOC would be the dominant crack growth mechanism. An extended discussion of DHC is presented in Appendix A.

3.3.2 Hydride Reorientation

A reduction in Zircaloy resistance to brittle fracture results from dissolution of circumferential hydrides followed by reprecipitation of radial hydrides when cladding hoop stresses are sufficiently high. The reprecipitation of radial hydrides occurs uniformly through the thickness of the cladding in contrast to the local hydride precipitation that occurs at a crack tip during DHC. Cracking caused by hydride radial reorientation is not time dependent but occurs quickly once initiated. Radial reorientation of hydrides depends on cladding texture (Kawanishi, Ishino, and Mishima 1974) and stress.

The stress required to radially reorient hydrides in Zircaloy is reported to be $100 \mathrm{MPa}$ (Coleman et al. 1985), although the photomicrographs in that reference show only a small percentage of reorientation to radial hydrides at stresses up to $250 \mathrm{MPa}$. Einziger and Kohli (1984) have reported observing radial hydrides at $145 \mathrm{MPa}$ but were unable to reach a conclusion as to the minimum stress required for hydride reorientation. Some evidence exists that indicates that cooling rates may affect the minimum stress at which hydride reorientation may occur (Northwood and Kosasih 1983; Einziger and Kohl i 1984).

Unfortunately, experimental data are not available at cooling rates representative of IDS. Cladding stress levels under IDS conditions are well below the 100-MPa threshold level identified by Coleman. For a PWR-type rod with a fill 
gas pressure of $6 \mathrm{MPa}$ at $25^{\circ} \mathrm{C}$, a hoop stress of $53 \mathrm{MPa}$ at $400^{\circ} \mathrm{C}$ would be predicted using Equation (4.1). This hoop stress is well below the stress required for hydride reorientation; thus, the formation of radial hydrides is not expected under IDS conditions.

\subsubsection{Hydrogen Redistribution}

Hydrogen redistribution within the cladding can occur during IDS because of temperature gradients along the length of a spent fuel rod. The rod ends are significantly cooler than the middle of the rod; hence, hydrogen transport down the temperature gradient could cause elevated hydrogen concentrations at the rod ends.

The magnitude of hydrogen transport was estimated based on the estimated hydrogen distribution in a spent fuel rod after irradiation and the estimated axial temperature profile during IDS. The calculations are presented in Appendix $C$. The predicted increase in hydrogen concentration at the rod ends $(-1.5 \%)$ was not significant, and enhanced embrittlement caused by hydrogen redistribution is not considered to contribute to degradation of Zircaloy cladding during IDS.

\subsection{OTHER DEGRADATION MECHANISMS}

Irradiation embrittlement, cladding and fuel oxidation, and strain rate embrittlement are known failure modes for Zircaloy. However, these Zircaloy degradation mechanisms are not viewed as being relevant to IDS. Each of these mechanisms is discussed in the following sections.

\subsubsection{Irradiation Embrittlement}

The critical stress intensity required to induce brittle fracture of Zircaloy is reduced as a result of irradiation. For nonirradiated Zircaloy, the critical stress intensity for brittle fracture is $>100 \mathrm{MPa} \cdot \sqrt{\mathrm{m}}$ for temperatures $>20^{\circ} \mathrm{C}$ (Hoagland, Bement, and Rowe 1967). After irradiation, the critical stress intensity for brittle fracture is reduced to $-40 \mathrm{MPa} \cdot \sqrt{\mathrm{m}}$ (Rowe and Hoagland 1969; Farwick and Moen 1979). Even with the irradiation-induced reduction, the critical stress intensity required for brittle fracture is much greater than that for $\mathrm{SOC}(3 \mathrm{MPa} \cdot \sqrt{\mathrm{m}})$ or $\mathrm{DHC}(12 \mathrm{MPa} \cdot \sqrt{\mathrm{m}})$. The estimated 
required crack size to produce a stress intensity of $40 \mathrm{MPa} \cdot \sqrt{\mathrm{m}}$ at a stress of $60 \mathrm{MPa}$, is $110 \mathrm{~mm}$, i.e., greater than the cladding thickness. Therefore, irradiation embrittlement of Zircaloy is not considered to be of concern during IDS.

A mechanism has not been identified that would subject irradiated Zircaloy to a stress intensity as high as $40 \mathrm{MPa} \cdot \sqrt{\mathrm{m}}$ during the dry storage period.

However, it might be postulated that transportation or handing of spent fuel could produce impact loads on the cladding. An analysis by Bosi (1981) of impact loading during transportation, handling, and storage (excluding transportation accidents and dropping accidents) concluded that the critical stress intensity for brittle fracture of irradiated Zircaloy was sufficiently high for the cladding to withstand peak stresses of $124 \mathrm{MPa}$ without through-wall crack propagation. The analysis by Bosi assumed a minimum critical stress intensity of $30 \mathrm{MPa} \cdot \sqrt{\mathrm{m}}$, which is much lower than the values presented by Rowe and Hoagland (1969) or Farwick and Moen (1979).

\subsubsection{Cladding Oxidation}

Oxidation of the cladding during IDS could cause a reduction in the cladding wall thickness and hence an increase in cladding stress. Cladding oxidation during IDS, however, is not significant because of the inert cover gas. (a) Therefore, cladding oxidation does not contribute to a greater likelihood of cladding failure during IDS.

\subsubsection{Fuel Oxidation}

Oxidation of the $\mathrm{UO}_{2}$ fuel during IDS could result in fuel-swelling-induced stress on the cladding that could lead to gross rupture. However, oxidation of the $\mathrm{UO}_{2}$ can occur only if 1 ) the cladding is breached and 2) the $\mathrm{UO}_{2}$ is exposed to an oxidizing atmosphere (i.e., air). The first condition has a probability

(a) If the inert cover gas should be lost during storage, then cladding and $\mathrm{UO}_{2}$ oxidation are possible. This report assumes the inert cover gas is maintained and does not address the question of loss of inert cover gas. 
of $<0.5 \%$ (a) (using the temperature limit provided in Section 4.1). The second condition is not possible because of the inert cover gas for the spent fuel. Fuel oxidation, therefore, cannot contribute to gross cladding rupture during IDS.

\subsubsection{Strain Rate Embrittlement}

Strain rate embrittlement is a known degradation mechanism for Zircaloy cladding and is associated with triple-point cracking. Based on the analysis of Chin, Khan, and Tarn (1986), triple-point cracking of Zircaloy occurs at stress levels $>150 \mathrm{MPa}$. Therefore, strain rate embrittlement is not expected during IDS because cladding stresses will be too low.

\subsection{SUMMARY OF DEGRADATION MECHANISMS AND MODELING}

The primary degradation mechanism for Zircaloy cladding during IDS is creep rupture. Deformation and fracture maps for Zircaloy have been developed, verified, and used to predict Zircaloy creep behavior under varying temperature/stress regimes. Other Zircaloy degradation mechanisms are not expected to result in cladding breach during IDS because mechanisms such as $S O C$ and $\mathrm{DHC}$ require cladding stress intensities greater than those expected for spent fuel in IDS. The possible Zircaloy degradation mechanisms are summarized in Table 3.1.

(a) The probability (failure rate) of $0.5 \%$ applies to spent fuel incurring cladding breach during IDS. It does not apply to spent fuel that might have incurred cladding breach prior to IDS; e.g., during in-reactor irradiation. 
TABLE 3.1. Summary of Zircaloy Cladding Degradation Mechanisms During IDS

\begin{tabular}{|c|c|c|c|}
\hline Mechanism & Basis for Concern & \multicolumn{2}{|l|}{ Requi rements } \\
\hline Creep rupture & $\begin{array}{l}\text { Known creep behavior; } \\
\text { long-term exposure of } \\
\text { cladding to stress }\end{array}$ & $\begin{array}{l}\text { Long-term exposure } \\
\text { to stress }\end{array}$ & $\begin{array}{l}\text { Primary degradation mechanism, set } \\
\text { cladding temperature limits on } \\
\text { basis of creep rupture }\end{array}$ \\
\hline $\begin{array}{l}\text { Hydride radial } \\
\text { reorientation }\end{array}$ & $\begin{array}{l}\text { Decreased fracture } \\
\text { toughness }\end{array}$ & Hydride; $a>100$ & Not likely because of low stress \\
\hline $\begin{array}{l}\text { Hydrogen } \\
\text { redistribution }\end{array}$ & $\begin{array}{l}\text { Hydrogen content of } \\
\text { irradiated Zircaloy }\end{array}$ & $\begin{array}{l}\text { Hydrogen transport } \\
\text { due to axial temper- } \\
\text { ature gradient }\end{array}$ & $\begin{array}{l}\text { Not likely because temperature } \\
\text { and temperature gradients } \\
\text { are too low }\end{array}$ \\
\hline $\begin{array}{l}\text { Zircaljy } / \mathrm{UO}_{2} \\
\text { oxidation }\end{array}$ & $\begin{array}{l}\text { Reduced cladding thick- } \\
\text { ness; } \mathrm{UO}_{2} \text { swelling } \\
\text { increases cladding } \\
\text { stress and strain }\end{array}$ & $\begin{array}{l}\text { Free oxygen; tem- } \\
\text { perature; time }\end{array}$ & $\begin{array}{l}\text { Inert cover gas precludes } \\
\text { oxidation }\end{array}$ \\
\hline $\begin{array}{l}\text { Strain rate } \\
\text { embrittlement }\end{array}$ & $\begin{array}{l}\text { Zircaloy ductility } \\
\text { reduced during rapid } \\
\text { strain }\end{array}$ & $a>200$ & Not likely because of low stress \\
\hline $\begin{array}{l}\text { (a) } K_{I C} \text { is the } \\
\sigma \text { Is the } s\end{array}$ & $\begin{array}{l}\text { itical stress intensity, } \\
\text { ss, MPa. }\end{array}$ & $\cdot \sqrt{m} ;$ I is the iodine & concentration, $\mathrm{g} / \mathrm{cm}^{2}$; and \\
\hline
\end{tabular}




\section{ZIRCALOY-CLAD SPENT FUEL}

Creep rupture has been identified to be the principal mechanism for breaching spent fuel cladding (Section 3). The primary variable for creep rupture that can be controlled during IDS is cladding temperature. Temperature affects Zircaloy creep through both the temperature dependence of creep and the temperature dependence of the spent fuel fill gas pressure that provides the cladding stress. The creep rupture model presented in Section 3.1 .2 has been used as the basis for determining maximum allowable spent fuel cladding temperatures during IDS. The methodology for specifying the maximum allowable cladding temperatures is presented in Section 4.1. This methodology is based on the CSFM creep model and will be referred to as the CSFM IDS cladding temperature model (or the CSFM IDS model).

The fill gas pressure for spent fuel during IDS may be affected by factors other than temperature. Other possible factors include a change in rod internal void volume, release of fission gas during IDS, and actinide decay producing helium during IDS. A brief discussion of these factors may be found in Section 4.1.3.

The temperature history used in the development of the CSFM IDS model was a generic IDS cladding temperature history. (a) Computer codes are available to, provide specific (i.e., dependent on cask design, decay heat history, etc.)

(a) The temperature history was based on COBRA-SFS predictions of spent fuel cladding temperature for TN-24P and MSF-IV (REA-2023) casks containing PWR and boiling water reactor (BWR) spent fuel aged for 1 year. During these calculations, it was found that the TN-24P cask containing PNR fuel had the slowest rate of cooling and therefore would provide the most conservative cladding temperature history. A simple fit to the COBRA-SFS predicted temperature was then developed. Temperature histories for fuel aged for more than 1 year were developed based on the 1-year history and accounting for the decrease of decay heat; those histories are more conservative than would be predicted by COBRA-SFS. A discussion of the development of this temperature history may be found in Levy et al. (1987). 
cladding temperature histories during IDS. A brief review of the codes and comparisons between predicted and measured cladding temperatures are presented in Section 4.2.

Spent fuel may be exposed to elevated temperatures during cask drying operations immediately prior to IDS. An evaluation of expected cladding temperatures and their relationship to the CSFM IDS model is presented in Section 4.3 .

\subsection{RECOMMENDED INERTED DRY STORAGE TEMPERATURE LIMITS}

In 1983 , a maximum initial cladding temperature limit of $380^{\circ} \mathrm{C}$ was recommended for IDS of Zircaloy-clad spent fuel. This limit was based on a review of the available information on dry storage of Zircaloy-clad spent fuel (Johnson and Gilbert 1983b). This guideline was chosen to represent a relatively conservative position with respect to the experience with Zircaloy-clad spent fuel and the results of modeling the behavior of Zircaloy-clad spent fuel.

In 1985, NRC safety evaluation reports on the CASTOR-IC and CASTOR-V/21 cask topical safety analysis reports (TSARS) did not unconditionally accept the recommended $380^{\circ} \mathrm{C}$ temperature guideline. Instead, the NRC developed and used an independent model to verify that unacceptable degradation would not result from the allowable spent fuel temperature limits for IDS specified in the TSARs. However, no NRC-accepted methods are available to cask vendors and utilities to calculate these temperature limits.

A study was performed under the CSFM Program at PNL (Levy et a1. 1987) that developed recommended generic temperature limits for all Zircaloy-clad spent fuel. The objectives of the recommended temperature limits were to prevent spent fuel failure by creep rupture during a 40-year IDS period and provide a procedure by which utilities could easily calculate IDS temperature limits for their specific spent fuel. The temperature limits were designed to accommodate the effects of variations in fuel design, burnup level, and fuel age (i.e., period from reactor discharge until start of IDS) in Zircaloy-clad spent fuel as well as the geometry and makeup of a variety of dry storage casks. 
The major results of that study are summarized in the following subsection. Detailed information can be found in Levy et al. (1987).

\subsubsection{Generic Inerted Dry Storage Cladding Temperature Model}

To accomniodate the effects of variations in fuel design, burnup level, fuel age, and the geometry and makeup of dry storage casks, a CSFM-developed model for predicting cladding temperature limits for IDS (Chin, Khan, and Tarn 1986) was enhanced and used to produce a family of generic temperature limit curves. To generate these curves, deformation and fracture equations for Zircaloy were combined with a declining temperature history, a declining stress history, and a life-fraction rule to account for damage accumulated under the various IDS temperature and stress histories.

Variations in fuel design and burnup levels result in a range of fuel rod internal pressures. In-reactor fuel rod gas pressures at a burnup level of -30 MWd/kgU may range from $<1.0 \mathrm{MPa}$ for an average-power BAR $8 \times 8 \mathrm{R}$ design rod to as high as $11.8 \mathrm{MPa}$ for a peak-power PWR $15 \times 15$ design rod. Extended burnups will lead to even higher pressures.

A generic temperature limit curve accomniodates the variation in spent fuel gas pressures because it defines, as a function of cladding hoop stress, the recommended maximum allowable initial cladding temperature to prevent cladding breach during a 40-year IDS period. Such a temperature limit curve is illustrated in Figure 4.1 for spent fuel aged 5 years prior to IDS. As the initial spent fuel cladding stress is increased, the initial maximum allowable cladding temperature must be reduced. The probability of cladding breach for spent fuel whose IDS cladding temperature and stress are described by a point on the generic temperature limit curve is $<0.5 \%$ ( $<5$ spent fuel rods in 1000). Most spent fuel in IDS will reside in the area below the temperature limit curve, where failure probabilities are even lower.

As spent fuel ages, its cooling rate decreases, extending its time in a given temperature range. Since creep damage could occur if the initial IDS cladding temperature were too high, a decrease in temperature lim it with increasing fuel age is necessary. In Figure 4.2, temperature Iim it curves are plotted for spent fuel aged from 5 to 15 years before IDS. At an initial 


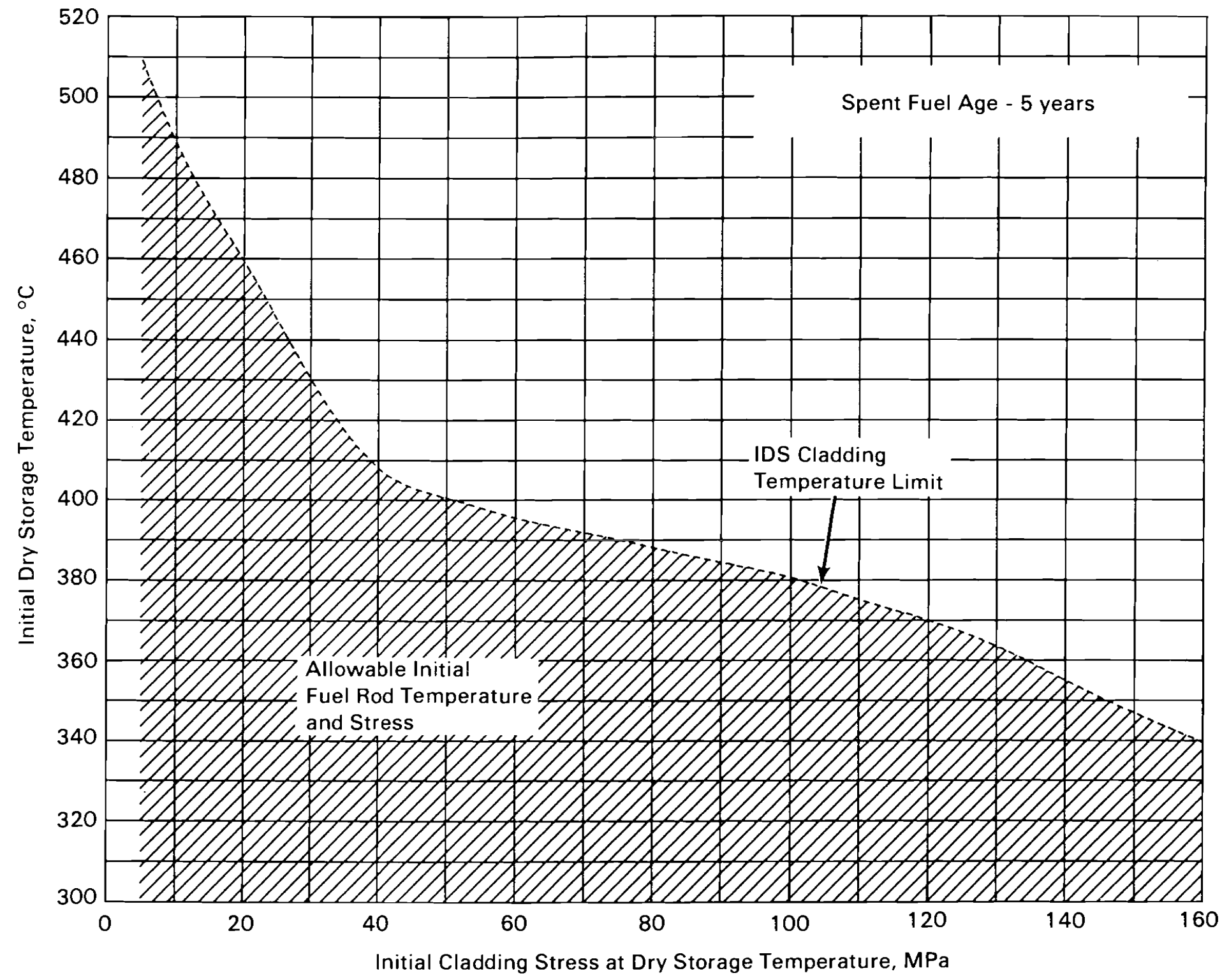

FIGURE 4.1. IDS Cladding Temperature Limits for Spent Fuel Aged 5 Years 


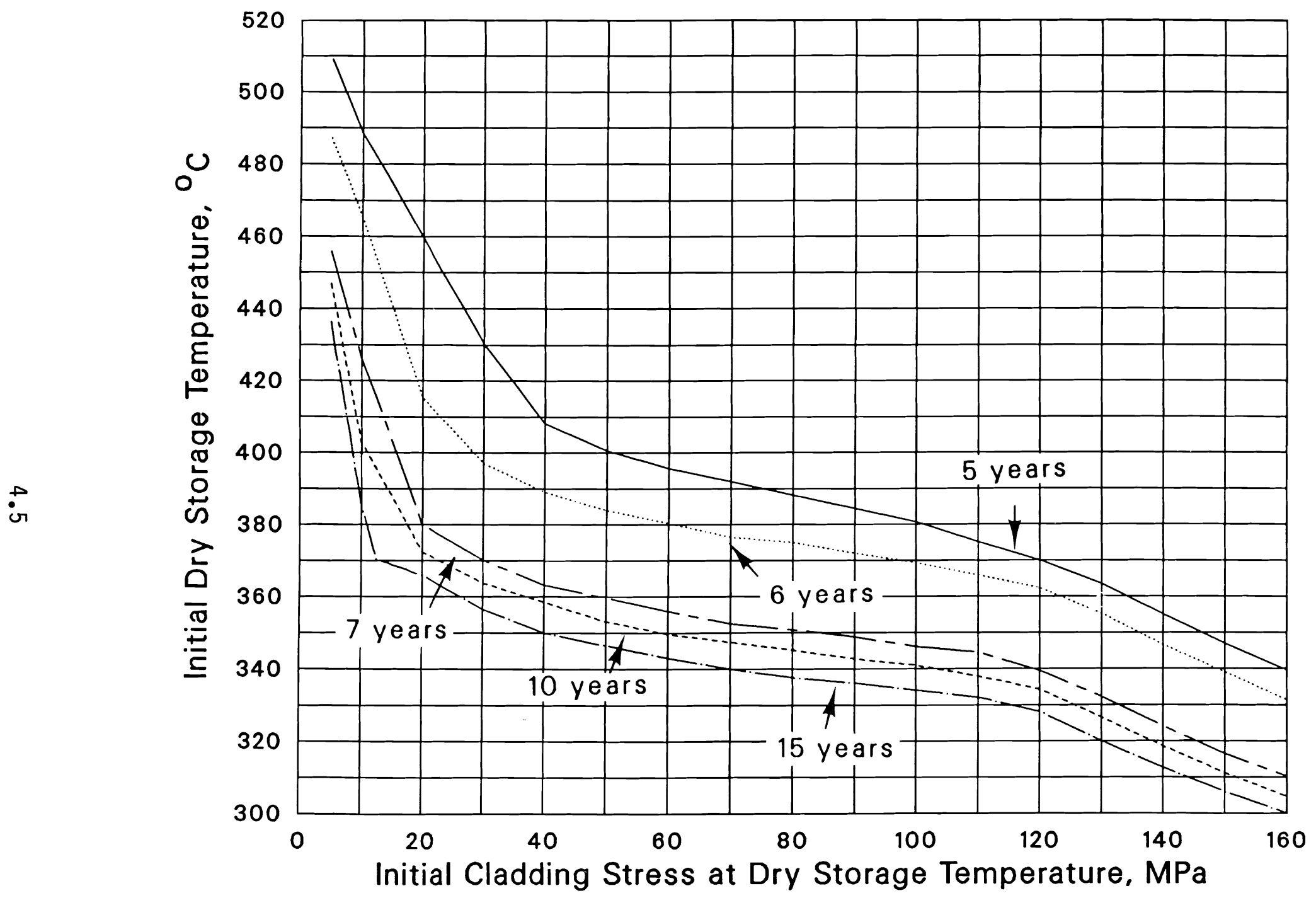

FIGURE 4.2. Comparison of IDS Cladding Temperature im- Curves for Spen uel of Varying Ages 
cladding stress of $70 \mathrm{MPa}$, the allowable cladding temperature for spent fuel aged for 15 years is $50^{\circ} \mathrm{C}$ lower than spent fuel aged for 5 years. Because older spent fuel requires lower cladding temperature limits, the generic limit curve for spent fuel at a specific age is conservative for all younger fuel.

Dry storage casks impose their own heat transfer characteristics on the natural cooling rate of the fuel. Due to the declining temperature history used in the CSFM IDS model, the generic temperature limit curves are conservative for a variety of dry storage cask designs, including helium-backfilled consolidated and unconsolidated casks, nitrogen-backfilled unconsolidated casks, and the NUHOMS concrete storage system. By substantial margins, these casks could not be thermally loaded to exceed the IDS cladding temperature limits.

Validation studies were performed on the CSFM IDS model. These studies included sensitivity studies on parameters used in the model, comparisons of the model predictions with experience in the FRG, and comparisons of the CSFM IDS model to the NAC model. The sensitivity analyses demonstrated that the CSFM IDS model predictions are realistic with a demonstrated measure of conservatism. Comparison of the model predictions with recent experience in the FRG showed that the FRG-recommended temperature 1 i mit of $450^{\circ} \mathrm{C}$ (Porsch, Fleisch, and Heits 1986) was consistent with that predicted by the CSFM IDS model when the higher creep rates used in the CSFM IDS model, compared to the RR analysis, were accounted for.

Comparison of the CSFM IDS model with the NRC model showed that there are minor differences between the predictions of the two models. These differences arise from assumptions regarding deformation and fracture mechanisms occurring at cladding stresses $>130 \mathrm{MPa}$ (the CSFM IDS model involves a mechanism change), spent fuel temperature history (the NRC model assumed a constant temperature after 5 years), and failure criteria (an addition of 5\% allowable cavitation to the NAC model brings the two models into close agreement when a continuous decaying temperature history is used in the NRC model). 
4.1. Inerted Dry Storage Cladding Temperature Limits for Specific Spent Fuel

A simple procedure has been developed by which the family of CSFM IDS cladding temperature limit curves can be used by a utility or cask vendor to generate specific cladding temperature limits. Cladding temperature limits based on peak-power spent fuel are recommended because of the availability of the necessary input data from fuel vendors' safety analysis reports. The limits calculated using this spent fuel would be conservative for $>99 \%$ of the spent fuel because the peak-power spent fuel represents $<1 \%$ of all spent fuel. However, specific cladding temperature limits can be generated for averagepower spent fuel (or other specific spent fuel) if similar data are available.

An equation was developed for calculating the initial IDS cladding temperature as a function of the initial cladding stress in IDS. The cladding stress changes from its in-reactor value to its IDS value principally due to two factors: the reduction in internal gas pressure due to the temperature reduction and the increase in internal rod volume due to differential contraction of the $\mathrm{UO}_{2}$ pellets and the cladding at IDS temperatures. The input data required for this equation are the internal gas pressure of the rod, the average gas temperature at which the pressure is determined, and the inner and outer cladding diameters. The results of evaluating this equation are then plotted on the generic cladding temperature limit curve graph for the specific spent fuel age. The intersection of the curve defined by the equation and the cladding temperature limit curve describes the specific cladding temperature limit. The equation to be used is

$$
\sigma_{\text {mhoop }}=\frac{(P)\left(D_{\text {mid }}\right)}{2 t} \cdot \alpha \cdot \frac{T_{2}}{T_{1}} \cdot \frac{69.684}{10,000}
$$

which is then transformed into the following equation for plotting on generic temperature stress curves such as Figure 4.1.

$$
T_{2}=\frac{\left(\sigma_{\text {mhoop }}\right)\left(T_{1}\right)(2 t)}{(P)\left(D_{\text {mid }}\right)(\alpha)} \cdot \frac{10,000}{69.684}
$$


where $\sigma_{\text {mhoop }}=$ dry storage cladding hoop stress, $\mathrm{MPa}$

$P=$ internal gas pressure of the rod, psi

$\mathrm{T}_{1}=$ temperature at which $\mathrm{P}$ was determined, $\mathrm{K}$

$\mathbf{t}=$ cladding wall thickness, in.

$D_{\text {mid }}=$ cladding midwall diameter, in .

$a=a$ factor, 0.95 for PWR rods or 0.90 for BNR rods

$10,000 / 69.684=$ a conversion factor

$\mathrm{T}_{2}=$ allowable storage temperature for $\sigma_{\text {mhoop }}, \mathrm{K}$.

An example of determining the maximum allowable cladding temperature limit for spent fuel is illustrated in Figure 4.3. The example is for 5-year-old fuel with a cladding stress of $70 \mathrm{MPa}$ at $400^{\circ} \mathrm{C}$; a cladding midwall diameter of $1.0 \mathrm{~cm}$, a wall thickness of $0.1 \mathrm{~cm}$, and a gas pressure of $6.5 \mathrm{MPa}$ at $25^{\circ} \mathrm{C}$ were assumed. In the figure, the intersection of the CSFM IDS generic temperature limit with the cladding temperature/stress relationship represents the CSFM IDS cladding temperature limit. For this example, the cladding temperature limit is $393^{\circ} \mathrm{C}$ at an initial cladding stress of $69.2 \mathrm{MPa}$. Spent fuel that had lower fission gas release during irradiation, and thus lower gas pressure and cladding stress at the end of irradiation, would have a higher temperature limit.

It should be noted that spent fuel in IDS may not reach the CSFM IDS cladding temperature limit (because of more efficient cooling than assumed in the analysis, because the cask/storage system is not full, etc.). Lower cladding temperatures during IDS, i.e., lower than allowed on the basis of the CSFM IDS model, will reduce the probability of cladding breach below the $0.5 \%$ predicted for peak-power spent fuel rods.

The CSFM IDS model can be summarized as follows:

- Substantial variations in spent fuel internal gas pressures and spent fuel age in the current and foreseeable U.S. spent fuel inventory as well as variations in storage cask designs require multiple temperature limits for IDS. The establishment of a single temperature limit to account for these factors would, in some situations, impose unnecessary conservatism and potential economic penalties for utilities and storage cask vendors. 


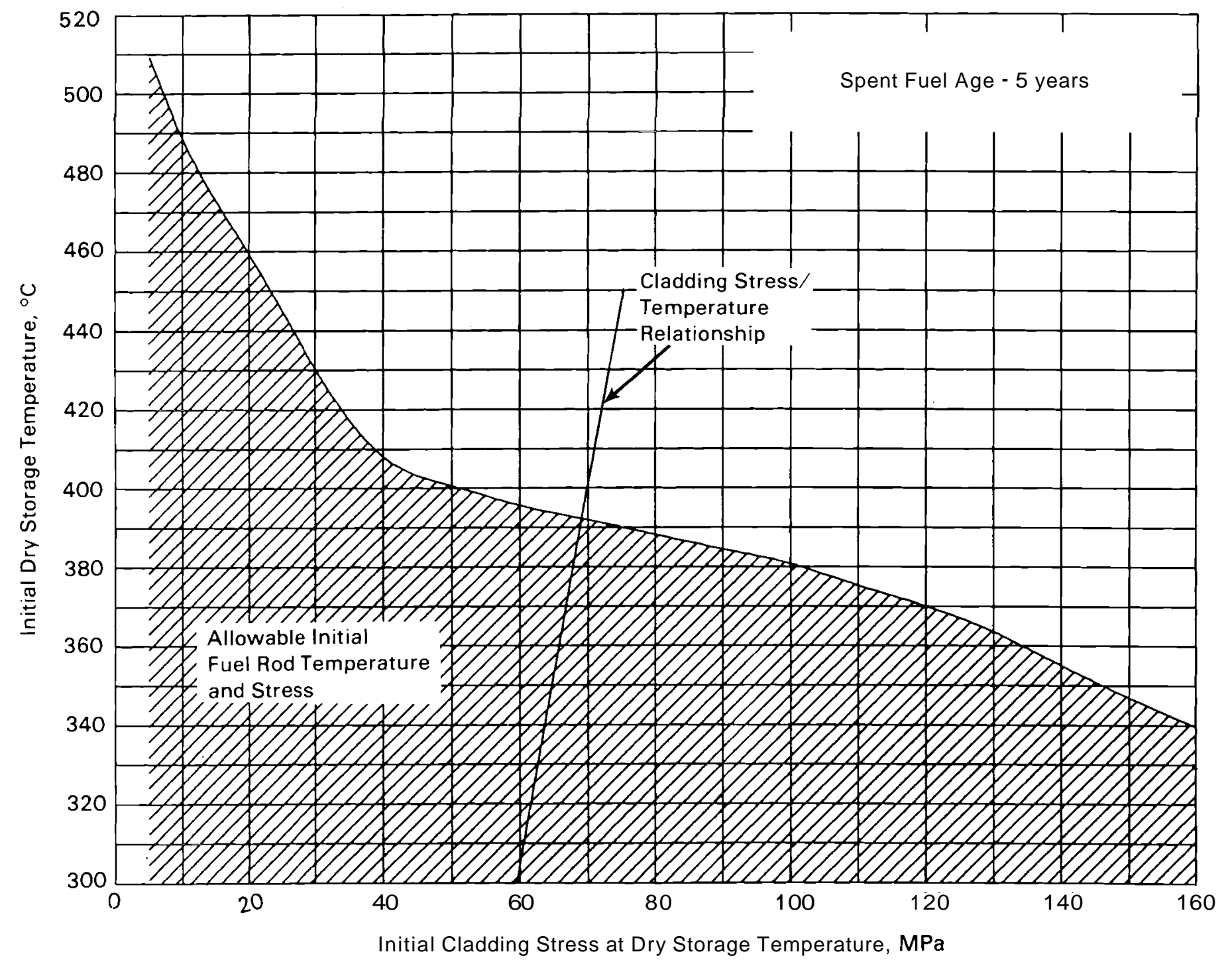

FIGURE 4.3. Graphical Determination of Specific IDS Cladding Temperature Limit for Example Spent Fuel 
- The CSPM IDS model produces a family of generic cladding temperature I imit curves to accommodate the variations in spent fuel. These curves establish the recommended temperature limits for spent fuel over a 40-year IDS period.(a)

- The CSFM IDS model has been verified by sensitivity analyses, comparison to experimental data, and comparison to the NRC model; the CSFM IDS model is technically sound and defensible.

- Cladding temperature limits for specific spent fuel can be readily generated.

\subsubsection{Factors Affecting Spent Fuel Gas Pressure During Dry Storage}

The CSFM IDS model presented above assumes that spent fuel gas pressure during IDS is described by the ideal gas law. That is, the initial void volume and the volume of fill gas remain constant during IDS and thus gas pressure is directly proportional to temperature. However, if either the void volume decreases or the volume of fill gas increases during IDS, then gas pressures will be greater than assumed by the CSFM IDS model for a specific spent fuel cladding temperature. This section discusses possible changes in spent fuel void volume and gas volume during IDS.

A void volume decrease during IDS will increase the gas pressure and thus the cladding hoop stress by compressing the gas. (A void volume increase, on the other hand, will decrease gas pressure.) A void volume decrease may occur by cladding creepdown or $\mathrm{UO}_{2}$ swelling. Cladding creepdown is not possible for spent fuel stored in a nonpressurized cask because the gas pressure inside the spent fuel will be greater than the gas pressure outside the spent fuel.

(a) The recommended temperature limits apply to typical spent fuel. If a specific fuel batch is known to be somewhat abnormal (for example, to have demonstrated a higher than normal in-reactor failure rate or to have sustained unusual conditions during shipping or handling), it may be advisable to consider such a fuel batch as a special case and evaluate a specific temperature limit. Summaries of spent fuel conditions during and after irradiation and wet storage may be found in Bailey (1987); Bailey and Johnson (1986); and Bailey and Wu (1986). 
Swelling of $\mathrm{UO}_{2}$ is an irradiation phenomenon and stops when the fuel is removed from the reactor. Therefore, loss of void volume is not a credible mechanism for gas pressure increases during IDS.

An increase in the volume (moles) of gas in the spent fuel rod during IDS is possible from two mechanisms: fission gas release from the $\mathrm{UO}_{2}$ matrix to the void volume and helium production from actinide decay followed by release from the $\mathrm{UO}_{2}$ matrix to the void volume. To estimate possible fission gas releases from the $\mathrm{UO}_{2}$ to the void volume, the ANS-5.4 fission gas release model (Turner et al. 1982) was used.(a) For stable isotopes, a simplified equation for the release fraction is given as

$$
F=4 \sqrt{D t}-\frac{3 D t}{2}
$$

where $D=$ diffusion coefficient, $s^{-1}=0.61 \times \exp (-36386 / T) \times 100(B U / 28000)$

$$
\mathbf{t}=\text { time, } \mathbf{s}
$$$$
\mathrm{T}=\text { temperature, } \mathrm{K}
$$

$\mathrm{BU}=$ burnup, MWd/MTM $\left(10^{3} \times \mathrm{MWd} / \mathrm{kgU}\right)$.

For fuel with a burnup of $40 \mathrm{MWd} / \mathrm{kgU}$ and stored for 40 years at a temperature of $400^{\circ} \mathrm{C}$, the resulting release fraction is $-3.0 \times 10^{-6}$. For a full-length commercial rod with a rod-average burnup of $40 \mathrm{MWd} / \mathrm{kgU}$, the fission gas production would be $-3600 \mathrm{~cm}^{3}$. Applying the above fission gas release fraction to the produced fission gas results in a fission gas release of $0.01 \mathrm{~cm}^{3}$ during 40 years at $400^{\circ} \mathrm{C}$. This amount of additional gas is negligible and has no effect on IDS of spent fuel. Two additional factors will reduce the fission gas release from the $\mathrm{UO}_{2}$ matrix: 1) the decreasing temperature history will reduce fission gas release from the fuel and 2) there is a minimal temperature profile within the fuel to aid in fission gas diffusion from the $\mathrm{UO}_{2}$ matrix to the void volume.

(a) Data are lacking regarding long-term, low-temperature fission gas release following irradiation. 
Decay of actinide isotopes occurs by the release of an alpha particle, i.e, a helium nucleus, and thus increases the inventory of helium in the $\mathrm{UO}_{2}$ matrix. This relationship is illustrated by the following reaction:

$$
{ }_{95}^{241} \mathrm{Am}+{ }_{93}^{237} \mathrm{~Np}+\mathrm{He}
$$

The isotopes that are the primary contributors to the helium inventory are ${ }^{241} \mathrm{Am},{ }^{238} \mathrm{Pu},{ }^{242} \mathrm{Cm}$, and ${ }^{244} \mathrm{Cm}$. Release of this decay-produced helium can increase the volume of free gas in the spent fuel.

An ORIGEN2 (Croff 1980) computer code prediction of actinide production and decay was made assuming an initial fuel enrichment of $3.2 \%{ }^{235} \mathrm{U}$ and a final burnup of $36 \mathrm{MWd} / \mathrm{kgU}$ (actinide production is approximately proportional to burnup). The predicted production of helium as a result of actinide decay is presented in Figure 4.4 as a function of decay time. The information in Figure 4.4 was converted to helium production in terms of cubic centimeters per spent fuel rod by assuming fuel with a diameter of $0.01 \mathrm{~m}$, an enriched length of $4 \mathrm{~m}$, and a density of $10.4 \mathrm{~g} / \mathrm{cm}^{3}$; this conversion is presented in Figure 4.5. The predicted helium production after 40 years of actinide decay is $52.0 \mathrm{~cm}^{3}$. For a spent fuel rod with an end-of-life void volume of $30 \mathrm{~cm}^{3}, 100 \%$ release of the produced helium would therefore result in a pressure increase of $<0.2 \mathrm{MPa}$. However, because of the relatively low IDS temperatures (compared with irradiation temperatures) and the decrease in IDS temperature with time, $100 \%$ release of the helium is not plausible and the true release is probably much lower. (a) Therefore, gas pressure increases due to helium production from actinide decay and the subsequent release of the helium to the free gas are not considered a problem for a 40-year IDS period.

(a) Analysis of fuel rod fill gases following irradiation has shown that lowtemperature pressurized rods usually lose helium from the fill gas due to absorption by the fuel while low-temperature nonpressurized rods gain a small amount of helium in the free gas from release of helium produced by tertiary fission and actinide decay. High fuel temperatures during irradiation lead to higher helium release as would be expected. However, $100 \%$ release of the produced helium has not been observed for rods operated at significantly higher temperatures than will be encountered during IDS. 


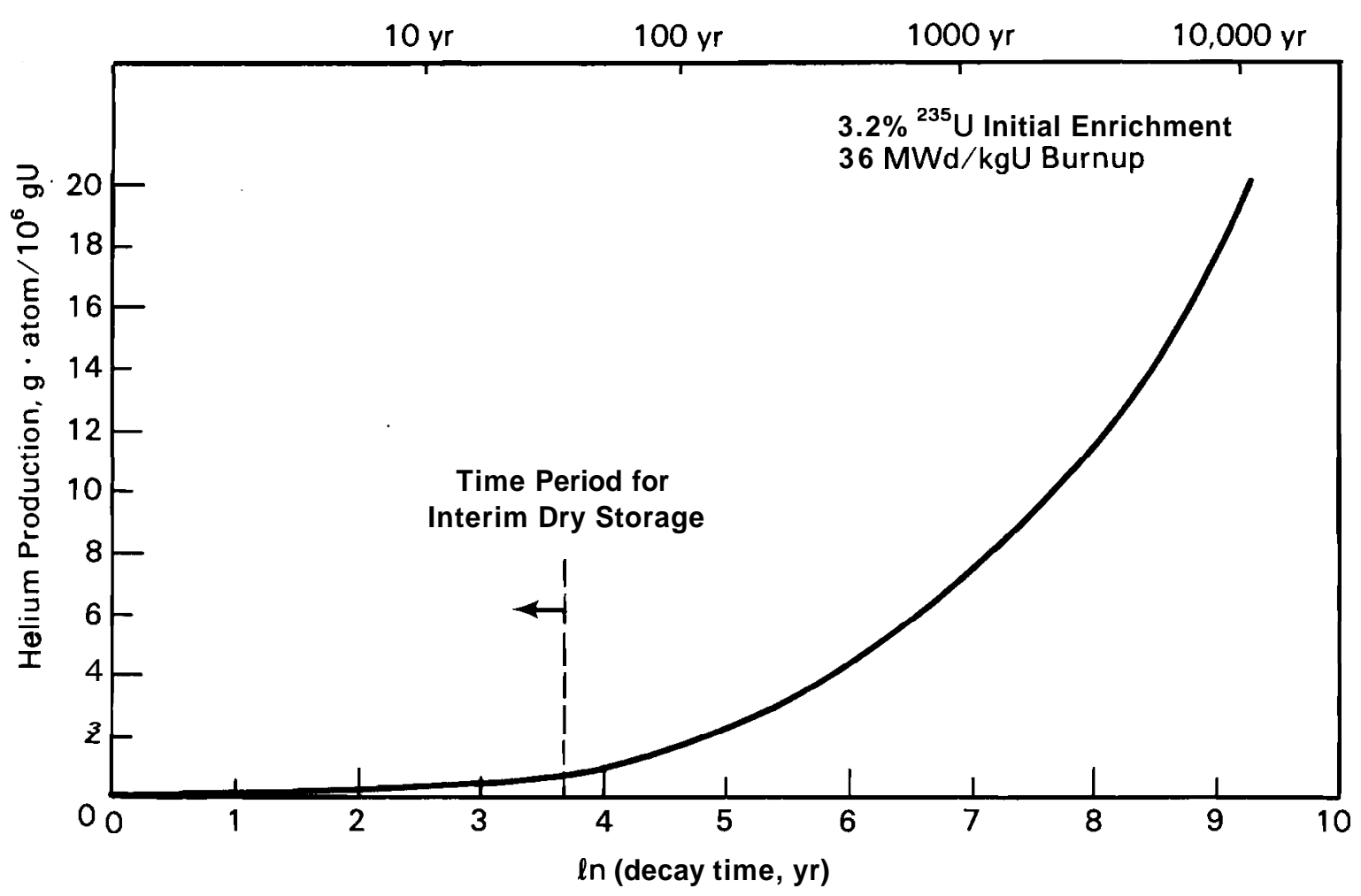

FIGURE 4.4. ORIGEN2-Predicted Helium Production from Actinide Decay

It should be noted, however, that helium production from actinide decay is an approximately exponential function and that for periods greater than 40 years the helium production is substantial. Therefore, if a mechanism exists that can release the produced helium from the fuel matrix to the free gas, the rod gas pressure increase for long storage periods could be substantial. A $100 \%$ helium release rate after 10,000 years would increase rod pressure by $4.1 \mathrm{MPa}$ (at the original IDS temperature). However, a $100 \%$ release rate is not plausible; therefore, gas pressure increases should be considerably lower.

\subsection{MODELING $O F$ INERTED DRY STORAGE CLADDING TEMPERATURES}

The temperature-time history of spent fuel in IDS is an important consideration in modeling spent fuel and storage cask integrity. Because materials generally degrade more rapidly at higher temperatures, limits must be set on 


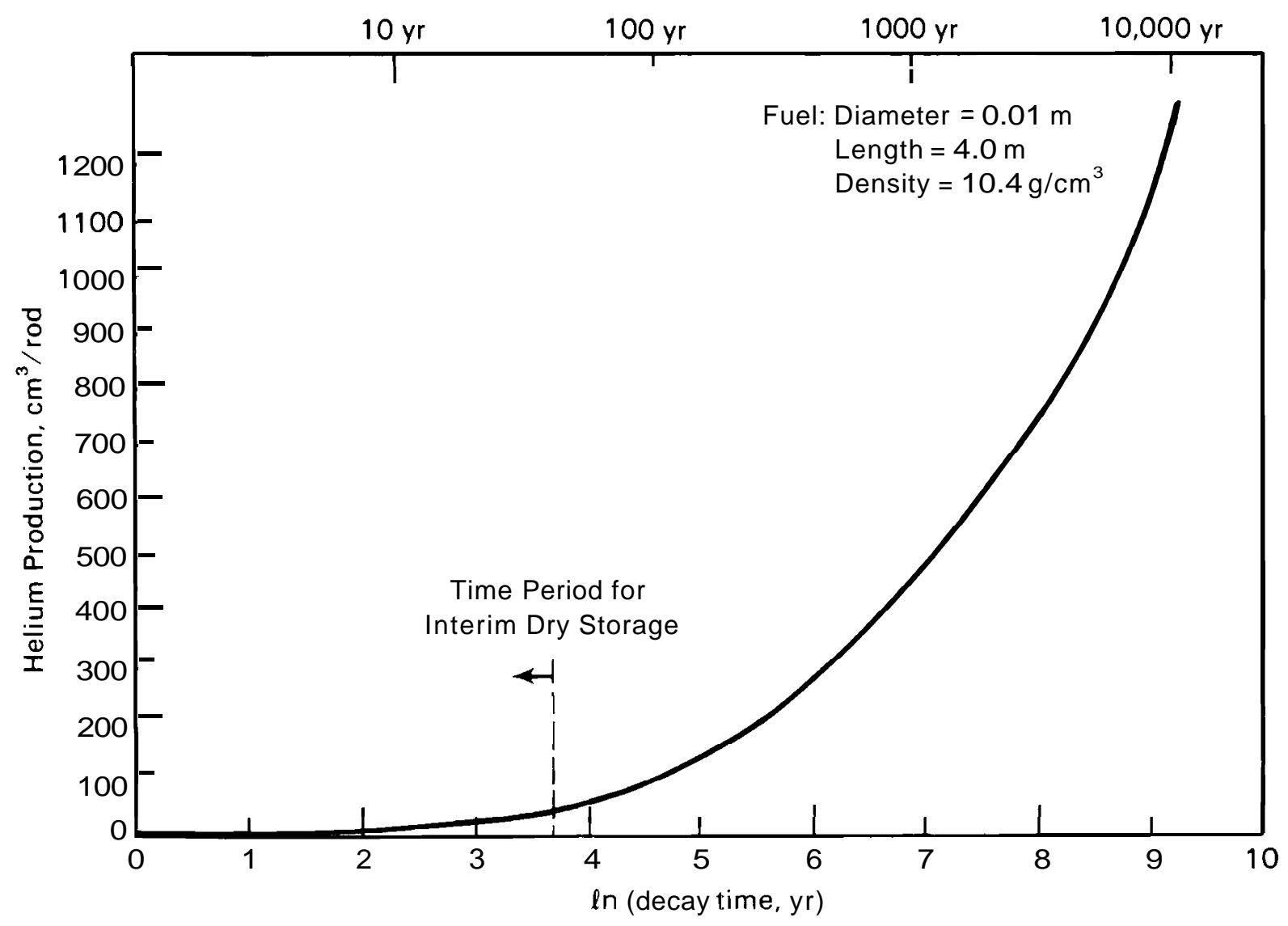

FIGURE 4.5. Predicted Helium Production from Actinide Decay for a Specific Spent Fuel Rod

maximum allowable spent fuel storage temperatures. Temperature limits based on material integrity tests conducted under isothermal conditions may be overly conservative. More realistic estimates of allowable storage temperatures may be obtained by modeling material integrity under the decreasing temperature history characteristic of radioactive decay in the fuel. This section discusses the prediction and modeling of the time dependence of fuel and cask temperatures under IDS conditions.

Spent fuel temperatures during IDS depend primarily on the decay heat power level in the fuel and on the rate at which this heat is dissipated to the environment. Decay heat levels decrease exponentially with time after discharge from the reactor, and the absolute magnitude depends on fuel burnup and the operating history under which the burnup was accumulated. The rate of heat 
transfer to the environment depends primarily on the geometric design of the storage system and the thermal properties of the materials used in the storage system. While storage temperatures generally decrease with time, predicting a specific temperature-time history requires detailed specification of cask design, fuel age, fuel burnup, and storage configuration.

Recent dry storage cask demonstrations have provided experimental data on spent fuel cladding temperatures for various metal cask designs during IDS. These tests have included the CASTOR-I and TN-1300 casks in the FRG (Spilker and Fleisch 1986; Geiser 1986), the CASTOR-V/21 cask (Creer and Schoonen 1986), the MSF-IV (REA-2023) cask (McKinnon et al. 1986a), the TN-24P cask (McKinnon et al. 1986b), and the MC-10 cask. Tests on the CASTOR-I and TN-1300 casks consisted of temperature measurements during vacuum drying operations and with a helium backfill. Tests on the CASTOR-V/21 and MSF-IV (REA-2023) casks involved vertical and horizontal orientations with a helium fill gas, a nitrogen fill gas, or vacuum; tests are also planned using consolidated fuel rods (Creer and Schoonen 1986).

Thermal analysis computer codes have recently been adapted to the problem of modeling the thermal behavior of dry storage casks, thus predicting the temperature history of the spent fuel. Two such codes are the COBRA-SFS and HYDRA thermal analysis codes developed at PNL (Wheeler et al. 1986). Both codes allow three-dimensional modeling and use a finite-difference formulation to solve the mass, momentum, and energy conservation equations to determine the pressure, temperature, and velocity fields. Heat transfer is modeled by fuidfluid conduction, solid-solid conduction, surface-to-surface radiation, and convection. HYDRA is a steady-state code that can model buoyancy-driven flows by defining the appropriate direction for the gravity vector. COBRA-SFS uses a steady-state subchannel formulation with the channels connected by thermal conduction and diversion cross-flow.

HYDRA and COBRA-SFS have both been shown to be effective in calculating temperature distributions in dry storage casks (Wheeler et al. 1986; Lombardo et al. 1986). Pretest predictions using nominal cask dimensions and nominal thermal property values for cask materials gave temperature values within 20 to $30^{\circ} \mathrm{C}$ of the actual measured data. Post-test calculations using more accurate 
as-built dimensions and thermal properties resulted in mean code-to-data differences of $\pm 10^{\circ} \mathrm{C}$ for HYDRA and $\pm 3^{\circ} \mathrm{C}$ for COBRA-SFS (Wheeler et al. 1986). These codes are now validated for use in dry storage cask analyses (Lombardo et al. 1986).

An additional component of modeling temperatures accurately during dry storage is correctly predicting the decay heat of the stored spent fuel as a function of decay time. It has been concluded (Beeman 1986) that the ORIGEN2 decay heat code (Heeb 1986) can predict decay heat within 10\% of the measured values for spent fuel with cooling times of up to 10 years. The code generally overpredicts the measured decay heat and is thus conservative for use in supplying decay heat levels to cask temperature codes.

\subsection{CLADDING TEMPERATURES DURING CASK DRYING OPERATIONS}

In addition to the long-term IDS period, spent fuel will also be exposed to elevated temperatures during cask loading and drying operations following pool storage. A common method of cask drying is a vacuum process that requires several hours (2 to 5) and a minimum gas pressure of $1 \times 10^{-4} \mathrm{MPa}$ (Fleisch and Ramcke 1983). Experience in the $\mathrm{RR}$ has shown that under relatively short drying cycles $\left(2\right.$ to $5 \mathrm{~h}$ ) temperature excursions above $380^{\circ} \mathrm{C}$ are unlikely.

If vacuum drying should cause temperature excursions above the CSFM IDS cladding temperature $1 \mathrm{imit}$ (Section 4.1), two approaches are suggested:

- implement special procedures to keep cladding temperatures below the CSPM IDS cladding temperature limit

- request a temperature variance for the relatively short period of the drying operation.

The technical basis to request a temperature variance for the short-term cask drying operations is supported by Zircaloy tests at temperatures $>500^{\circ} \mathrm{C}$ (Table E.I) for times of 30 days or more with no cladding failures (Einziger et al. 1982). The absence of cladding failures in these tests indicates that the short period required for cask drying will probably not compromise cladding integrity for fuel with cladding hoop stresses near, or below, those of the fuel types that were high-temperature tested. At temperatures near or above 
$400^{\circ} \mathrm{C}$, some annealing of irradiation damage is likely, even in a few hours. Annealing results in higher cladding ductility and therefore tends to improve, rather than degrade, subsequent cladding integrity (Lowry et al. 1981).

Although cladding breach during drying operations is not likely, unacceptable levels of cladding strain could occur if the spent fuel was exposed to elevated temperatures for extended periods of time. Using the CSFM cladding creep model and assuming $70 \mathrm{MPa}$ cladding stress for $24 \mathrm{~h}$, predicted cladding strain would be $0.10 \%$ at $436^{\circ} \mathrm{C}, 0.23 \%$ at $450^{\circ} \mathrm{C}$, and $3.37 \%$ at $500^{\circ} \mathrm{C}$. The associated cumulative damage factors for the three temperatures are $5.7 \%, 12.1 \%$, and $48.8 \%$. Obviously, strain is a function of time at temperature and therefore shorter periods of exposure would reduce the strain predicted for the above temperatures.

A cladding strain limit of $0.1 \%$ during cask drying operations is recommended. This level of plastic strain is approximately equivalent to the elastic strain at the yield stress limit and will result in a minimal level of damage to the spent fuel cladding. With a $0.1 \%$ strain limit, a temperature of $450^{\circ} \mathrm{C}$ would be acceptable for an 8 -h working shift.

Some cladding oxidation may occur due to reaction with moisture as drying proceeds. However, the moisture levels will rapidly dissipate during drying to levels where cladding oxidation will be insignificant. Temperatures greater than $600^{\circ} \mathrm{C}$ are required to cause substantial Zircaloy oxidation over a 1-day period, even at high oxidant levels (Johnson, Gilbert, and Guenther 1983; Johnson and Gilbert 1983a).

Based on the above discussion, it is concluded that cask drying operations should not compromise spent fuel cladding integrity. 


\subsection{REFERENCES}

Bailey, W. J. 1987. Categorization of Failed and Damaged Spent LWR Fuel Current1y in Storaae. PNL-5882. Pacific Northwest Laboratorv. Richland. Washington.

Bailey, W. J., and A B. Johnson, Jr. 1986. Fuel and Pool Component Performance in Storage Pools. EPRI NP-4.561, Electric Power Research Institute, Palo Alto, California.

Bailey, W. J., and S. Wu 1986. Fuel Performance Annual Report for 1985. NUREG/CR-3950, PNL-5210, Pacific Northwest Laboratory, Rich1and, Washington.

Beeman, G. H 1986. "Storage System Modeling and Analysis Workshop." In Proceedings of Third International Spent Fuel Storage Techno1ogy Symposium/ Workshop, CONF-860417, pp. W-93 to W-96.

Blackburn, L. D., et al. 1978. Maximum Allowable Temperature for Storage of Spent Nuclear Fuel; An Interim Report. HEDL-TME 78-37, Hanford Engineering Development Laboratory, Richland, Washington.

Bosi, D. M. 1981. An Assessment of Spent Fuel Structural Integrity Under Disposal Cycle Conditions. HEDL-TME 80-84, Hanford Engineering Development Laboratory, Richland, Washington.

Chin, B. A., M. A. Khan, and J. Tarn. 1986. Deformation and Fracture Map Methodology for Predicting Cladding Behavior During Dry Storage. PNL-5998, Pacific Northwest Laboratory, Richland, Washington.

Coleman, C. E., et al. 1985. "Minimizing Hydride Cracking in Zirconium Alloys." Candian Metallurgical Quarterly 24(3):245-250.

Creer, J. M, and D. H. Schoonen. 1986. "CASTOR-V/21 PNR Spent Fuel Storage Cask Performance Test." In Proceedings of Third International Spent Fuel Storage Technology Symposium/Workshop, CONF-860417, pp. S-20 to S-42.

Croff, A. G. 1980. ORIGEN2--A Revised and Updated Version of the Oak Ridge Isotope Generation and Depletion Code. ORNL-5621, Oak Ridge National Laboratory, Oak Ridge, Tennessee.

Cubicciotti, D., and R. L. Jones. 1978. EPRI-NASA Cooperative Project on Stress Corrosion Cracking of Zircaloys. EPRI NP-717 (RP 455-1), Electric Power Research Institute, Palo Alto, California.

Cubicciotti, D., R. L. Jones, and B. C. Syrett. 1980. Stress Corrosion Cracking of Zircaloy. EPRI NP-1329, Electric Power Research Institute, Palo Alto, California. 
Einziger, R. E., et al. 1982. "High Temperature Postirradiation Materials Performance of Spent Pressurized Water Reactor Fuel Rods Under Dry Storage Conditions." Nucl. Tech. 57:65-80.

Einziger, R. E., and R. Kohli. 1984. Low-Temperature Rupture Behavior of Zircaloy Clad Pressurized Water Reactor Spent Fuel Rods Under Dry Storage Conditions. HEDL-7400, Hanford Engineering Development Laboratory, Richland, Washington.

Farwick, D. G., and R. A Moen. 1979. Properties of Light Water Reactor Spent Fuel Cladding. HEDL-TME 79-20, Hanford Engineering Development Laboratory, Richland, Washington.

Fleisch, J., and K Ramcke. 1983. "Exgerience with a Shipping and Storage Container of the CASTOR Type in the Wurgassen Nuclear Power Plant." Atomwirtshaft.

Geiser, H. 1986. "Experimental Tests and Theoretical Analysis of the Heat Transfer Performance of CASTOR Casks." In Proceedings of Third International Spent Fuel Storage Technology Symposium/Workshop, CONF-860417, pp. W-113 to W-133.

Genks, G. H 1979. Effects of Gaseous Radioactive Nuclides on the Design and Operation of Repositories for Spent LR Fuel in Rock Salt. ORNL-5578, Oak Ridge National Laboratory, Oak Ridge, Tennessee.

Heeb, C. M. 1986. "Comparison of Spent Fuel Decay Heat Rate ORIGEN2 Predictions and Calorimeter Measurements." In Proceedings of Third International Spent Fuel Storage Technology Symposium/Workshop, CONF-860417, pp. W-103 to W-112.

Hoagland, R. G. A. L. Bement, and R. G. Rowe. 1967. "Applications of Fracture Mechanics in Evaluating Initiation and Propagation of Brittle Fracture in Reactor Structural Components." In Effects of Radiation on Stuctural Metals, ASTM STP 426, pp. 328-345.

Hoffman, P., and J. Spino. 1985. "Conditions Under Which Cs I Can Cause SOC Failure of Zircaloy Tubing." J. Nucl. Mat. 127:205-220.

Johnson, A. B., Jr., and E. R. Gilbert. 1983a. "Reaction of Fuel Cladding with Cover Gases Under Dry Storage Conditions." In Proceedings of Spent Fuel/Cladding Reaction During Dry Storage, NUREG/CP-0049. Gaithersburg, Maryland.

Johnson, A. B., Jr., and E. R. Gilbert. 1983b. Technical Basis for Storage of Zircaloy-Clad Spent Fuel in Inert Gases. PNL-4835, Pacific Northwest Laboratory, Richland, Washington.

Johnson., A. B... Jr.. E. R. Gilbert., and R. J. Guenther. 1983. Behavior of Spent Nuclear Fuel and Storage System Components in Dry Interim Storage. PNL-4189, Rev. 1, Pacific Northwest Laboratory, Richland, Washington. 
Kawanishi, H., S. Ishino, and Y. Mishima. 1974. "Directionality of the Grain Boundary Hydride in Zircaloy-2." In Zirconium in Nuclear Applications, ASTM STP 551, pp. 201-211.

Keusseyan, R. L. 1985. Grain Boundary Sliding and Related Phenomena. Ph.D. Thesis, Cornell University. University Microfilms International, Ann Arbor, Michigan.

Kohn, E. 1977. "In-Reactor Creep of Zr-2.5 Nb Fuel Cladding." In Zirconium in the Nuclear Industry, ASTM STP 633.

Kreyns, P. H., G. L. Spahr, and J. E. McCauley. 1976. "An Analysis of lodine Stress Corrosion Cracking of Zircaloy-4 Tubing." J. Nucl. Mat. 61:203-212.

Kubo, T., et al. 1985. "Effects of Crystallographic Orientation on Plastic Deformation and SCC Initiation of Zirconium Alloys." J. Nucl. Mat. 132:1-9.

Levy, I- S., et al. 1987. Recommended Temperature Limits for Dry Storage of Spent Light Water Reactor Zircaloy-Clad Fuel Rods in Inert Gas. PNL-6189, Pacific Northwest Laboratory, Richland, Washington.

Lombardo, $\mathrm{N}$ J., et a1. 1986. COBRA-SFS: A Thermal-Hydrauli c Analysis Computer Code; Volume III - Validation Assessments. PNL-6049, Pacific Northwest Laboratory, Richland, Washington.

Lowry, L. M, et al. 1981. Evaluating Strength and Ductility of Irradiated Zircaloy - Task 5. NUREG/CR-1729. Vol. 1. Battell e Columbus Laboratories. Columbus, Ohio.

MacDonald, E. 1984. Certificate of Compliance for Radioactive Materials Packages. U.S. Nuclear Regulatory Commission, No. 9016, Rev. 6, Washington, D.C.

Maki, H. and T. Hara. 1975. "Out-of-Reactor Study on External Pressure Creep of Zircaloy-2 Fuel Cladding Tubes." J. Nucl. Sci. and Tech. 12:43-52.

Mattas, R. F., L. A Neimark, and F. L. Yaggee. 1980. Characterization of Irradiated Zircaloy: Susceptibility to Stress Corrosion Cracking, EPRI NP-1557, Electric Power Research Institute, Palo Alto, California.

Mckinnon. M. A.. et al. 1986a. "REA-2023 BNR Cask Performance Test." In Proceedings of Third International Spent Fuel Storage Technology Symposium/ Workshop. CONF-860417, pp. S-45 to S-60.

McKinnon, M. A, et al. 1986b. TN-24P RR Spent Fuel Storage Cask Performance Testing and Analyses. EPRI NP-5128, Electric Power Research Institute, Pa10 Alto, California.

Northwood, D. 0., and U. Kosasih. 1983. "Hydrides and Delayed Hydrogen Cracking in Zirconium and Its Alloys." International Metals Reviews 28(2):92-121. 
Pahutova, M., and J. Cadek. 1973. "Zirconium in Terms of Effective Stress and Dislocation Dynamics." Engineering 11:151-162.

Pahutova, M, K Kucharova, and J. Cadek. 1977. "Some Basic Creep Characteristics of Zr-Sn-Mo and Zr-Sn-Mo-Nb Alloys -- Part II. Fracture in Creep." Mat. Sc. and Eng. 27: 249-255.

Peehs, M, et al. 1983. "Zircaloy Post-Pile Creep Experimental Procedure, Test Samples and First Results." Paper presented at IAEA Seminar of Technical and Environmental Aspects of Spent Fuel Management, September 27-30, 1983, Madrid, Spain.

Peehs, M., R. Bokelmann, and J. Fleisch. 1986. "Spent Fuel Dry Storage Performance in Inert Atmosphere." In Proceedings of Third International Spent Fuel Storage Technology Symposium/Workshop, CONF-860417, pp. S-215 to S-230.

Peehs, M., and J. Fleisch. 1986. "LWR Spent Fuel Storage Behavior." J. Nucl. Mat. 137:190-202.

Porsch, G, J. Fleisch, and B. Heits. 1986. "Accelerated High-Temperature Tests With Spent PNR and BNR Fuel Rods Under Dry Storage Conditions." $\mathrm{Nucl}_{\text {. }}$ Tech. 74:287-298.

Rolfe, S. T., and J. M. Barsom. 1977. Fracture and Fatigue Control in Structures; Applications of Fracture Mechanics. Prentice-Hall Inc., Englewood Cliffs, New Jersey.

Rowe, R. G. and R. G. Hoagland. 1969. "The Effect of Cold Work, Thermal Transient, and Neutron Irradiation on the Fracture Toughness of Zircaloy-2." In Irradiation Effects in Structural Alloys for Thermal and Fast Reactors, ASTM STP 457, pp. 3-16.

Spilker, H, and J. Fleisch. 1986. "Dry Storage Demonstrations of CASTOR-I and TN-1300 Casks." In Proceedings of Third International Spent Fuel Storage Technology Symposium/Workshop, CoNF-860417, pp. S-1 to S-18.

Tasooji, A, R. E. Einziger, and A. K Miller. 1984. "Modeling of Zircaloy Stress-Corrosion Cracking: Texture Effects and Dry Storage Spent Fuel Behavior." In Zirconium in the Nuclear Industry: Sixth International Symposium, ASTM STP 824, pp. 190-202.

Turner, S. E., et al. 1982. Background and Derivation of ANS-5.4 Standard Fission Product Release Model. NUREG/CR-2507. Southern Science Adplications. Inc., Dunedin, Florida.

Van Echo, J. A, and S. W. Porembka. 1965. Long-Term Creep Rupture of Sintered Aluminum Powder and Zircaloy-2 Alloys. BMI-X-10113, Battelle Memorial Institute, Columbus, Ohio. 
Wheeler, C. L, et al. 1986. "HYDRA and COBRA-SFS Temperature Calculations for CASTOR-IC, REA-2023, CASTOR-V/21, and TN-24P Casks." In Proceea'ings of Third International Spent Fuel Storage Technology Syrnposium/Workshop, CONF-860417, pp. S-77 to S-98.

Wood, D. S, and B. Watkins. 1971. "A Creep Limit Approach to the Design for Zircaloy-2 Reactor Pressure Tubes at $275^{\circ} \mathrm{C} . "$ J. Nucl. Mat. 41:327-340. 
APPENDIX A

ZIRCALOY DEGRADATION MECHANISMS: STRESS CORROSION CRACKING AND HYDROGEN 
APPENDIX A

\section{ZIRCALOY DEGRADATION MECHANISMS: STRESS CORROSION CRACKING AND HYDROGEN}

Crack growth in Zircaloy can occur by three mechanisms in addition to creep: brittle fracture, stress corrosion cracking (SCC), and delayed hydride cracking (DHC). To cause crack propagation, each mechanism requires a stress intensity, i.e., stress and flaw size, greater than a critical (or threshold) level. Above that critical stress intensity, crack propagation can occur either by a rapid unstable mechanism or by a slow (time-dependent) stable mechanism.

Brittle fracture is a rapid unstable process whereas $\mathrm{DHC}$ and $\mathrm{SOC}$ are slow, stable growth mechanisms during inerted dry storage (IDS). Brittle fracture is a mechanical process influenced by radiation and hydride precipitation while $\mathrm{DHC}$ and $\mathrm{SOC}$ are chemical-based processes influenced by hydride precipitation and iodine. In the following discussion, the effects of stress intensities are evaluated, and it is assumed that sufficient hydrogen and iodine exist to cause cracking. Additional detailed analyses are presented in Sections A.l through A.3.

The dependency of crack growth on the stress intensity factor at $350^{\circ} \mathrm{C}$ and the range of stress intensity factors expected for Zircaloy cladding during IDS are shown in Figure A.1. The critical (threshold) stress intensity factors and the regimes for stable crack growth are indicated. All crack growth mechanisms require stress intensities that are larger than expected for IDS. The critical stress intensities are 3,12 , and $>40 \mathrm{MPa} \cdot \sqrt{\mathrm{m}}$ for SCC, DHC, and brittle fracture, respectively. The $S O C$ growth kinetics are based on the analysis of Kreyns, Spahr, and McCauley (1976); and the DHC growth kinetics are based on the analysis of Ambler (1984).

The SCC mechanism dominates at lower stress intensities, and the unstable brittle crack growth mechanism dominates at higher stress intensities. The DHC mechanism is significant at intermediate stress intensities but is never the dominant crack growth mechanism at $350^{\circ} \mathrm{C}$. At temperatures below $350^{\circ} \mathrm{C}$, DHC 


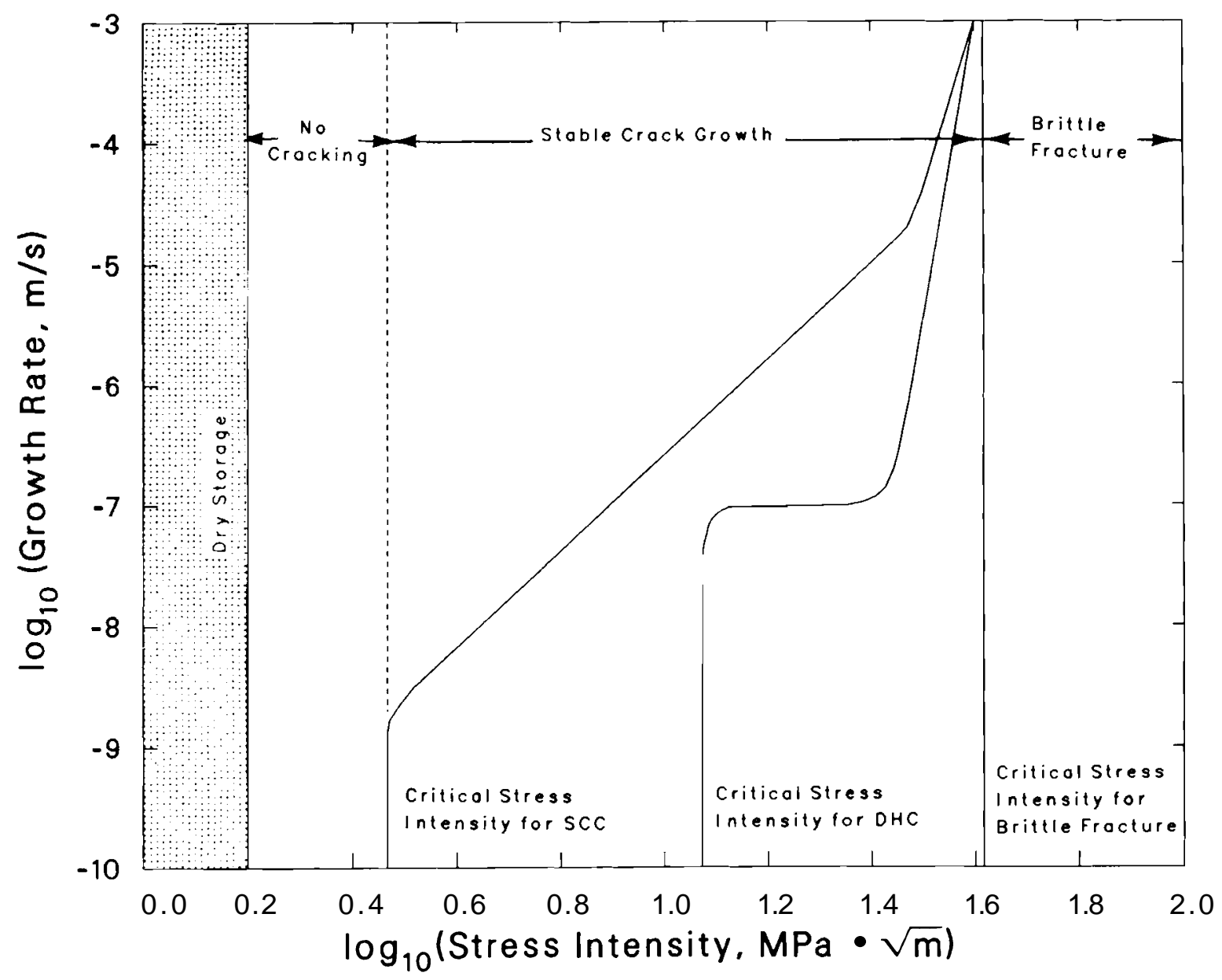

FIGURE A.1. Relationship Between Stress Intensity and Crack Growth Rate for Zircaloy at $350^{\circ} \mathrm{C}$

growth rates are predicted to be faster than SCC growth rates at intermediate stress intensities. These intermediate stress intensities, however, are much greater than those expected during IDS.

Experimentally observed stress intensity thresholds are subject to uncertainty, particularly because of the difficulty of experimentally measuring very slow crack growth rates. If the observed stress intensity thresholds were not present, crack growth rates at low stress intensity levels would be predicted by extrapolating high stress intensity crack growth kinetics. Such an extrapolation is presented in Figure A2 with crack growth rates for $\mathrm{SOC}$ and DHC extrapolated to a stress intensity of $1.6 \mathrm{MPa} \cdot \sqrt{\mathrm{m}}$ (cladding stress of $70 \mathrm{MPa}$ and initial crack size of $0.13 \mathrm{~mm}$ ). The extrapolated $\mathrm{DHC}$ growth rate is 
$2130 \mathrm{~mm} /$ year, and the extrapolated $\mathrm{SOC}$ growth rate is $5 \mathrm{~mm} /$ year. Both mechanisms would, in the absence of a critical stress intensity, generate a cladding breach.

The conclusion that $S O C$ and $D H C$ will not cause cladding breach during IDS, therefore, depends on the validity of the measured threshold stress intensities for $S O C$ and DHC. If crack growth can be initiated below the known threshold values (which has not been observed), then the crack growth rates would be sufficiently fast to cause cladding breach during IDS at the CSFM IDS temperature 1 imit (Section 4.1).

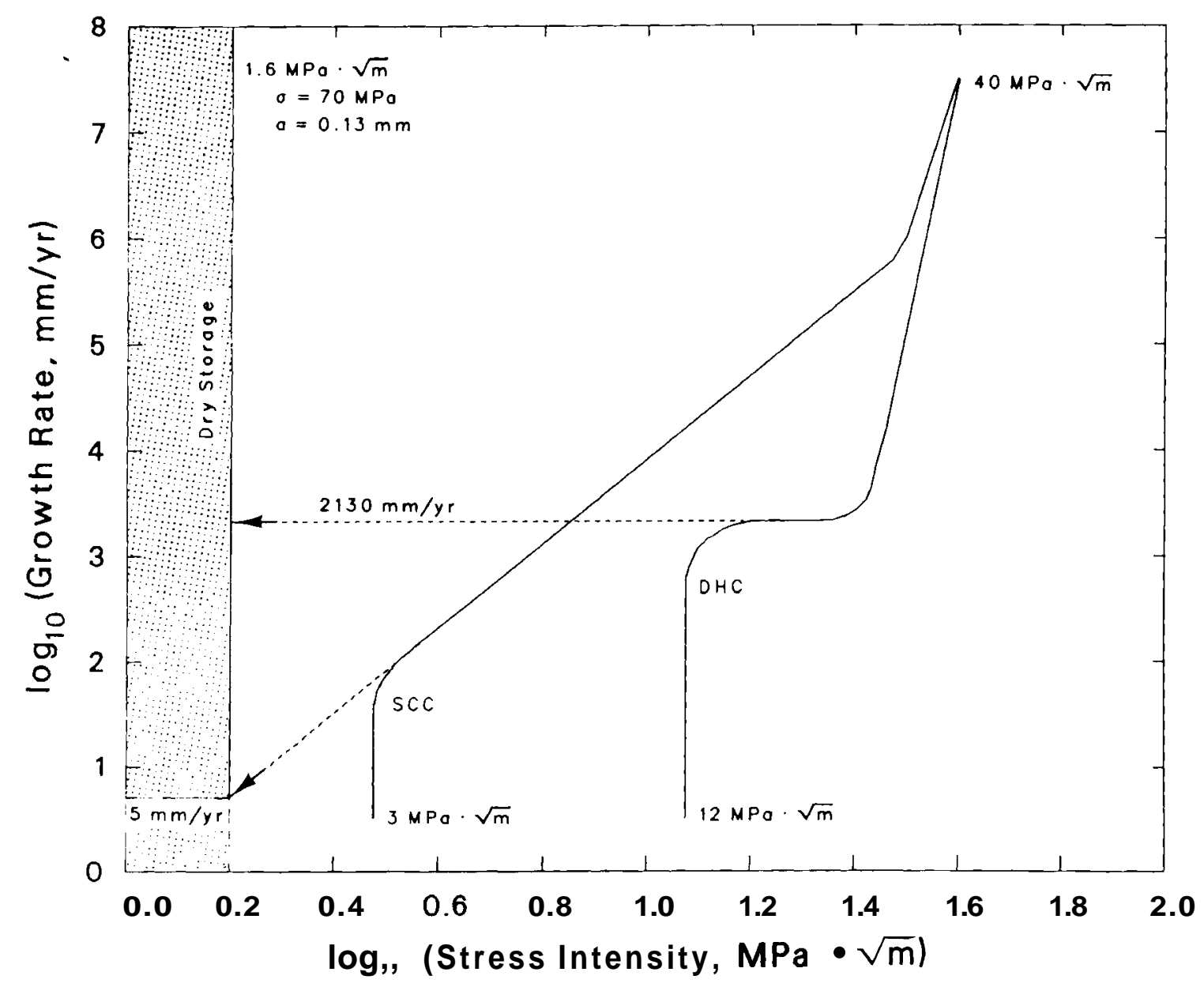

FIGURE A.2. Crack Growth Rates Extrapolated to a Stress Intensity of $1.6 \mathrm{MPa} \cdot \sqrt{\mathrm{m}}$ for Zircaloy at $350^{\circ} \mathrm{C}$ 


\section{A.I STRESS CORROSION CRACKING}

Stress corrosion cracking is an important Zircaloy degradation mechanism during IDS because it may directly cause crack growth through the full thickness of the cladding. Also, SCC may cause cladding breach indirectly by producing deep cracks that may subsequently extend through the cladding by another mechanism such as DHC.

Causes for cracks and mechanistic requirements for SCC are described in this section. Estimates of temperature limits for IDS are given based on crack growth mechanisms and data. Stress corrosion cracking is not expected during IDS because threshold iodine concentrations and threshold stress intensities are not exceeded by spent fuel during IDS (Figure A.1). Crack growth predictions, assuming that crack growth is possible below these thresholds and extrapolating the experimentally observed behavior, indicate that crack growth would be rapid enough to cause cladding breach at temperatures less than the CSFM IDS temperature limit.

To evaluate crack growth, the existence of cracks of some size and number must be assumed. These cracks originate from mechanical flaws that were not eliminated by examination before irradiation and from pellet-cladding interaction mechanisms during irradiation. Cracks propagate during irradiation as a result of reactor power maneuvers (ramping), noncorrosive creep cracking, and $s \propto C$ induced by iodine and other corrosive species. If the cracks in the cladding have not grown through the cladding by the time the fuel rods are removed from the reactor and placed into storage, it may be statistically possible that some cracks would continue to grow under storage conditions either by continued SCC or by other mechanisms until the crack breached the cladding.

Steinberg, Peehs, and Stehle (1983) inspected the surfaces of nonirradiated cladding specimens that had been pressurized and found a plurality of induced cracks with a log-normal distribution of depths. With increasing strain and the presence of iodine, the mean crack depth (and length) grew, but the number of cracks that were growing decreased. Less strain was required to produce crack extension and perforation at lower temperatures. According to Steinberg, Peehs, and Stehle, cladding breach would statistically be expected to occur when one crack reached a depth equal to the cladding wall thickness.

\section{A. 4}


Both crack coalescence and individual crack growth would contribute to the overall growth of the cracks. Using these data and methods, it would be possible to calculate a size distribution of incipient cracks and find the number of cracks in a size band that might be extended by $50 \mathrm{C}$ or DHC.

The mechanisms of I-SCC are discussed in Cubicciotti and Jones (1978). The $\mathrm{ZrO}_{2}$ film protects the Zircaloy from iodine; and until the oxide is ruptured by mechanical strain, SOC does not proceed. Cladding creep due to internal pressure stress may eventually provide sufficient strain to rupture the brittle oxide layer; but "oxide film penetration is not the critical step in the overall iodine-SCC process."(a) They believe that because the exposure of Zircaloy by cracking of the oxide layer is so small it is the formation of the crack in the Zircaloy that is critical. They suggest that it is stress rather than stress intensity or strain that is the key factor in forming the crack: "the threshold stress is the stress required to form crack nuclei at chemical inhomogeneities and that their propagation causes iodine-induced failure." Crack initiation and propagation occur if the stress is large enough ( $>315 \mathrm{MPa}$ ) and the iodine concentration is sufficient (iodine $>5 \times 10^{-6} \mathrm{~g} / \mathrm{cm}^{2}$ ). Note that the stress specified by Cubicciotti and Jones is much greater than that expected for IDS conditions.

Williford (1984) suggested that strain rate sensitivity of the I-SCC process is caused by competition between chemical reaction and material creep rate phenomena, rather than by stress thresholds or by the requirement that a complete monolayer of $\mathrm{ZrI}_{4}$ form on the crack tip. He says that failure times are dominated by the time required to initiate active crack growth. He proposes a chemically assisted creep cracking model that permits "thresholdN concepts to be treated as very slow processes whose physical manifestations are too small to be measured in usual experiments.

When a crack (longitudinal cracks that grow across the wall perpendicular to the hoop stress in the cladding) is of sufficient size to allow continuum mechanics to be applied, the minimum stress intensity for iodine cracking is

(a) Cubicciotti and Jones (1978) state that the smallest strain associated with iodine-induced failure in their Zircaloy- 4 tubing tests was $0.3 \%$. 
$9 \mathrm{MPa} \cdot \sqrt{\mathrm{m}}$. Cubicciotti and Jones (1978) point out that this value is in agreement with I-SCC data of other investigators, although the minimum stress intensity may be less in irradiated cladding. They indicate that a valid ASTM test did not generate a failed crack at stress intensities as low as 2.4 to 3.3 $\mathrm{MPa} \cdot \sqrt{\mathrm{m}}$. The controlling factor for crack growth changes from stress to stress intensity at a crack depth of 0.1 to $0.2 \mathrm{~mm}$ (approximately $15 \%$ to $35 \%$ of the cladding thickness).

Peehs (1980) believes that (during IDS) no new cracks will be formed; i.e., no cracks in addition to those that already existed in the cladding in the reactor. Under the theory that crack growth rate depends on the stress intensity factor (Kreyns 1976), the value of this factor is of great importance. Reductions in the critical stress intensity factor would entail more cracking. In commenting on the value of the factor, Peehs says that the reduction in critical stress intensity is more severe when iodine is present, and the reduction due to iodine is greater than the reduction due to hydriding or by irradiation. Peehs uses I-SCC stress intensity factors as a basis for a conservative estimate of crack extension in IDS. The actual values to be used require some judgment because different observers have reported different values. Assuming a lower bound value for stress intensity of $3 \mathrm{MPa} \cdot \sqrt{\mathrm{m}}$ at $300^{\circ} \mathrm{C}$, (a) Peehs predicts that cracks up to 0.4 mrn deep (about $60 \%$ of the wall thickness) would not extend to a through-wall crack after 20 years.

In a paper by Miller et al. (1981), a phenomenological model was developed to predict the crack growth in Zircaloy. Data are quoted that indicate that $75 \%$ of the time to failure is spent in growing a crack to $10 \%$ of the wall thickness. Subsequent growth proceeds ever more rapidly as the crack extends. Considering a probabilistic distribution of initial flaw sizes, the Miller model is used to show the probable time to failure of various numbers of fuel rods. For example, the distributions show that the critical stress is lower for a fuel rod than for a test specimen because of the higher probability of having a large flaw in the large area of cladding in a reactor.

(a) Peehs references were Cubicciotti and Jones (1978) and Simpson and Cann (1984). 
Using some methods and information from Miller et al. (1981), an estimate can be made of the size distribution of cracks after some amount of time in the reactor. The subsequent growth of these cracks in storage could then be estimated for both I-SCC and DHC. Tasooji, Einziger, and Miller (1984) have done this to some extent for I-SCC. They show that at the end of reactor service, the maximum incipient crack size in unbreached rods would be $20 \%$ of the wall thickness at a failure probability of $1 \%$. Then using a "typical" case of $1 \%$ fission gas release, a maximum internal pressure $\left(15.2 \mathrm{MPa}\right.$ at $\left.315^{\circ} \mathrm{C}\right)$, and a burnup of $50 \mathrm{MWd} / \mathrm{kgU}$ with a nominal iodine concentration and an inert cover atmosphere, they indicate that a temperature of $450^{\circ} \mathrm{C}$ would be allowed for a 1000 -year storage period before failure. For a more "conservativen case of $20 \%$ fission gas release (higher than expected), the 1000-year storage limiting temperature was predicted to be $280^{\circ} \mathrm{C}$ or less. Shorter storage times, such as 100 years, would allow higher limiting temperatures. Peehs and Fleisch (1986) state that crack propagation will not occur for crack sizes smaller than $0.3 \mathrm{~mm}$ ( $\leqslant 50 \%$ of wall thickness) at temperatures lower than $450^{\circ} \mathrm{C}$.

Crack growth was calculated based on the growth model of Kreyns (1976), a standard spent fuel cooling history (given in Section 4.2), a 0.13-mm-deep initial crack, and a cladding stress of $70 \mathrm{MPa}$. These stress and crack sizes correspond to a stress intensity of $1.6 \mathrm{MPa} \cdot \sqrt{\mathrm{m}}$ and are reasonable bounding values for dry storage. The maximum allowable temperature for arrest of crack propagation caused by the decreasing temperature with time was determined to be $290^{\circ} \mathrm{C}$. At $300^{\circ} \mathrm{C}$, the crack was predicted to propagate through the cladding thickness, resulting in failure after 3 years of storage. The calculated increase in crack depth and the calculated decrease in temperature with increasing time are shown in Figure A.3. (a)

The $290^{\circ} \mathrm{C}$ temperature 1 imit is $-100^{\circ} \mathrm{C}$ lower than the creep rupture temperature limit for a stress of $70 \mathrm{MPa}$ (see Figure 4.3). Therefore, if SCC could initiate, then SCC could occur for storage temperatures allowed by the CSFM IDS temperature $1 \mathrm{imit}$ at and above $300^{\circ} \mathrm{C}$. However, crack initiation is not expected because neither the threshold iodine concentration nor the threshold

(a) This analysis is based on ignoring the SCC threshold stress intensity of $3 \mathrm{MPa} \cdot / \mathrm{m}$. 


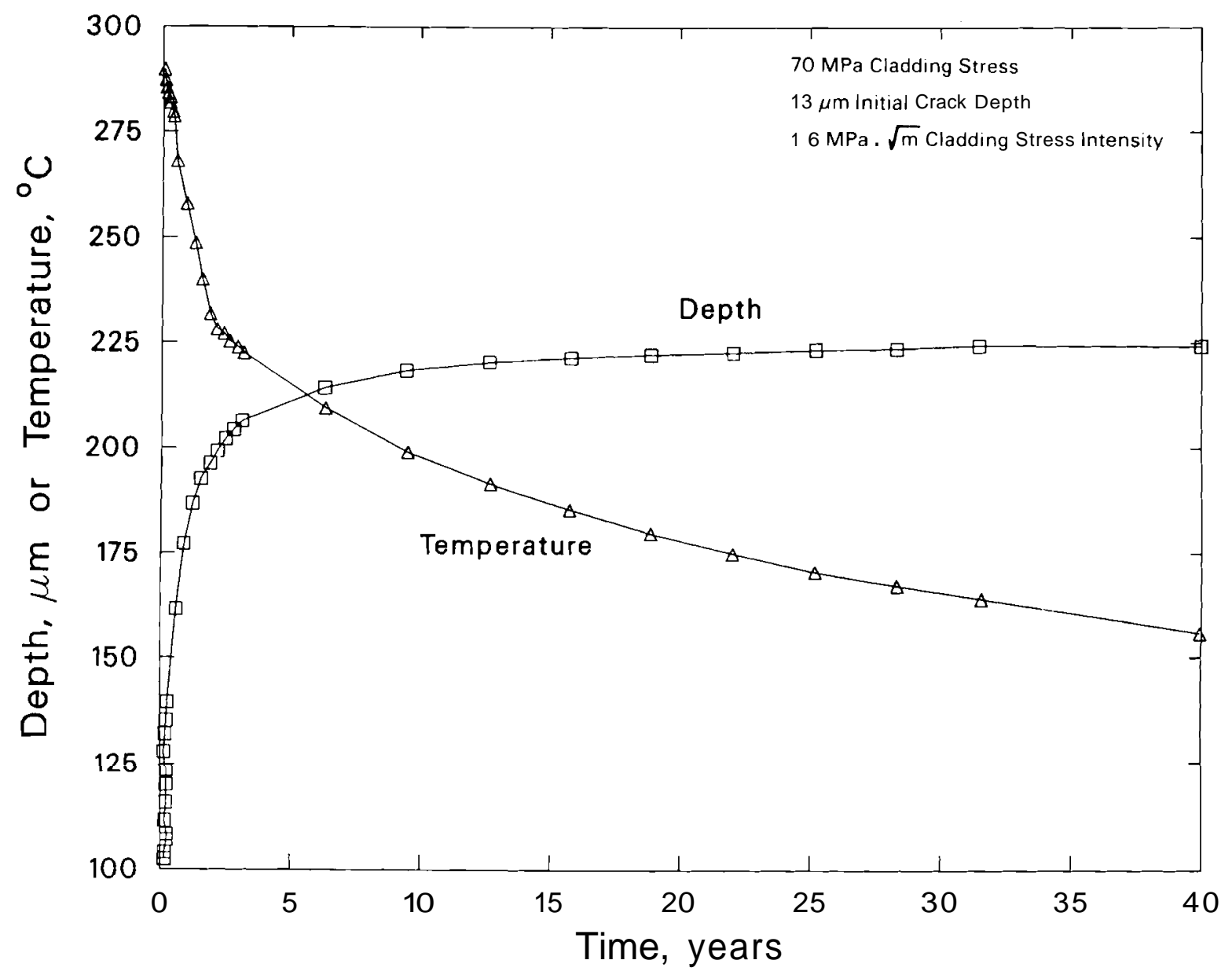

FIGURE A.3. Stress Corrosion Crack Depth for Zircaloy as a Function of Time for an IDS Temperature History

stress intensity is exceeded (see Section 3.2). Furthermore, the lack of SCC failures during dry storage demonstration tests indicates that cladding breach due to SCC has not occurred even though crack growth kinetics would be adequate to produce cladding breaches if thresholds were ignored.

A2 DELAYED HYDRIDE CRACKING

Delayed hydride cracking can occur in stressed Zircaloy during cooling when the conditions are appropriate. When cracking is observed, the measured crack growth rates are rapid, but only for conditions of high stress intensity. In this section, it is demonstrated that DHC will not be likely during IDS 
because $S O C$ is more dominant than $D H C$ at stress intensities above the stress intensity threshold for DHC. As was presented in Figure A.1, the stress intensities required for DHC are not expected during IDS.

For DHC to occur in Zircaloy, three conditions must be met: 1) an incipient defect or crack must exist; 2) hydride must be present at or near the crack tip; and 3) sufficient stress must be present to propagate the crack. The data and theory that allow the determination of these conditions are not totally unequivocal. In the discussion that follows, the factors that have been experimentally and theoretically connected to DHC in Zircaloy will be presented. For the following discussion, the presence of cracks (the first condition for DHC) will be assumed.

A DHC nucleation and growth model has been proposed by Sawatzky (1986) that may explain the observed DHC growth behavior better than the commonly used Dutton model (Dutton, Puls, and Simpson 1982).(a) In the Sawatzky model, as in the Dutton model, an "incubation period" is defined. During this incubation period, hydrogen diffuses to the stressed tip of the incipient crack from hydride platelets beyond the tip. However, once the hydride has formed at the crack tip and fractured, the hydride provides the closest source of hydrogen for further diffusion to the crack tip for crack propagation, which would account for the observed delay in initial cracking followed by an almost constant crack growth rate. Sawatzky has suggested detailed equilibrium solubility mechanisms as functions of stress and temperature rate of change that might be used to develop a quantitative model, but this has not yet been done.

Typical delay times for DHC are short $(40 \mathrm{~h})$ relative to the IDS time; thus, the DHC growth rate may be used for estimating the time to cladding breach. Unlike I-SCC, the crack growth rate does not depend on the stress intensity factor. After DHC has begun, the crack growth rate is independent of stress (provided the stress is sufficient to fracture the hydride or hydrided Zircaloy) but is a function of the temperature-dependent hydrogen diffusion rate. This discussion is further expanded in Appendix $C$.

(a) The Sawatzky model has only recently been proposed and has not yet been fully peer reviewed. 
For DHC to occur during IDS requires sufficiently high cladding stress intensities under IDS conditions. The critical stress intensity that Sawatzky (1986) states as being necessary for DHC in spent fuel is compared to predicted stress intensities in Figure A.4.(a) The same critical stress intensity value $(12 \mathrm{MPa} \cdot \sqrt{\mathrm{m}})$ was given by Dutton, Puls, and Simpson (1982) on the basis of measurements. (b) Pure bulk hydride was experimentally determined to have a critical stress intensity for cracking of -1 to $3 \mathrm{MPa} \cdot \sqrt{\mathrm{m}}$. Pure hydride is not believed to be formed at the crack tip. Some metal also exists in the stress field, resulting in a higher value of toughness results (which is affected by the orientation of the metal grains). Walker and Kass (1974) have measured much higher toughness values for irradiated, hydrided (250 ppm) Zircaloy-4 than for pure bulk hydride. In the temperature range of 100 to $300^{\circ} \mathrm{C}$, their measurenients give toughness increasing in the range of 30 to $50 \mathrm{MPa} \cdot \sqrt{\mathrm{m}}$ for a texture representative of cladding. Their data also show a large effect of texture. The Walker and Kass data also show that radiation does not significantly decrease the toughness of severely hydrided Zircaloy at room temperature and above.

The rate of crack propagation as a function of temperature has been calculated from the equations of Dutton, Puls, and Simpson (1982) and Kreyns, Spahr, and McCauley (1976) and is presented in Figure A.5. (c) At temperatures above about $285^{\circ} \mathrm{C}$ and at stress intensities above the critical stress intensity, DHC

(a) The curves in Figure A.4 were calculated based on typical spent fuel fill gas pressures and cladding stresses for pressurized water reactor (PWR) rods in IDS. The gas pressures and dimensions given by Levy et al. (1987) were used to calculate the stress intensity factor for various crack lengths using the methods and results of Delale and Erdogan (1982) and a power-law temperature decay with time given by Tarn, Madsen, and Chin (1986).

(b) Dutton, Puls, and Simpson (1982) give a lower critical stress intensity for $\mathrm{Zr}-2.5 \% \mathrm{Nb}$, and the difference between the two alloys is explained as being due to the difference in texture, which limits the maximum amount of hydride that can be formed at the crack tip.

(c) The crack growth rates given by Dutton, Puls, and Simpson (1982) for DHC are for Zircaloy-2, and the rates given by Kreyns, Spahr, and McCauley (1976) for I-SCC are for Zircaloy-4. It is assumed that the results of Kreyns, Spahr, and McCauley would have been similar to those of Dutton, Puls, and Simpson if they had used Zircaloy-2. 


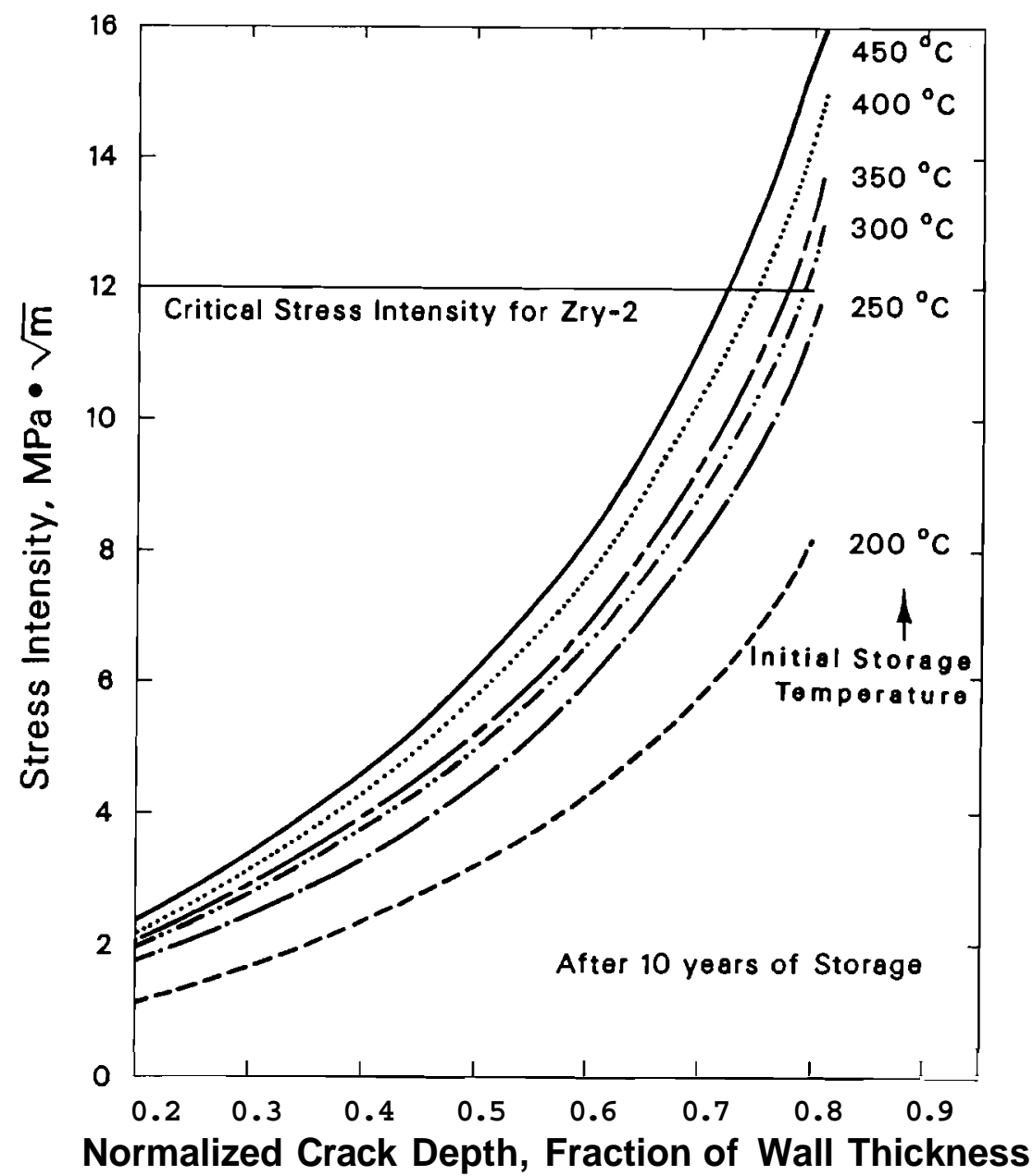

FIGURE A.4. Initial Cladding Stress Intensity for Various Crack Depths in Zircaloy Spent Fuel Cladding

is slower than I-SCC. Thus, a crack that had progressed by I-SCC to or through a zone of stress intensity greater than $12 \mathrm{MPa} \cdot \sqrt{\mathrm{m}}$ would move more slowly by the DHC mechanism. Therefore, it appears that DHC is not as likely to cause cladding breach as is I-SCC (discussed in Section A.I). Therefore, the I-SCC crack growth rates and criteria will probably bound those of DHC for long-term IDS. At temperatures below $285^{\circ} \mathrm{C}$ and at stress intensities high enough to cause $D H C$, Figure A.5 indicates that DHC would propagate a crack faster than I-SCC.

An additional point of interest related to DHC deals with the direction of approach, either heating or cooling, to a test temperature. Ambler (1984) has 


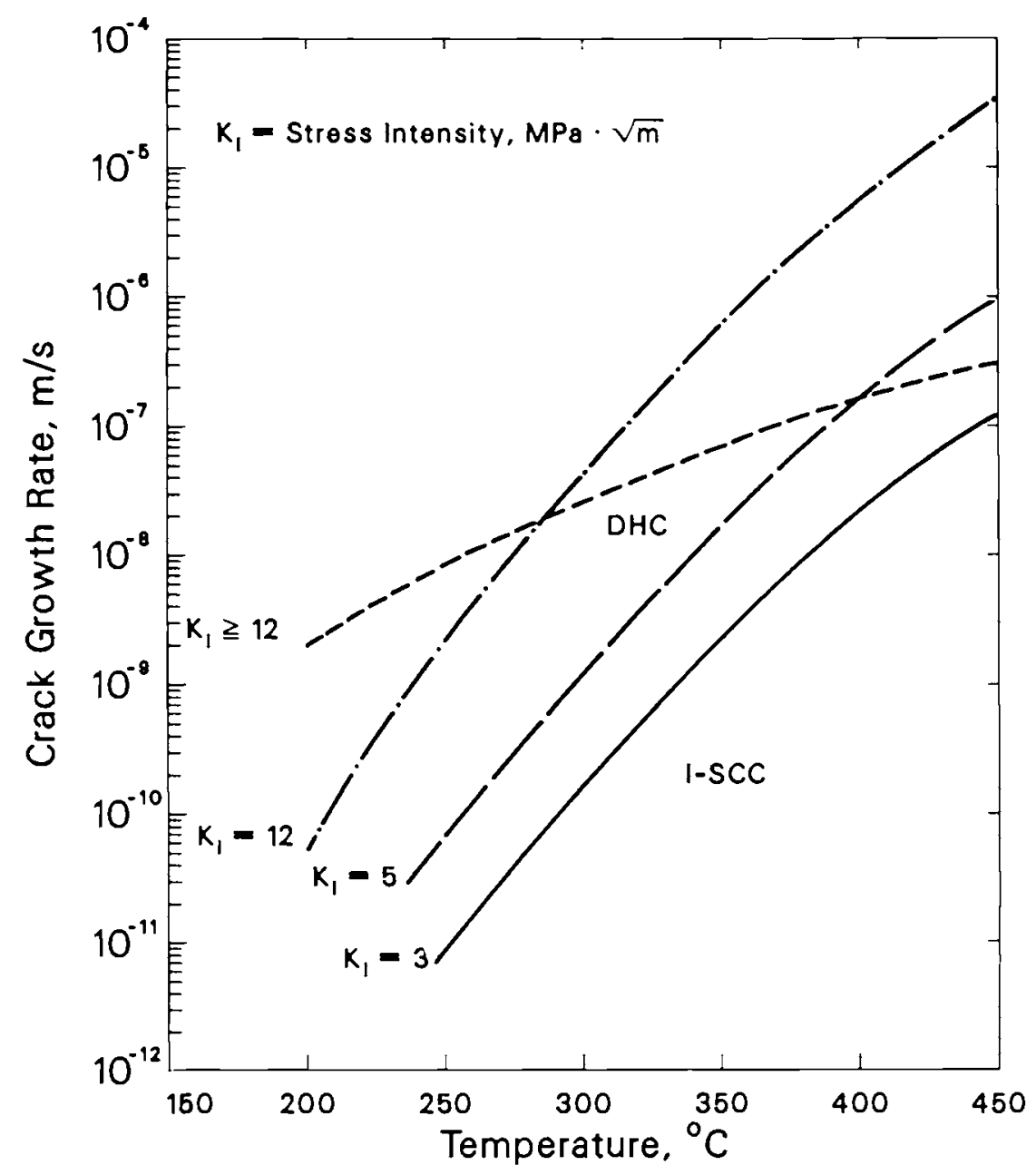

FIGURE A.5. Crack Growth Rates in Zircaloy-2 Due to I-SCC and DHC

shown that DHC behavior of $\mathrm{Zr}-2.5 \% \mathrm{Nb}$ is affected by whether the test temperature is approached by cooling or heating. Both Ambler (1984) and Sawatzky $(1986)^{(a)}$ provide theoretical explanations of this effect. In summary, if the test temperature is reached by cooling from a higher temperature, the measured crack growth rate is an Arrhenius function of temperature. If the sample is first cooled and then heated to the test temperature, the measured crack growth rate still follows the same Arrhenius function but only up to a certain temperature. About $50^{\circ} \mathrm{C}$ beyond that temperature, the crack growth rate is perhaps 100 to 1000 times slower than when the test temperature was reached by cooling.

(a) See Appendix C for Sawatzky's discussion. 
This observed effect may be due to the precipitation of the hydride in a constrained condition that is released upon heating and thus lowers the driving force for diffusion to the crack tip.

Preparation of fuel rods for dry storage (cooling in the reactor and storage pool followed by self-heating in dry storage) is similar to Ambler's heating technique and has been suggested by Coleman et al. (1985) as a technique for minimizing $\mathrm{DHC}$ at temperatures between $177^{\circ} \mathrm{C}$ and $327^{\circ} \mathrm{C}$. Because the cladding temperature can rise to an annealing level in IDS, the temperature for the crack growth rate reduction effect also depends on the hydrogen concentration in the cladding. This is because the hydrogen concentration determines the annealing temperature at which all hydride would be redissolved upon heating in IDS. (a) If the IDS temperature rises above the annealing temperature, then hydride is precipitated upon cooling in storage and crack growth rates are those assumed in the above discussions. However, if reheating does not reach the annealing temperature, the crack growth rates will be lower. Thus, a large hydrogen concentration raises the annealing temperature and, consequently, the upper temperature limit for which the heating approach may be beneficial for reducing crack growth rates. Therefore, if DHC were to occur in fuel rods in IDS, the cooling/heating history may provide much-reduced DHC crack growth rates relative to the body of the discussion presented here.

\section{A3 HYDROGEN CONTENT AND DISTRIBUTION}

The hydrogen content and distribution in spent fuel cladding can affect the cladding resistance to fracture during IDS. Hydrogen pickup and transport mechanisms are described in this section, and two example calculations are presented for redistribution of hydrogen and hydride precipitation during IDS. The predictions indicate that hydrogen redistribution during IDS is not significant and will not significantly affect the cladding fracture resistance.

(a) The annealing temperature is the terminal solid solution temperature and depends on the amount of hydrogen present in the cladding; e.g., the annealing temperature is $340^{\circ} \mathrm{C}$ for $96 \mathrm{ppm}$ hydrogen and $400^{\circ} \mathrm{C}$ for $190 \mathrm{ppm}$ hydrogen. 
A fraction of the hydrogen released during Zircaloy oxidation is assumed to be picked up by the Zircaloy and then to diffuse along decreasing temperature gradients. Peehs (1980) assumed a hydrogen pickup fraction of $20 \%$ [Peehs' reference was Stehle, Kaden, and Manzel (1975)]; this fraction agrees with data and examinations of extended burnup fuel by Garde (1986). Garde gives an average hydrogen absorption of $15.9 \%$, although the values ranged as high as $20.1 \%$. The limit of total hydrogen concentration to which the cladding remains ductile was taken as 500 ppm [Peehs' reference was Slattery (1969)]. For the case of gross brittle failure, Peehs deduced an allowable storage temperature of $310^{\circ} \mathrm{C}$ at constant temperature, or up to $460^{\circ} \mathrm{C}$ initially, depending on the temperature-time cooling profile.

The dissolved hydrogen diffuses because of gradients of concentration and/or temperature. At cold locations (and in regions of relatively high tensile stress) where hydrides precipitate, the hydrogen concentration is the terminal solid solubility (TSS), which, being lower than the hydrogen concentration elsewhere, provides a large concentration gradient and thus a driving force for diffusion of hydrogen toward the hydride. Hydrogen transport is also driven by a temperature gradient. Peehs' calculations indicate that the change in concentration of hydrogen by temperature gradient movement is negligible compared with the concentration obtained through hydrogen takeup. An analysis of hydrogen diffusion provided in Appendix $C$ also reaches that conclusion.

Sawatzky (1986) has calculated the axial diffusion of hydrogen in spent fuel cladding under IDS conditions. (a) The temperature profile of a central fuel rod in an IDS cask was obtained with a COBRA code prediction similar to those discussed by Wheeler et al. (1986a; 1986b). An upper limit of experimentally observed hydrogen content in spent fuel cladding (Atkin 1981) was taken by Sawatzky as the initial hydrogen distribution; the hydrogen concentration ranged from 43 to $100 \mathrm{ppm}$. Higher hydrogen concentrations observed by others and the value of 500 ppm assumed by Peehs (1980) may not be typical. Examinations of a BWR high-burnup fuel rod (Strain and Johnson 1985) show hydrogen concentrations ranging from 100 ppm in the center to over 200 pprn at

(a) Sawatzky's discussion of hydrogen diffusion is partially reproduced in Appendix C. 
the ends. According to Strain and Johnson, the hydrogen concentration profile shows the effect of hydrogen diffusion toward the colder ends of the cladding while in the reactor. The thickness of the oxide could be roughly correlated with the hydrogen distribution axially, but rather large azimuthal variations did not correlate. Sawatzky estimated that thermal diffusion alone could not account for the axial variation and that the distribution measured by Strain and Johnson may be due to the specific coolant chemistry that gave different radiolysis leading to the variations in hydrogen absorption along (and around) the cladding.

Sawatzky's hydrogen diffusion model (Appendix C) considers the axial temperature profile and its decrease with time in IDS. Hydrogen was assumed to precipitate as a hydride in the coolest region, the end caps. His results (assuming the initial axial distribution of hydrogen discussed above) indicate very little change $((1.5 \%)$ between the initial and final concentrations of hydrogen. [This finding agrees with Peehs' (1980) conclusion.] The amount of solid hydride in the coolest part of the end cap (the corner rim) has a depth of $0.1 \mathrm{~mm}$ or less after 10 years; there is little further change after that. Sawatzky predicts that hydride will have precipitated from the dissolved hydrogen at the cooler ends and along the full length of the fuel tube after 3 years in IDS under helium and after 5 years under nitrogen. It appears, then, that hydrides will remain present along the length of the cladding where incipient cracks (due to manufacturing defects and I-SCC) may be present.

The hydrogen diffusion model developed by Sawatzky was also used to analyze a second assumed axial hydrogen distribution. A prediction was made for a high-burnup case in which the measured hydrogen in the cladding had a U-shaped axial concentration profile with hydrogen concentrations ranging from $87 \mathrm{ppm}$ in the middle to 220 to $280 \mathrm{ppm}$ at the ends (Strain and Johnson 1985). Using an IDS temperature history similar to the first case, the level of hydrogen for this case was predicted to be sufficient to develop hydride throughout the cladding length in $<2$ years of IDS. The diffusion concentration gradient is therefore almost entirely given by the TSS at the temperatures assumed. Again, the result was that very little hydrogen would be moved during a storage 
period of 100 years. Hydride remains present along the cladding length throughout the storage period, and the shift in hydride toward the cooler ends is negligible after 10 years. The total hydrogen reaching the cladding ends would be $1.9 \times 10^{-5} \mathrm{~g} / \mathrm{cm}^{2}$. For the higher part of the temperature range under consideration, the actual TSS may be 10 to $20 \mathrm{ppm}$ lower than assumed in these predictions, according to data of Mishra and Asundi (1971), which would mean earlier precipitation of hydride and thus less hydrogen diffusion than predicted by Sawatzky.

\section{A.4 REFERENCES}

Ambler, J.F.R. 1984. "Effect of Direction of Approach to Temperature on the Delayed Hydrogen Cracking Behavior of Cold-Worked Zr-2.5\%Nb." In Zirconium in the Nuclear Industry: Sixth International Symposium, ASTM STP 824, pp. 653-674.

Atkin, S. D. 1981. Destructive Examination of 3-Cycle LUR Fuel Rods from Turkey Point Unit 3 for the Climax-Spent Fuel Test. HEDL-TME 80-89. Hanford Engineering Development Laboratory, Richland, Washington.

Coleman, C. E., et al. 1985. "Minimizing Hydride Cracking in Zirconium A110ys." Canadian Metallurgical Quarterly 24(3):245-250.

Cubicciotti. C.., and R. L. Jones. 1978. EPRI-NASA Cooperative Proiect on Stress Corrosion Cracking of Zircaloys. EPRI NP-717 (RP 455-1), Electric Power Research Institute, Palo Alto, California.

Delale, F., and F. Erdogan. 1982. "Stress Intensity Factors in a Hollow Cylinder Containing a Radial Crack." Int. J. of Fracture 20:251-265.

Dutton, R., M. P. Puls, and L. A. Simpson. 1982. "Hydride-Induced Crack Growth in Zirconium Alloys." In Proceedings of Conference on Fracture Problems and Solutions in the Energy Industry. Pergamon Press, Oxford, United Kingdom, pp. 13-25.

Garde, A. M. 1986. Hot Cell Examination of Extended Burnup Fuel from Fort Calhoun. DOE/ET/34030-11, CEND-427, Combustion Engineering, Inc., Windsor, Connecticut.

Kreyns, P. H. 1976. WAPD-TM-1203, Bettis APL, Westinghouse Electric Corporation, West Mifflin, Pennsylvania.

Kreyns, P. H., G. L. Spahr, and J. E. McCauley. 1976. "An Analysis of lodine Stress Corrosion Cracking of Zircaloy-4 Tubing." J. Nucl. Mat. 61:203-212. 
Levy, I- S, et al . 1987. Recommended Temperature Limits for Dry Storage of Spent Light Water Reactor Zircaloy-Clad Fuel Rods in Inert Gas. PNL-6189, Pacific Northwest Laboratory, Richland, Washington.

Miller, A K et al. 1981. SSCIG: A Phenomenological Model for lodine Stress Corrosion Cracking of Lircaloy. EPRI NP-1798, Electric Power Research Tnstitute, Pato Alto, California.

Mishra, S, and M K Asundi. 1971. "Determination of Solid Solubility Limit of Hydrogen in Alpha Zirconium by Internal Friction Measurements." In Zirconium in Nuclear Applications, ASTM STP 551, pp. 63-71.

Peehs, M 1980. Untersuchungen zum Verhalten abgebrannter LWR-Brennelemente bei der Lanzeitlagerung. BMFT-KWA 154711980, Kraftwerk Union AG, Erlangen, Federal Republic of Germany.

Peehs, M., and J. Fleisch. 1986. "LWR Spent Fuel Storage Behavior." J. Nucl. Mat. 137:190-202.

Sawatzky, A 1986. Axial I-lydrogen Diffusion. Contracted communication between Sawatzky Consultants, Pinawa, Manitoba, Canada, and Pacific Northwest Laboratory, Richland, Washington.

Simpson, L A, and C. D. Cann. 1984. "The Effect of Microstructure on Rates of Delayed Hydride Cracking in Zr-2.5\% Nb Alloy." J. Nucl. Mat. 126:70-73.

Slattery, G F. 1969. Application Related Phenomena in Zirconium and Its Alloys. ASTM STP 458, pp. 95.

Stehle, $H$ W. Kaden, and R. Manzel. 1975. "External Corrosion of Cladding in PWRs." Nucl. Eng. and Des. 33:155-169.

Steinberg, E . M Peehs, and H Stehle. 1983. "Development of the Crack Pattern During Stress-corrosion in Zircaloy Tubes." J. Nucl. Mat. $118: 286-293$.

Strain., C. F.. and C. E. Johnson.. 1985. Extended Burnup Demonstration Reactor Fuels Program: Hot Cell Examination of Big Rock Point High Burnup Fuel. XN-NF-84-76, Exxon Nuclear Company, Richland, Washington.

Tarn, J. C, L, N H Madsen, and B. A Chin. 1986. "Predictions of Dry Storage Behavior of Zircaloy Clad Spent Fuel Rods Using Deformation and Fracture Map Analyses." In Proceedings of Third International Spent Fuel Storage Technology Symposium/Workshop, CONF-860417, pp. S-279 to S-313.

Tasooji, A, R. E Einziger, and A, K Miller. 1984. "Modeling of Zircaloy Stress-Corrosion Cracking: Texture Effects and Dry Storage Spent Fuel Behavior." In Zirconium in the Nuclear Industry: Sixth International Symposium, ASTM STP 824, pp. 190-202. 
Walker, T. J., and J. N Kass. 1974. "Variation of Zircaloy Fracture Toughness With Irradiation." In Zirconium in Nuclear Applications, ASTM STP 551, pp. 328-354.

Wheeler, C. L, et al. 1986a. BNR Spent Fuel Storage Cask Performance Test: Volume II: Pre- and Post-Test Decay Heat, Heat Transfer, and Shielding Ammilysis.e PNL-5777, Vol. II, Pacific Northwest Laboratory, Richland, Washington.

Wheeler. C. L. et al. 1986b. "HYDRA and COBRA-SFS Temperature Calculations for CASTOR-IC, REA-2023, CASTOR-V/21, and TN-24P Casks." In Proceedings of Third International Spent Fuel Storage Technology Symposium/Workshop, CONF-860417, pp. S-77 to S-98.

Williford, R E 1984. "The lodine-Induced Strain Rate Sensitivity of Zircaloy Fuel Rod Cladding." Nucl. Eng. and Des. 78:23-36. 
APPENDIX B

THEORETICAL DISCUSSION ON DELAYED HYDRIDE CRACKING 
APPENDIX B(a)

THEORETICAL DISCUSSION ON DELAYED HYDRIDE CRACKING

Delayed hydride cracking (DHC) of $\mathrm{Zr}-2.5 \% \mathrm{Nb}$ was first observed in fuel cladding near the fusion line between the cladding and the end cap (Simpson and Ells 1974). The magnetic force resistance welding used in fuel element fabrication set up high residual stresses in this region that are believed to have caused the DHC. Cracks were detected in elements held at room temperature for as little as 5 weeks after welding. Zirconium hydride platelets were found at the roots of internal notches between cladding and end cap. A postweld stress relief $\left(24 \mathrm{~h}\right.$ at $\left.400^{\circ} \mathrm{C}\right)$ eliminated hydride growth and subsequent cracking.

The next reported case of DHC was the growth of small through-wall cracks in $69 \mathrm{Zr}-2.5 \% \mathrm{Nb}$ pressure tubes of Units 3 and 4 of the Pickering power station (Perryman 1978). These tubes had been incorrectly rolled into steel end fittings, resulting in high residual stresses just inboard of the end fittings where the cracks occurred. The banded appearance of the oxide on the crack surfaces indicated conclusively that cracking had occurred during shutdown when the pressure tube temperature was low enough to precipitate hydrides.

\section{B.1 THE DUTTON, NUTTAL, PULS, AND SIMPSON MODEL}

The basic model for DHC used today (1986) in zirconium alloys was developed by Dutton et al. (1977a). In this model, a hydride platelet is nucleated at the high-stress region near the crack tip, grows to some critical size by means of hydrogen diffusion from nearby hydrides, and cracks. The process is then repeated.

(a) This appendix is a near-reproduction of a portion of the discussion provided in Sawatzky (1986); limited editing has been performed where necessary for clarity and brevity. Some terminology used in this appendix (and Appendix C) may not match that used in the balance of the report. 
On the basis of irreversible thermodynamics, both concentration and stress gradients provide a driving force for diffusion such that the hydrogen flux density, J, is approximately given by

$$
J=\nabla \frac{D}{A}\left[\nabla C-\frac{C \nabla}{3 R T} \cdot V\left(\sum_{i=1}^{3} \quad \sigma_{i j}\right)\right]
$$

where $\bar{V}=$ molal volume of hydrogen in a-Zircaloy

$D=$ diffusion coefficient for hydrogen in a-Zircaloy

$A=$ atomic volume of Zry in a-Zircaloy

$\mathrm{C}=$ atom fraction of hydrogen in a-Zircaloy

$\nabla=$ divergence operator

$\mathrm{R}=$ gas constant

$\mathrm{T}=$ absolute temperature

$\sigma_{i j}=$ principal stress components in the vicinity of the crack tip (assumed positive if tensile).

Thus, for a tensile load, the stress gradient provides a driving force for hydrogen diffusion towards the high-stress region near the crack tip. Also included in the model is the fact that at a given temperature, the terminal solid solubility (TSS) decreases with increasing hydrostatic stress.

Cylindrical geometry was assumed, as shown in Figure B.1. Equation (B.I) can be solved (Dutton 1978) to give the following:

$$
\frac{d n}{d t}=\frac{2 \pi D}{\ln \left(\frac{L}{\ell}\right)}\left(C_{L}-C_{\ell}\right)
$$

where $\mathrm{dn} / \mathrm{dt}$ is flux of hydrogen atom per unit length of cylinder and $C_{L}$ and $C_{\ell}$ are TSS at $r=L$ and $r=\ell$ (Figure B.1), respectively, and given by 


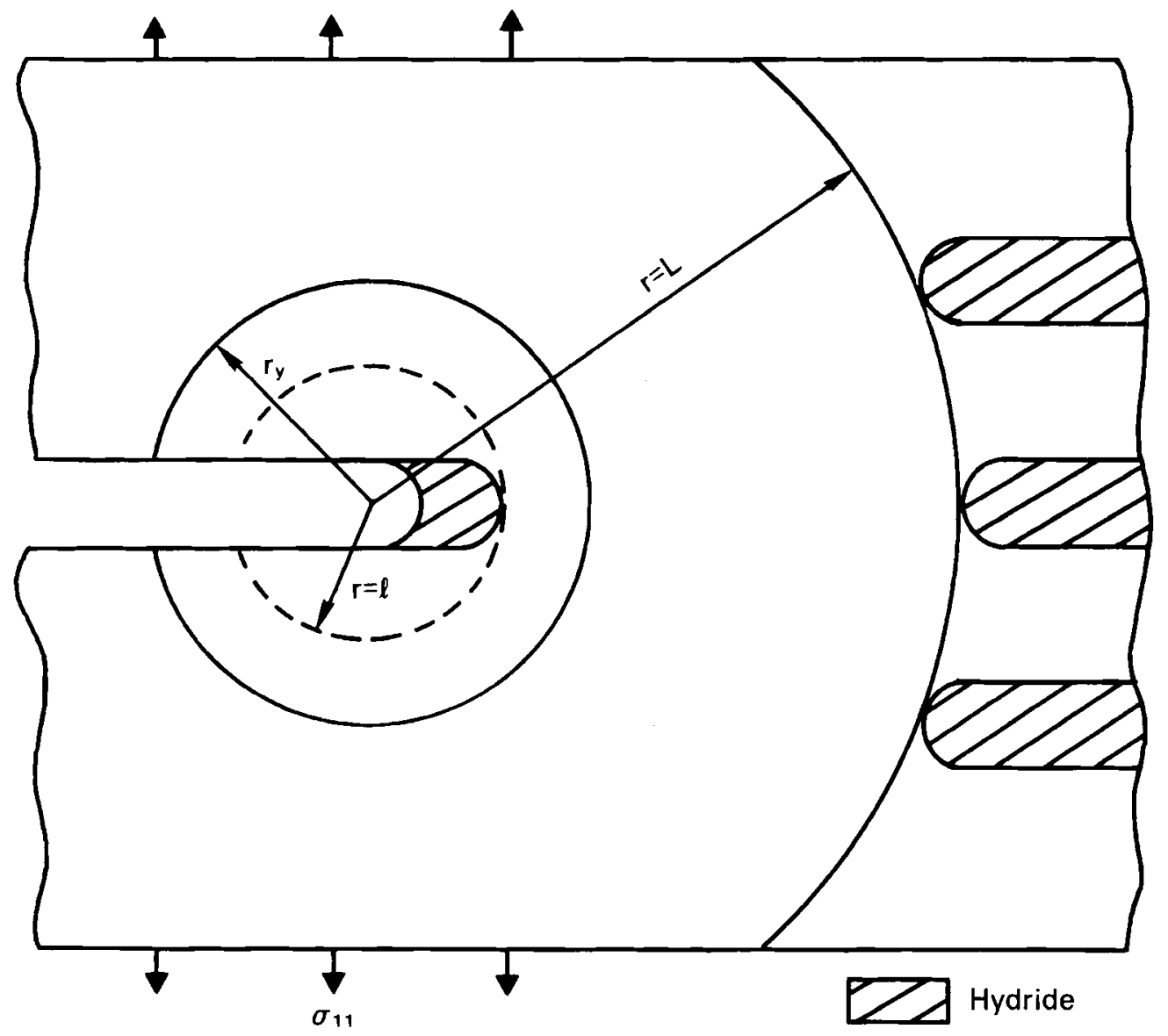

FIGURE B.1. Schematic of Crack Geometry

and

$$
\begin{aligned}
& c_{L}=c_{0} \exp \left(-\frac{P_{L} V^{\prime}}{R T}\right) \\
& c_{\ell}=c_{0} \operatorname{ex,}\left(-\frac{P_{\ell} V^{\prime}}{R T}\right)
\end{aligned}
$$

where $C_{0}=$ TSS under zero stress

$\mathbf{P}=$ hydrostatic stress, which is assumed to vary with $r$ as shown in Figure B.2; see Equation (0.4)

$V^{\prime}=$ the local volume change associated with the transfer of hydrogen from solution to the hydride phase. 


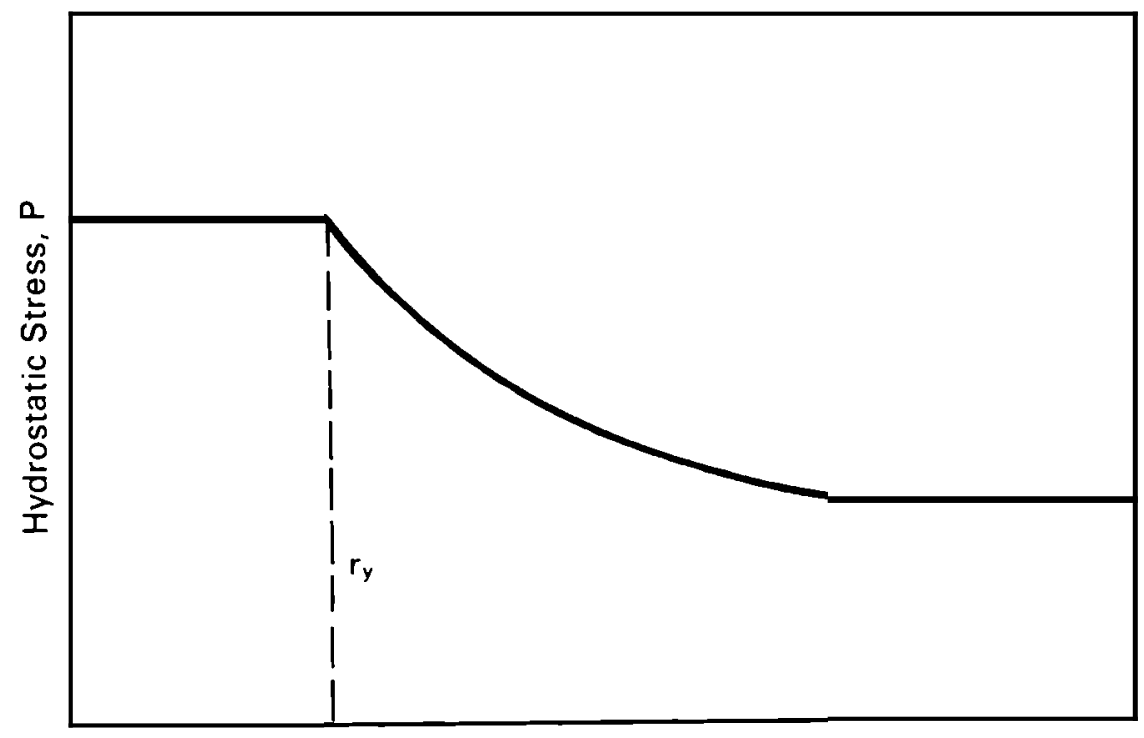

Radial Distance from Crack Tip, $r$

FIGURE B.2. Hydrostatic Stress as a Function of Distance from Crack Tip

$$
P=\frac{\sigma_{11}+\sigma_{22}+\sigma_{33}}{3}
$$

In the theory of elastic-plastic fracture mechanics, the radius of the plastic zone $r_{Y^{\prime}}$ found next to the crack as shown in Figure B.1, increases as the square of the stress intensity factor $K_{I}$. Two stages of cracking are considered: one for small $K_{I}$ values (Stage I) and the other for large $K_{I}$ values (Stage II).

Stage I applies to small $K_{I}$ values and hence small $r_{y}$ values. It is assumed that the hydride platelet growing from the crack tip extends beyond the plastic zone before it fractures. As $K_{I}$ is increased, $P_{\ell}$ increases more rapidly than $P_{L}$, thereby increasing the driving force for hydrogen diffusion and hence the crack velocity, $v$, as shown in Figure B.3a.

Stage II applies to $K_{I}$ values greater than some critical value $K_{I C}$ such that the plastic zone is large enough to completely contain the hydride platelet when it fractures. The stress is assumed to be uniform in the plastic zone and given by Mo ${ }_{Y^{\prime}}$ where $M$ is a constant greater than 1 and $\sigma_{y}$ is the yield 
stress. Since $P$ is independent of $K_{I}$ and $P_{\ell}>P_{L}$ as $K$ increases [on the basis of Equations (B.2), (B.3a), and (B.3b)], dn/dt and hence crack velocity are decreased, as shown in Figure B.3a.

Accurate crack velocities are difficult to obtain experimentally, and early data (Dutton et al. 1977a) seemed to substantiate the above model. Later and more careful experimental work (Simpson and Puls 1979) showed that the relationship between crack velocity and stress intensity factor is more nearly represented by Figure B.3b. There seems to be a threshold in $K_{I}$, say $K_{I H}$, such

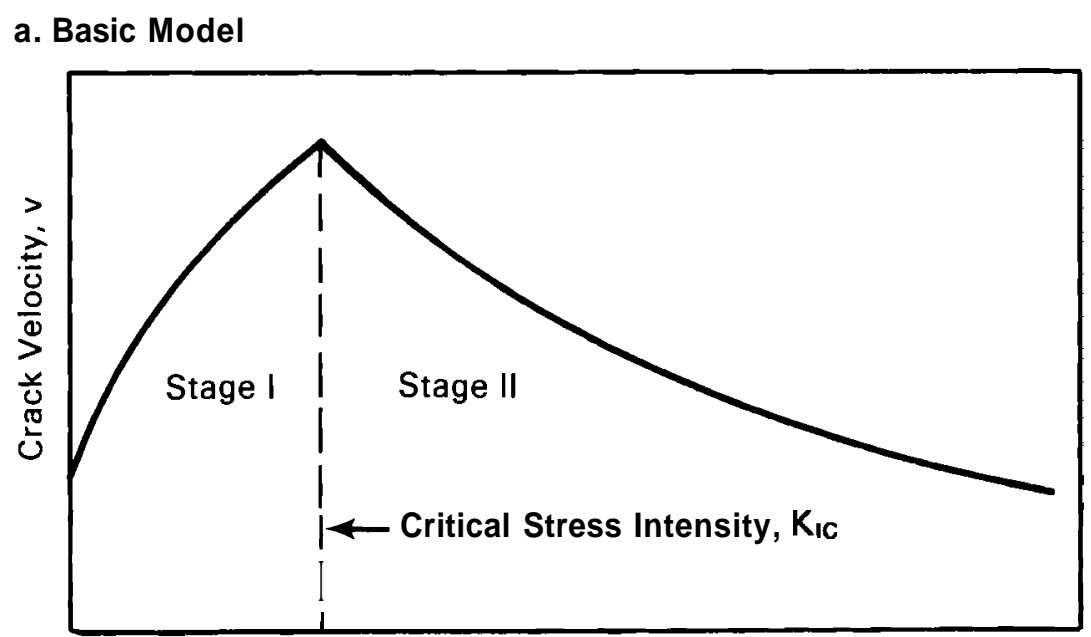

Stress Intensity, $\mathrm{K}$

b. Experimental Results

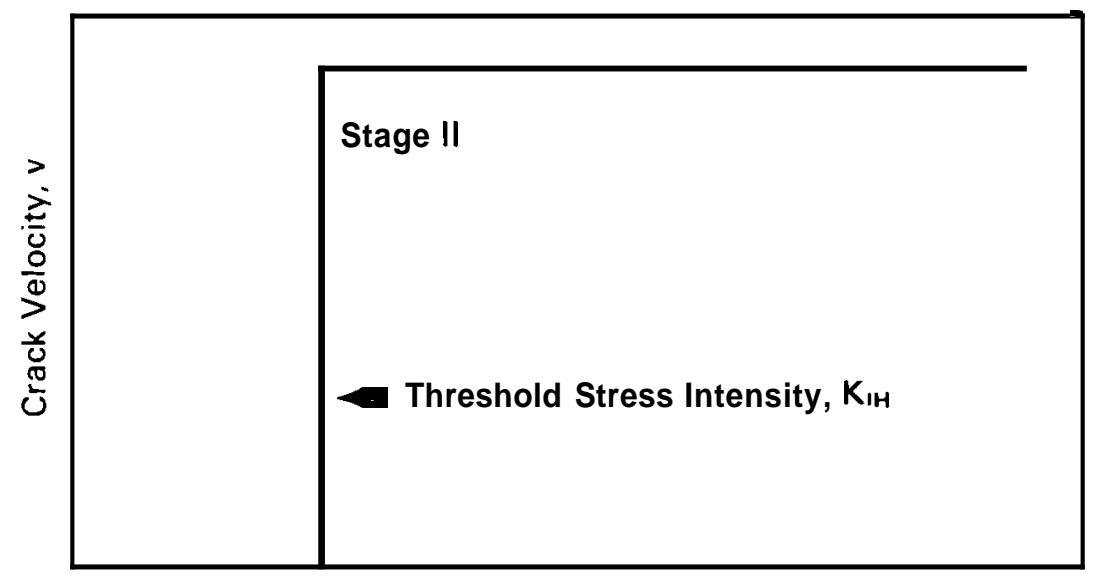

Stress Intensity, K

FIGURE B.3. Schematic of Relationship Between Crack Growth Rate and Stress Intensity 
that $v=0$ for $K_{I}<K_{I H}$ and $v=$ constant for $K_{I}>K_{I H} ; i . e .$, there is no Stage I- Changes to the basic model seemed necessary and some have been made (Dutton et al. 1977b).

It has been suggested that, at least for small hydrogen concentrations, the main source of hydrogen for hydride formation at the crack tip is the justfractured platelet. A supporting observation was the lack of hydride on the fracture surface of defective $2 r-2.5 \% \mathrm{Nb}$ fuel cladding (Simpson and ElTs 1974). This model provides the shortest hydrogen diffusion path; and, since the hydride is on a free surface, the driving force for diffusion between it and the new hydride platelet being formed would be greater than for the case of the other hydrides under tension. Since neither the hydride on the free surface nor the one being formed are greatly affected by $K_{I}$, the crack velocity should be fairly independent of $K_{I}$, as was observed.

This model could also account for the fact that the incubation period may be much longer than the time for subsequent growth/cracking cycles as seen by Coleman and Ambler (1979). During the incubation period, the hydrogen source is the neighboring hydrides, as in the basic model of Dutton et al. (1977a). In subsequent cycles, the main hydrogen source is the "just cracked" hydride.

Puls, Simpson, and Dutton (1981) point out that their model does not show a $K_{I H}$ because they assumed pure zirconium hydride to have zero resistance to fracture. In fact, its $\mathrm{K}_{\mathrm{IH}}$ is between 1 and $3 \mathrm{MPa} \cdot \sqrt{\mathrm{m}}$, whereas that for $\mathrm{Zr}-2.5 \% \mathrm{Nb}$ is $-6 \mathrm{MPa} \cdot \sqrt{\mathrm{m}}$. They suggest that hydrides at the crack tips precipitate out only in grains having a preferred orientation with respect to stress. Cracking therefore occurs through a mixture of hydride and metal, which would have higher $\mathrm{K}_{\mathrm{IH}}$ values than pure hydride. Criteria for cracking of the hydride have been postulated (Dutton et al. 1977b; Simpson 1981). On the basis of this model, a hydride will grow at the crack tip when TSS is exceeded but wi11 not necessarily fracture.

\section{B.2 NUCLEATION AND GRONTH MODEL}

It has been suggested that $\mathrm{K}_{\mathrm{IH}}$ might also be explained by the classical nucleation and growth theory. The basic DHC model by Dutton et al. (1977a) implicitly assumed a hydride nucleus to be present at the crack tip and all 
growth to occur at steady state. These assumptions accommodated a relatively simple mathematical treatment of the model; but, as already indicated, it does not give a very satisfactory explanation for some of the experimental observations. In this section, a qualitative description of the model that seems somewhat more realistic will be provided.

A basic assumption of the proposed model is that supersaturation is necessary for hydride nucleation. (a) Also, it is believed that the transient hydrogen diffusion preceding steady state must be considered.

Figure B.4 represents a section perpendicular to the crack tip where the area between points $a$ and $b$ is the extent of the plastic zone, point $c$ is the position of the nearest hydride platelet, and point $d$ is a hydride layer on the crack surface. The hydrostatic stress $P$ as a function of position (Figure B.4) is shown in Figure B.5.

At equilibrium there is no hydrogen flux $(\mathrm{J}=0)$; thus, from Equations (B.I) and (B.4):

$$
C(X)=c_{T}(c) \cdot \exp \left(\frac{\bar{V}}{3 R T}\right) \cdot[P(X)-P(c)]
$$

where $C(X)$ is the equilibrium hydrogen concentration at $X$ in the presence of a stress gradient and $C_{T}(c)$ is TSS at $X=c$.

Because $P(X)>P(C)$, the equilibrium hydrogen concentration $C(X)$ increases with increasing $P$, as shown in Figure B.6. From Equations (B.3a) and (B.3b):

$$
C_{T}(X)=C_{T}(c) \cdot \exp \left(\frac{-V^{\prime}}{3 R T}\right) \cdot[P(X)-P(c)]
$$

where $C_{T}(X)$ is TSS at $X$, which decreases with increasing $P$, as shown in Figure B.6.

(a) In a paper in which he shows theoretically that, due to lattice constraints, TSS should be greater during cooling than heating, Puls (1984) uses the term "undercooling," but this seems to be different from the term "supersaturation" used above. 


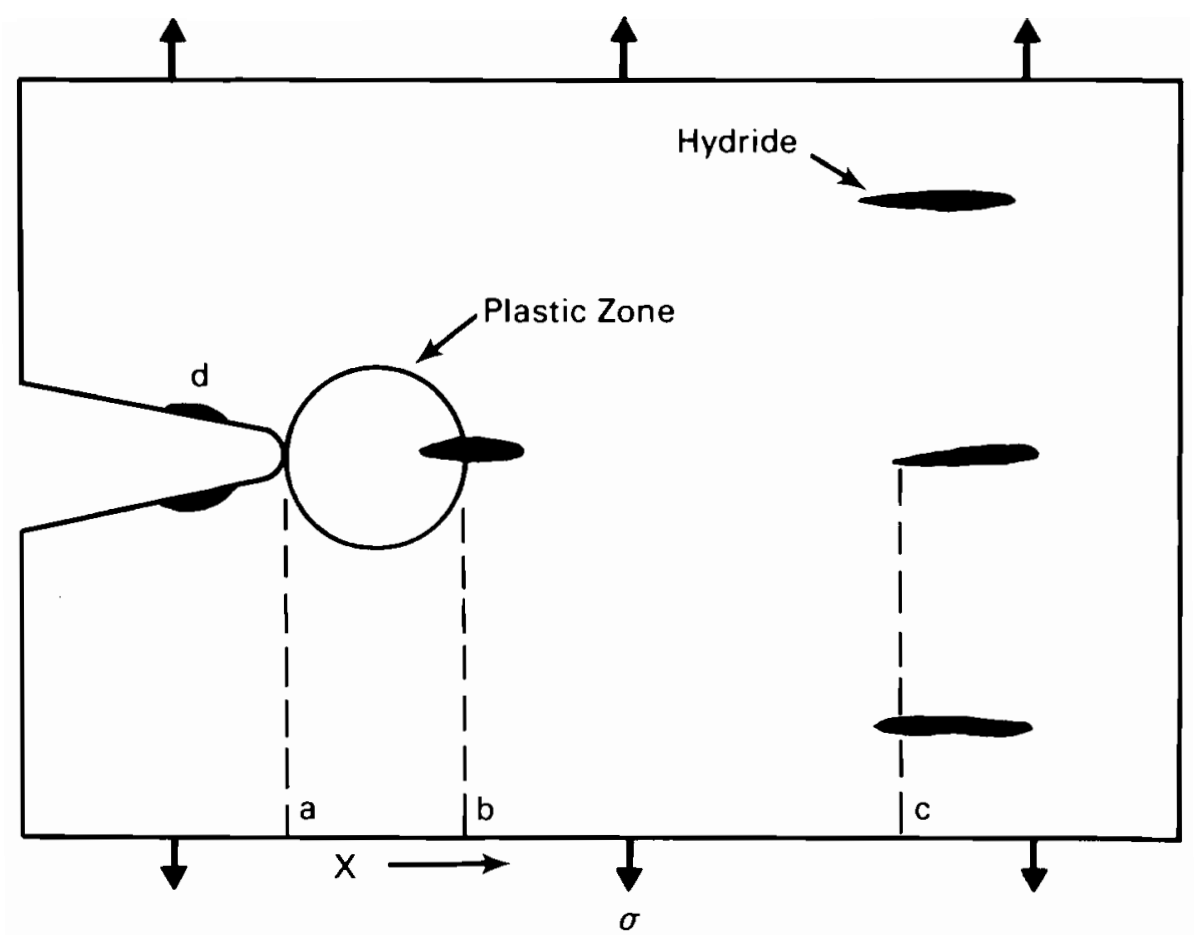

FIGURE B.4. Crack Geometry with Definition of Plastic Zone

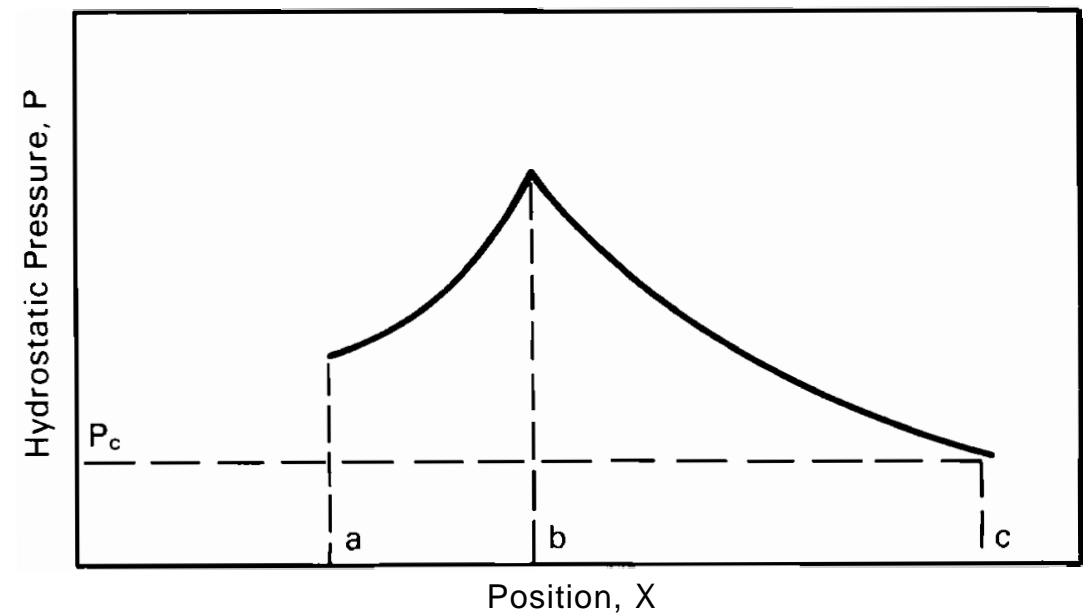

FIGURE B.5. Hydrostatic Stress as a Function of Position 


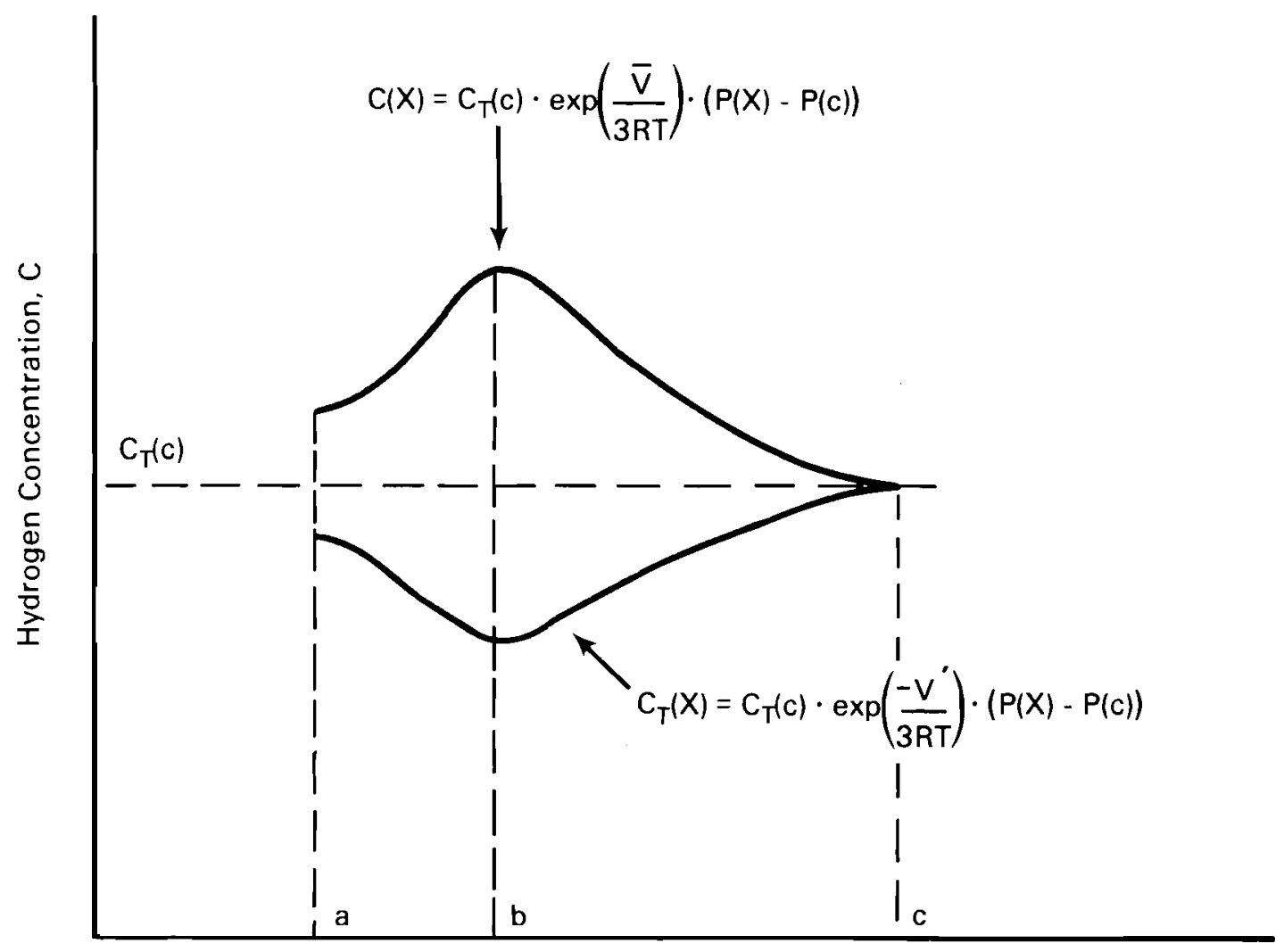

Position, $\mathrm{X}$

FIGURE B.6. Hydrogen Concentration as a Function of Position

The above results, together with the requirement of supersaturation for hydride nucleation, are used to obtain a qualitative criterion for $\mathrm{K}_{\mathrm{IH}}$. A specimen in which the hydrogen in solution is uniformly distributed with concentration $C_{T}(c)$ is shown in Figure B.7. If a tensile load is applied as in Figure B.5, it may be seen from Figure B.6 that TSS at $X=b, C_{T}(b)$ will be lowest, and new hydride would be most likely to be precipitated there. Let the degree of supersaturation be such that a concentration $C_{1}^{\prime}(b)$ in Figure 0.7 is necessary to nucleate a hydride at $b$. Since $C_{T}(b)>C_{1}^{\prime}(b)$, a hydride would be nucleated at $b$ as soon as the load was applied.

Suppose, however, that a higher concentration, $C_{2}^{\prime}(b)$, is needed for hydride nucleation at $b$ (see Figure B.7). Since $C_{T}(c)<C_{2}^{\prime}(b)$, a hydride would not be nucleated immediately on the application of a load. However, the load would cause redistribution of the hydrogen until equilibrium was reached. If equilibrium was given by Curve 1 in Figure B.7, a hydride would never be 


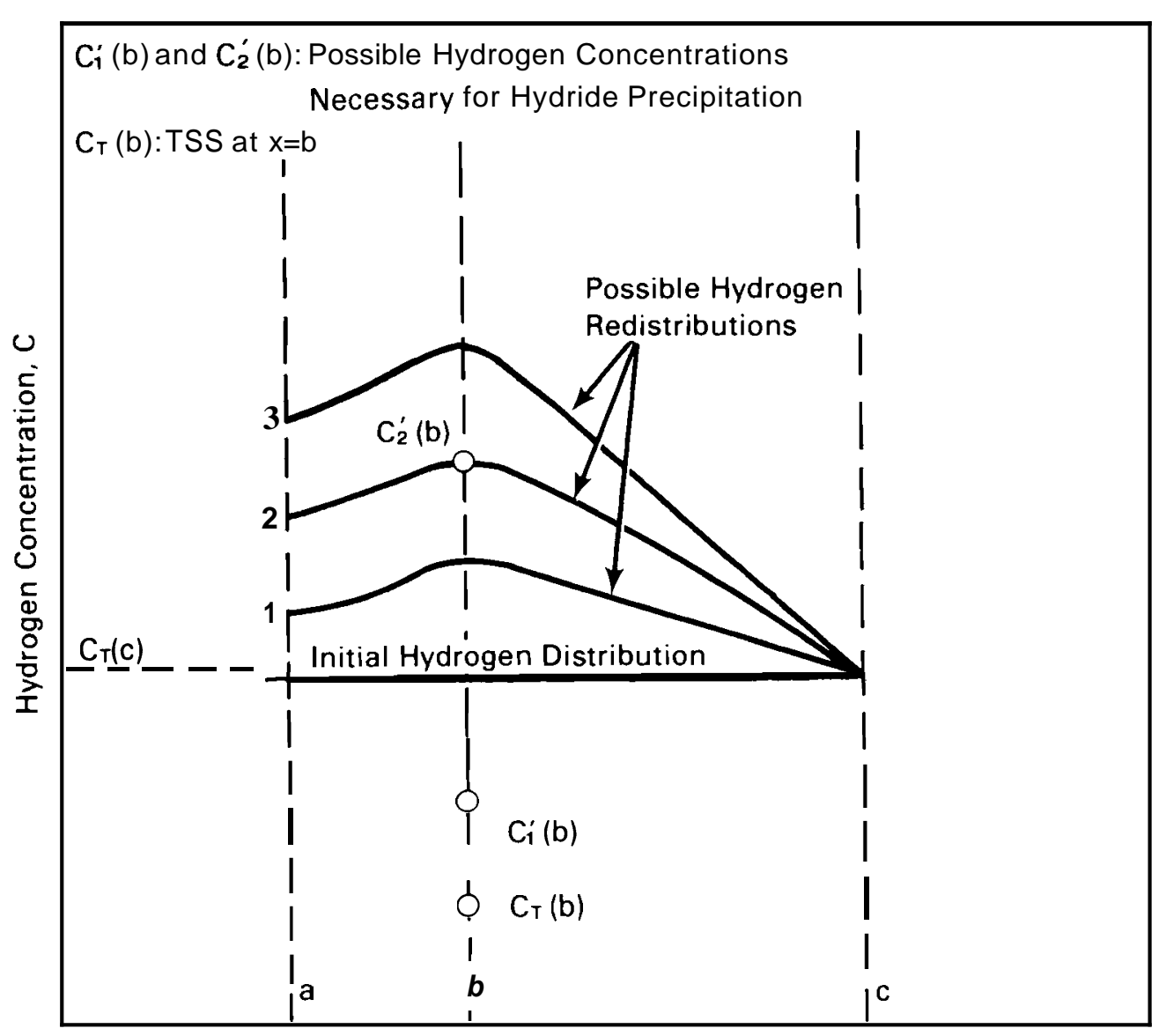

Position, $\mathrm{X}$

FIGURE B.7. Schematic of Criteria for Hydride Nucleation

precipitated at $b$. If the equilibrium hydrogen distribution was given by Curves 2 or 3 , a hydride would eventually be precipitated. Curve 2 corresponds to the minimum stress intensity factor at which a hydride could be nucleated, namely $\mathrm{K}_{\mathrm{IH}}$ •

The time evolution of hydrogen redistribution is now presented. To begin, a specimen has a constant hydrogen concentration (C) as a function of position (Figure B.8); $C_{1}$ is assumed to be TSS at zero stress. With the application of a load, the steady-state TSS will evolve from $C_{1}$ to $C_{T}(c)$ at $c$ (a slight decrease from $C_{1}$ ) and $C_{T}(b)$ at $b$ (a large decrease from $C_{1}$ ). A sufficient load to precipitate a hydride at $b$ is applied, and the resulting hydrogen redistribution is presented in Figure B.8. Hydrogen now diffuses up the stress 


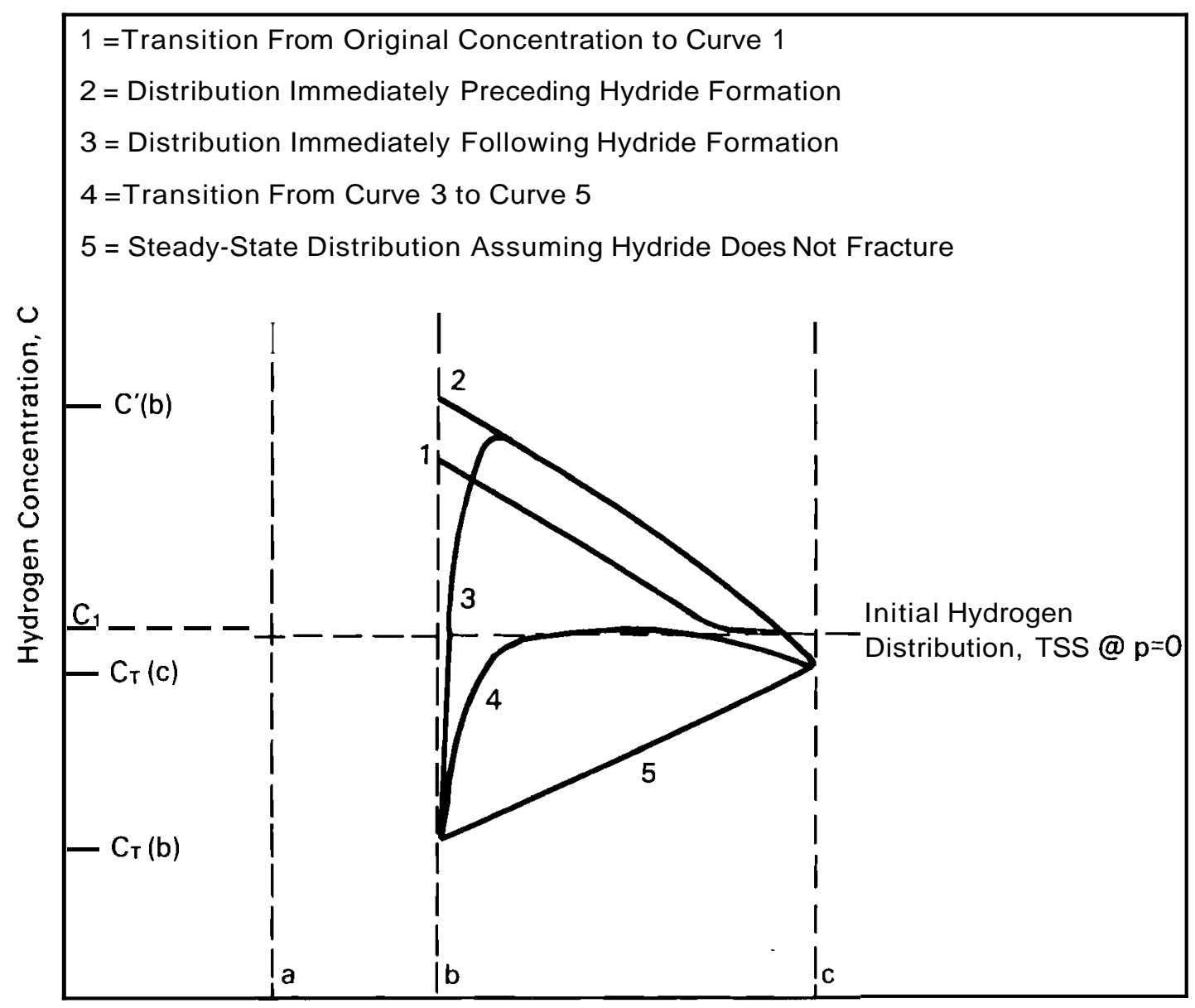

Position, $\mathrm{X}$

FIGURE B.8. Time Evolution of Hydrogen Redistribution During Hydride Nucleation and Growth

gradient from $c$ to $b$ at a steadily decreasing rate because the concentration gradient, built up as shown by Curve 1, tends to retard hydrogen diffusion. When the hydrogen concentration at $b$ reaches $C^{\prime}(b)$ (Curve 2 ), a hydride platelet is precipitated. The hydrogen concentration in the matrix at this point immediately drops to its equilibrium value $c_{T}(b)$, as shown in Curve 3 . The steep hydrogen concentration gradient near the hydride now is in a direction to enhance diffusion. The hydrogen flux is immediately sharply increased but then decreases gradually as the concentration gradient decreases, as shown by Curve 4. Provided the hydride does not fracture in the meantime, a steadystate hydrogen distribution, as shown by Curve 5 , is eventually developed. 
The above description of growth and cracking applies to the first cycle corresponding to incubation. As already mentioned, Coleman and Ambler (1979) found the time for subsequent cracking cycles to be appreciably shorter, and this may indicate that the "just cracked" hydride is the principal source for hydride precipitation at the crack tip.

\section{B.2.1 Cracking Behavior During Cooling}

In Figure B.9, an initial temperature $T_{7}$ is assumed with hydrides at a and $b$ and an equilibrium hydrogen concentration $C_{T}\left(T_{7}\right)$. Equilibrium over the hydride surfaces is assumed during cooling. Because TSS decreases with temperature, the hydrides are sinks for hydrogen diffusion. Because of finite diffusion rates, hydrogen distribution curves are set up for several temperatures as shown in Figure B.9. At lower cooling rates, the curves will become flatter; during rapid cooling, new hydrides may be precipitated. Thus, for a given temperature, the hydrogen concentrated at a crack tip (point 0 in Figure B.9) would be greater during cooling than at equilibrium.

In Figure B.10, the equilibrium hydrogen concentration under stress is shown [as given by Equation (B.5)]. The equilibrium hydrogen concentration for a tensile stressed specimen $C(b)$ is less than the nucleation concentration, $C_{T}(b)$, so that a hydride will not be nucleated at a constant temperature T. If the unstressed specimen is slowly cooled to T (Curve 1), a hydride will still not be nucleated at b. However, with more rapid cooling (Curve 2), hydrogen does not have time to diffuse from $b$, and a hydride will be nucleated as soon as the stress is applied. However, once the temperature is maintained at $T$ and the equilibrium hydrogen distribution is approached, hydriding at b would stop and, eventually, cracking would stop. The same would apply to a stressed specimen during cooling; then most of the cracking might occur during cooling. Such an effect has been observed by Nuttall (1977).

Even though cracking may occur in the absence of cooling (e.g., Curve 3 of Figure B.7), it would be expected to occur more rapidly during cooling under stress, and it would slow down to a constant crack velocity some time after the steady-state temperature was reached. Such an effect was seen by Ambler (1984). 


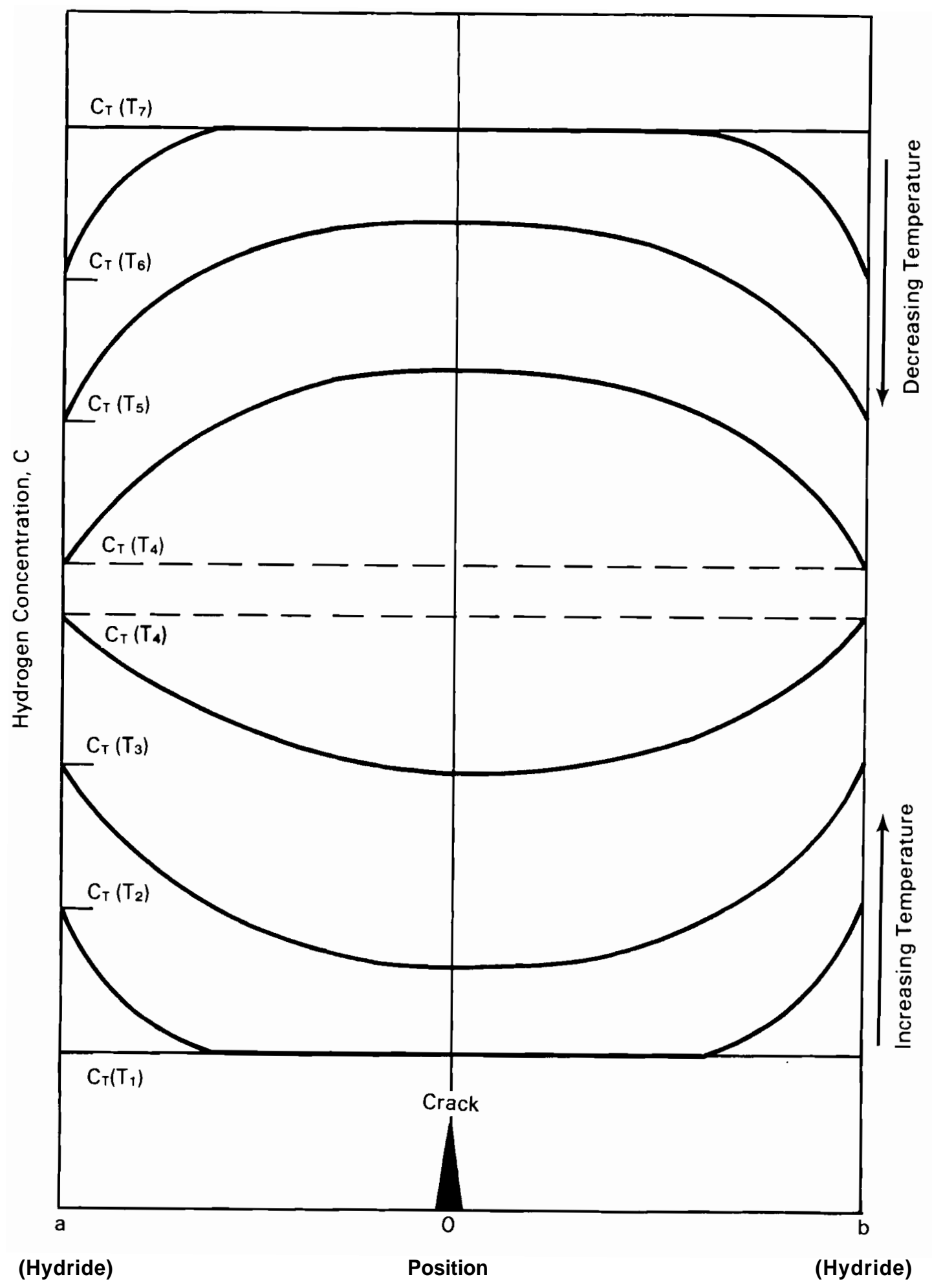

FIGURE B.9. Hydrogen Redistribution During Heating or Cooling 


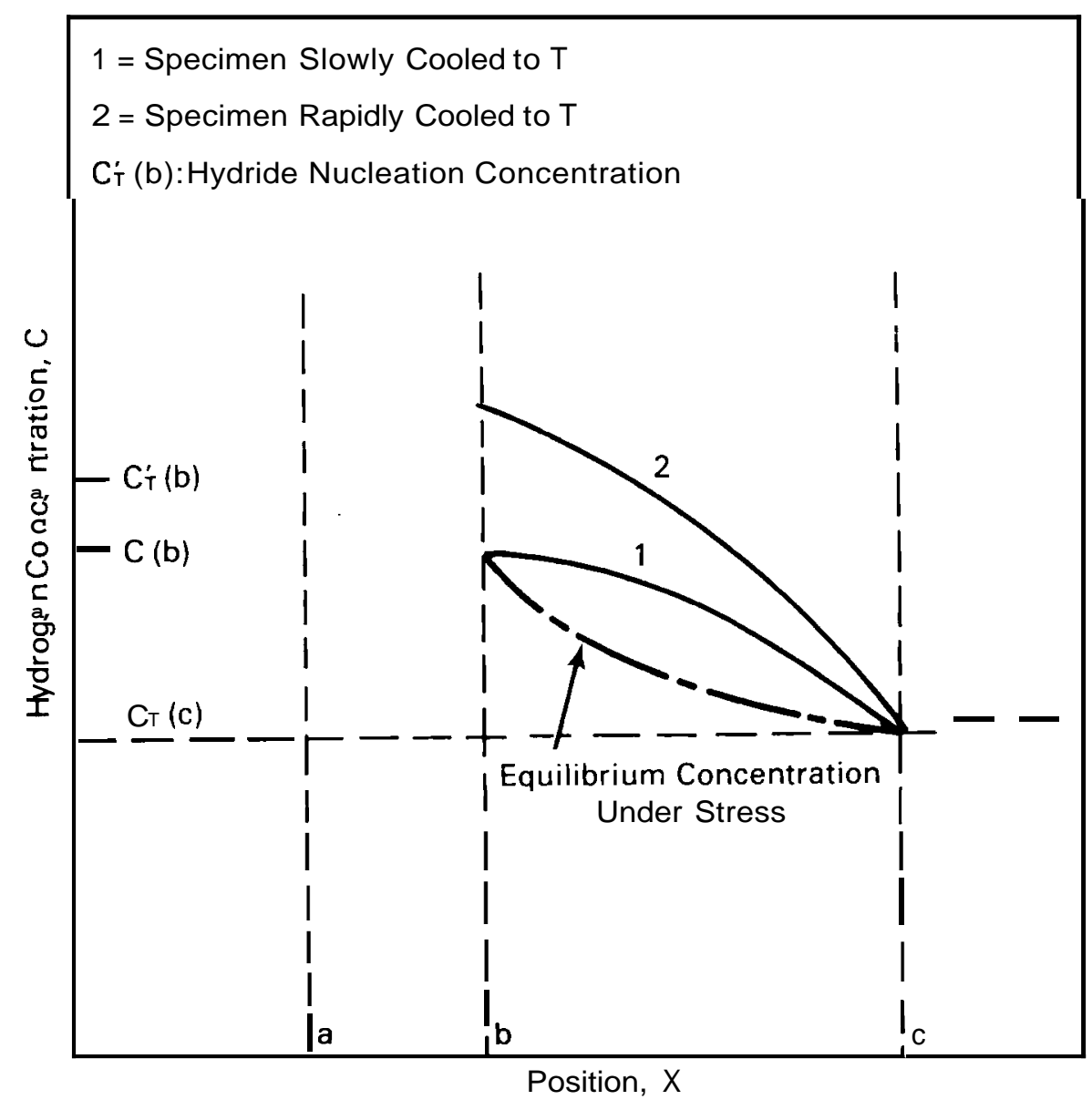

FIGURE B.10. Hydrogen Redistribution During Cooling

He found that the time required for the crack velocity to decrease to a constant value depended on the final temperature, as given in Table B.1. For fairly rapid cooling, this time may be given roughly by the following:

$$
t=L^{2} / D
$$

Using the value of $\mathrm{D}$ for $\mathrm{Zr}-2.5 \% \mathrm{Nb}$ from Sawatzky et al. (1981) and Ambler's time to equilibrium crack velocity at $100^{\circ} \mathrm{C}$ (Ambler 1984), Equation (B.7) yields $L=0.033 \mathrm{~cm}$ as hydride spacing. Assuming the same $L$, the time to equilibrium was estimated for other temperatures. As seen in Table B.1, agreement with the experiment is fairly reasonable. 
TABLE B.1. Time to Constant Crack Growth Rate as a Function of Temperature

Temperature, $\mathrm{K}$

373

423

473

\begin{tabular}{|c|c|}
\hline \multicolumn{2}{|c|}{ Time, $\mathrm{h}$} \\
\hline Amble r (1984) & Theoretical \\
\hline $\begin{array}{l}40.0 \\
15.0 \\
15\end{array}$ & $\begin{array}{l}40.0 \\
10.0\end{array}$ \\
\hline 1.5 & 3.32 \\
\hline
\end{tabular}

\section{B.2.2 Cracking Behavi or During Heating}

In Figure B.9, there are hydrides at $a$ and $b$ with a crack tip at 0 . The initial temperature for the heating evaluation is $T_{1}$, and the hydrogen concentration of the matrix is uniform at $C_{T}\left(T_{1}\right)$, the TSS on heating. The TSS increases with heating so the hydrides act as sources for hydrogen diffusion. It is assumed that TSS at a given temperature is less during cooling than heating, as shown at temperature $\mathrm{T}_{4}$ [as does Puls (1984)]. At a given stress intensity factor, there would be hydride formation and cracking during cooling but not during heating. In Figure B.9, the hydrogen concentration at the crack tip is less when approaching $T_{4}$ by heating than by cooling. Therefore, even if cracking occurs at $T_{4}$ in the case of a stress-free specimen heated to $T_{4}$ from $\mathrm{T}_{1}$ and then stressed, more hydrogen must be redistributed before a hydride can be nucleated at the crack tip than in the cooling mode. This would require a longer incubation time in the case of heating.

In the Dutton et al. (1977a) model, the diffusion of hydrogen from neighboring hydrides to the crack tip is assumed to occur at steady state, and the mathematical treatment is fairly simple. In the nucleation and growth model, the hydrogen concentration at the crack tip may first have to be built up by stress gradient-driven diffusion until a hydride platelet can be nucleated, after which growth occurs by further diffusion. Although the model may be difficult to treat mathematically, it does provide a feasible qualitative explanation for many of the experimental observations. 


\section{B.3 REFERENCES}

Ambler, J.F.R. 1984. "Effect of Direction of Approach to Temperature on the Delayed Hydrogen Cracking Behavior of cold-worked $\mathrm{Zr}-2.5 \% \mathrm{Nb}$." In Zirconium in the Nuclear Industry: Sixth International Symposium, ASTM STP 824, pp. 653-673.

Coleman, C. E, and J.F.R. Ambler. 1979, "Delayed Hydrogen Cracking in $\mathrm{Zr}-2.5 \% \mathrm{Nb}$ Alloy." Rev. Coatings and Corrosion 3:105.

Dutton, R. 1978. "Hydrogen Embrittlernent Effects in Hydride-Forming Metals." Metall. Soc. CIM, annual volume featuring hydrogen in metals, pp. 16.

Dutton, $R$, et a1. 1977a. "Mechanisms of Hydrogen Induced Delayed Cracking in Hydride Forming Materials." Met. Trans. 8A: 1553-1562.

Dutton, R, et a1. 1977b. "The Mechanism of Hydrogen-Induced Delayed Cracking in Zirconium Metals." Presented at Second International Conference on Hydrogen in Metals, Paris, France, Paper 306.

Nutta11, K 1977. "The Effect of Stress and Thermal Cycling on Hydride Reorientation and Slow Crack Growth in Zirconium Alloys." Presented at Second International Congress on Hydrogen in Metals, Paris, France, Paper 307.

Perryman, ECW. 1978. "Pickering Pressure Tube Cracking Experience." Nucl. Energy 17(2) : 95-105.

Puls, M P. 1984. "Elastic and Plastic Accomodation Effects on Metal-Hydride Solubility.' Acta Metal1. 32:1259-1269.

Puls, M. P, L. A Simpson, and R Dutton. 1981. "Hydride-Induced Crack Growth in Zirconium Alloys." In Proceedings of Conference on Fracture Problems and Solutions in the Energy Industry, Winnipeg, Canada, pp. 13-25.

Sawatzky, A 1986. Axial Hydrogen Diffusion. Contracted communication between Sawatzky Consultants, Pinawa, Manitoba, Canada, and Pacific Northwest Laboratory, Richland, Washington.

Sawatzky, A., et al. 1981, "Hydrogen Diffusion in Zirconium-Niobium Alloys." In Proceedings of Miami International Symposi um on Metal-Hydrogen Systems, Miami Beach, Florida, pp. 109-120.

Simpson, L A 1981. "Criteria for Fracture Initiation at Hydrides in Zirconium-2.5\% Niobium Alloy." Met. Trans. 12A:2113-2124.

Sirnpson, C, J., and C. E Ells. 1974. "Delayed Hydrogen Embrittlement i n $\mathrm{Zr}-2.5 \% \mathrm{Nb}$." J. Nucl. Mat, 52:289-295.

Simpson, L A, and M. P. Puls. 1979. "The Effects of Stress, Temperature and Hydrogen Content on Hydride-Induced Crack Growth in $\mathrm{Zr}-2.5 \% \mathrm{Nb}$." Met. Trans. 10A:1093-1105. 
APPENDIX C

AXIAL HYDROGEN DIFFUSION

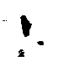


APPENDIX $c^{(a)}$

AXIAL HYDROGEN DIFFUSION

\section{C.1 BASIC EQUATIONS}

The hydrogen flux under a temperature gradient in a single-phase region is given by the following (Sawatzky 1960):

$$
J=-D \frac{\partial C}{\partial x}-\frac{D Q^{\star} C}{R T^{2}} \frac{d T}{d x}
$$

where $J=$ hydrogen flux

$D=$ diffusion coefficient

$\mathrm{C}=$ hydrogen concentration

$x=$ axial position on the fuel tube

$Q^{*}=$ heat of transport

$R=$ gas constant

$\mathrm{T}=$ absolute temperature.

Conservation of hydrogen requires the following:

$$
\frac{\partial c}{\partial t}=-\frac{\partial J}{\partial x}
$$

where $\frac{a c}{a t}$ is the rate of hydrogen increase at $x$.

Substituting Equation (C.1) into (C.2) results in the following:

$$
\frac{\partial C}{\partial t}=\frac{\partial}{\partial x}\left(D \frac{\partial C}{\partial x}\right)+\frac{\partial}{\partial x}\left(\frac{D Q^{\star} C}{R T^{2}} \frac{d T}{d x}\right)
$$

(a) This appendix is a near-reproduction of a portion of the discussion provided in Sawatzky (1986); limited editing has been performed where necessary for clarity and brevity. Some terminology used in this appendix (and Appendix B) may not match that used in the balance of the report. 
The diffusion coefficient is given by

$$
D=D_{0} \cdot \exp \frac{-Q}{R T}
$$

where $D_{0}$ is the frequency factor and $Q$ is the activation energy for diffusion. Equation (C.4) is substituted into Equation (C.3), and since $T$ is a function of $x$, the following equation is obtained:

$$
\frac{\partial c}{\partial t}=\left\{\frac{\partial^{2} c}{\partial x^{2}}+\left(\frac{Q^{\star}+Q}{R T^{2}}\right)\left(\frac{d T}{d x}\right)\left(\frac{\partial c}{\partial x}\right)+\left[\frac{Q^{\star}}{R^{2} T^{4}}(Q-2 R T)\left(\frac{d T}{d x}\right)^{2}+\frac{Q^{\star}}{R T^{2}} \frac{d^{2} T}{d x^{2}}\right] c \mid\right.
$$

Equation (C.5) applies only to a single-phase region (here the solid solution alpha phase) where $\frac{a c}{\partial t}$ is the time rate of change of the hydrogen concentration at $x$. However, a simple model for thermal diffusion in the alpha-plushydride region is available (Sawatzky 1960). The hydrogen is assumed to diffuse only in the alpha matrix for which the hydrogen concentration is given by the terminal solid solubility (TSS). The hydride is assumed to serve only as a source or sink for hydrogen. This assumption is good to -2000 to 3000 ppm. The TSS is given by the following equation:

$$
c^{\prime}=c_{0} \cdot \exp \frac{-H}{R T}
$$

where $\mathrm{H}$ is the heat of mixing and $\mathrm{c}_{0}$ is a constant. Differentiating $\mathrm{c}^{\prime}$ gives

$$
\frac{\partial C^{\prime}}{\partial x}=\frac{C_{0} H}{R T^{2}} \cdot \exp \left(\frac{-H}{R T}\right) \frac{d T}{d x}
$$

and

$$
\frac{\partial^{2} c^{\prime}}{\partial x^{2}}=\frac{C_{0} H}{R T^{4}}\left[\left(\frac{H}{R}-2 T\right)\left(\frac{d T}{d x}\right)^{2}+T^{2} \frac{d^{2} T}{d x^{2}}\right] \exp \left(\frac{-H}{R T}\right)
$$


Setting $c=C^{\prime}$ and substituting Equations (C.4), (C.6), and (C.7) into Equation (C.1) results in the following:

$$
J=\frac{-D_{0} C_{0}}{T^{2}}\left(\frac{H+Q^{\star}}{R}\right) \exp \left(-\frac{H+Q}{R T}\right) \frac{d T}{d x}
$$

Substituting Equations (C.4), (C.6), (C.7), and (C.8) into the left-handside of Equation (C.5) gives

$$
\frac{\partial C}{\partial t}=\frac{D_{0} C_{0}}{T^{4}}\left(\frac{H+Q^{\star}}{R}\right)\left[\left(\frac{H+Q}{R}-2 T\right)\left(\frac{d T}{d x}\right)^{2}+T^{2} \frac{d^{2} T}{d x^{2}}\right] \exp \left(-\frac{H+Q}{R T}\right)
$$

where $\frac{a c}{a t}$ is the time rate of change of the hydrogen concentration in the alphaplus-hydride region.

\section{C.2 APPLICATION TO AXIAL DIFFUSION}

The equations developed in Section $\mathrm{C} .1$ can be used to determine hydrogen redistribution along the fuel tube. It is necessary to know the axial temperature profile as a function of time. As presented in Figure C.1, the temperature is assumed to be symmetric along a spent fuel storage cask and can be represented by a sine function. (a) The temperature profile along a fuel rod may be given by

$$
T=T_{0}+A(t) \cdot \sin \frac{\pi}{L}\left(x+x_{0}\right)
$$

The origin $x=0$ is taken as the upper end of the fuel tube, as seen in Figure C.1. The temperature at the ends of the cask is $T_{0}$ and is taken to be constant with time. In general, the temperature profile is time dependent, as shown by $A(t)$, which is a function of time only. In Equation (C.11), $L$ is the

(a) An example of the symmetric axial temperature profile may be found in Creer and Schoonen 1986. 


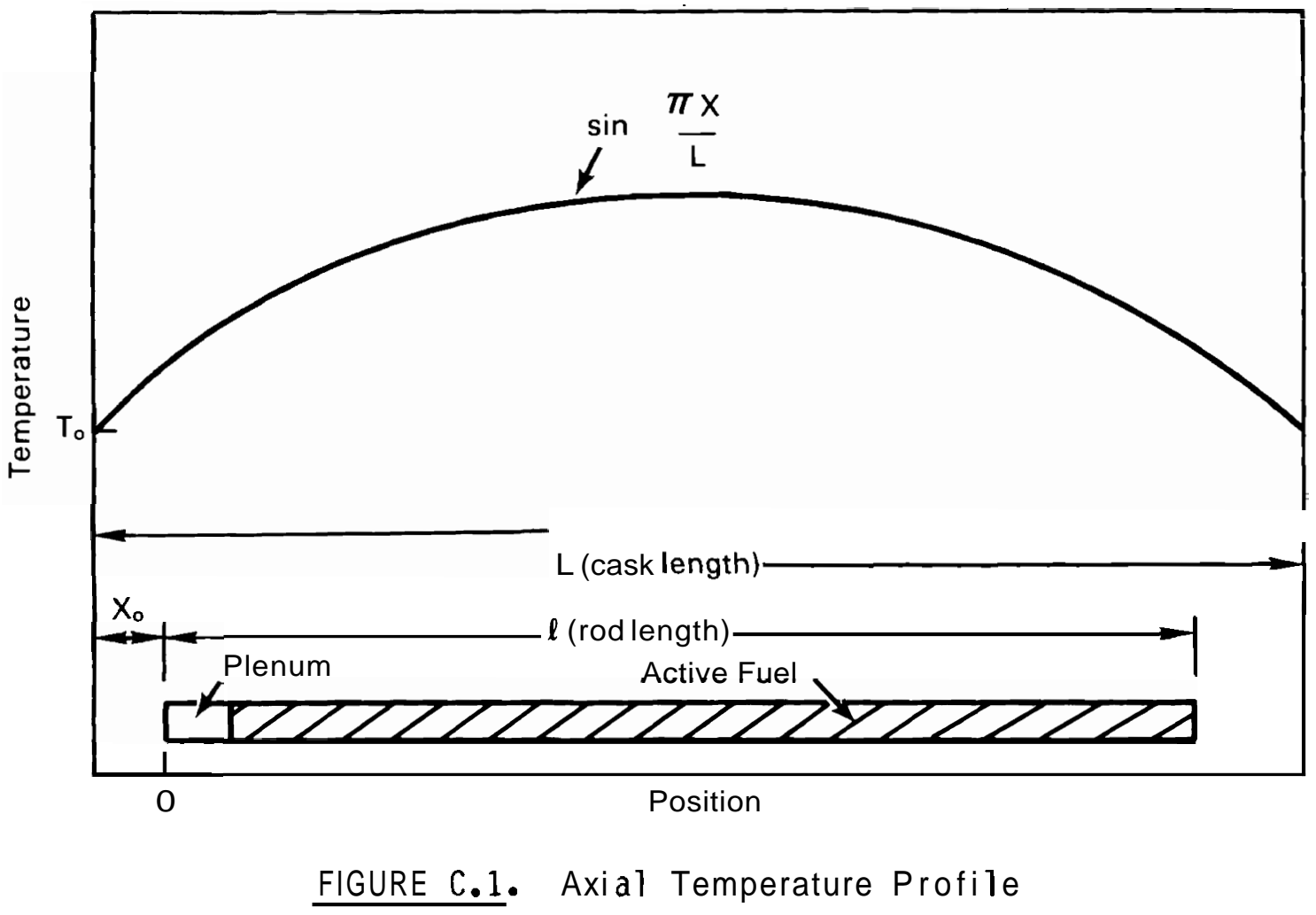

length of the cask and $x_{0}$ is the distance between upper ends of fuel cask and fuel tube. For computing purposes, the length of the fuel tube is divided into w segments. The temperature profile is then given by

$$
T=T_{0}+A(t) \cdot \sin \frac{\pi}{L}\left(\frac{l}{w} x+x_{0}\right)
$$

where $\ell$ is the length of the fuel tube and $X$ is the number of the segment starting at $x=0$. The derivatives of $T$ with respect to $x$ are given by

$$
\begin{gathered}
\frac{d T}{d x}=\frac{\pi}{L} A(t) \cos \frac{\pi}{L}\left(x+x_{0}\right)=\frac{\pi}{L} A(t) \cos \frac{\pi}{L}\left(\frac{l}{w} x+x_{0}\right) \\
\frac{d^{2} T}{d x^{2}}=-\left(\frac{\pi}{L}\right)^{2} A(t) \sin \frac{\pi}{L}\left(\frac{l}{w} x+x_{0}\right)
\end{gathered}
$$


An analytical expression for $A(t)$ is now developed. The maximum fuel tube temperatures as a function of decay heat are given in Figure $\mathrm{C} 2$ for helium and nitrogen cover gases. Using Figure $\mathrm{C} 2$ and Table C.1, the maximum fuel temperature versus time after discharge can be obtained (see Figure C.3).

A semi-log plot of maximum temperature versus time is shown for helium cover gas as Curve $1 \mathrm{in}$ Figure C.4. Curve 2 is the difference between the maximum and ambient temperatures. It is fairly linear for long times and is shown extended to shorter times as Curve 3 Curve 4 is the difference between Curves 2 and 3 and is also linear. Expressing Curves 3 and 4 as exponentials and adding results in the following:

$$
T\left({ }^{\circ} \mathrm{C}\right)=27+A(t)
$$

where

$$
A(t)=300 \cdot \exp (-0.28 t)+117 \cdot \exp (-0.0134 t)
$$

For a nitrogen cover gas

$$
A(t)=590 \cdot \exp (-0.41 t)+200 \cdot \exp (-0.0106 t)
$$

The simplest finite-difference expressions for $\frac{\partial c}{\partial x}$ and $\frac{\partial^{2} c}{\partial x^{2}}$ are used in the single-phase region, namely:

$$
\begin{gathered}
\frac{\partial c}{\partial x}=\frac{w}{\ell}[c(x)-c(x-1)] \\
\frac{a^{2} c}{\partial x^{\frac{2}{2}}}-\left(\frac{w}{l}\right)^{2}[c(x+1)-2 c(x)+c(x-1)]
\end{gathered}
$$

These expressions, together with Equations (C.12), (C.13), and (C.14), are substituted into Equation (C.5). The hydrogen distribution as a function of time can now be obtained, using 


$$
c(x, t+\Delta t)=c(x, t)+\Delta t \frac{\partial[c(x, t)]}{\partial t}
$$

where $A t$ is the time increment and $\frac{a}{a t}[c(X, t)]$ is given by Equations (C.5) or (C.10).

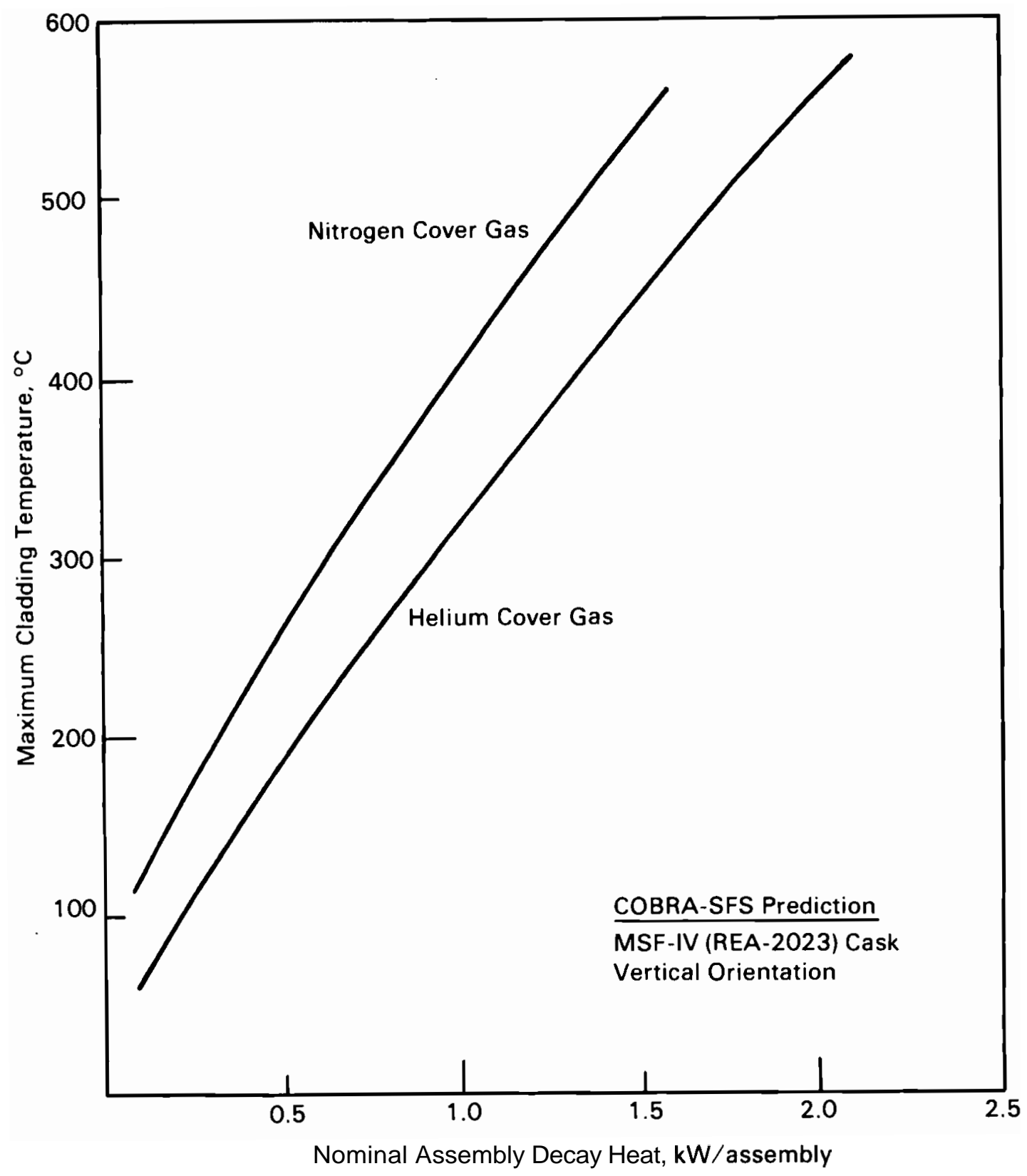

FIGURE C2 Maximum Cladding Temperature as a Function of Decay Heat

$$
\text { C.6 }
$$


TABLE C.1. Decay Heat for BNR Spent Fuel as Determined from ORIGEN2 Predictions

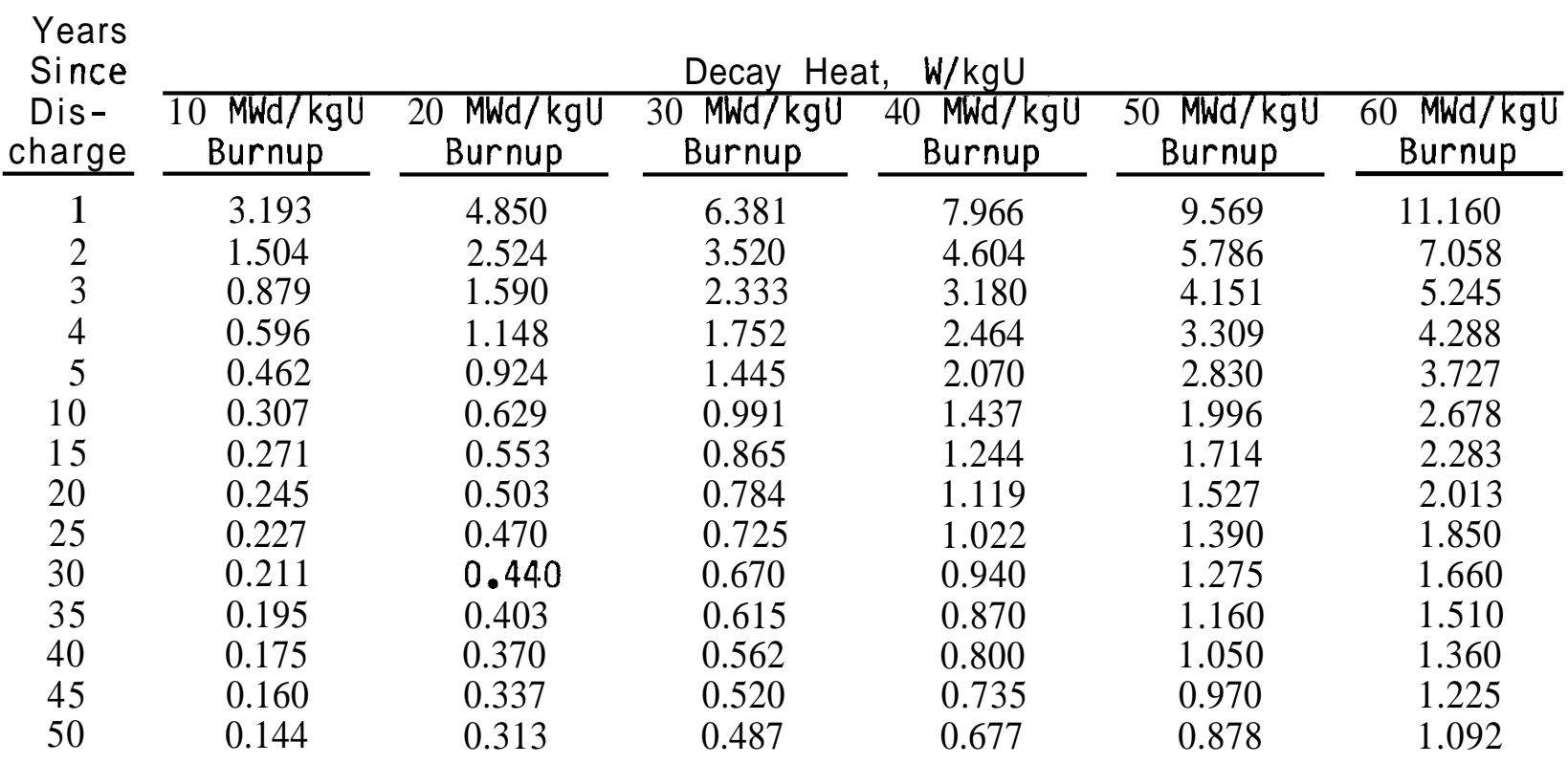

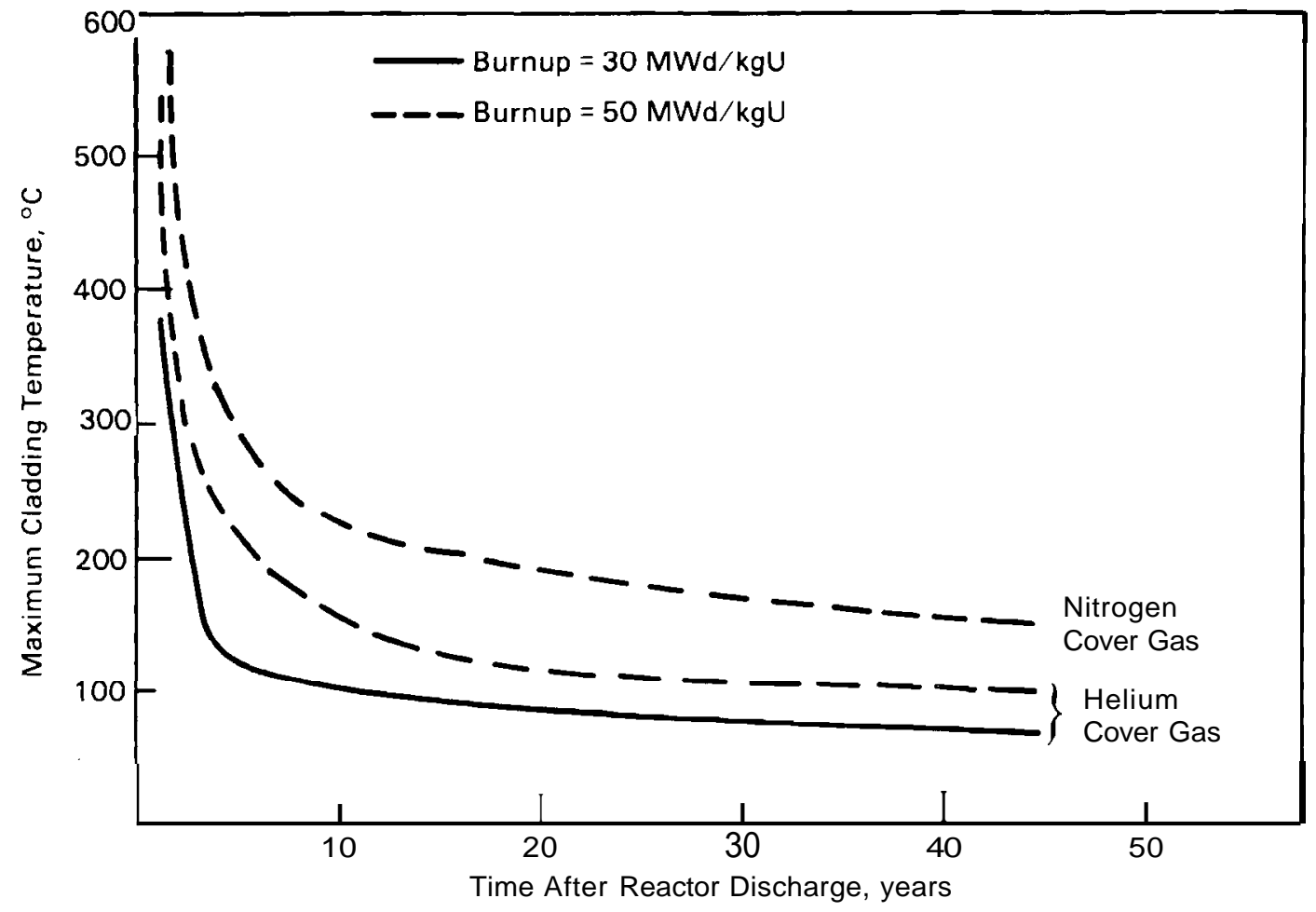

FIGURE C.3. Maximum Cladding Temperature as a Function of Time After Reactor Discharge 
When TSS is exceeded and an alpha-plus-hydride region exists at the end of the fuel tubes, the hydrogen flux is given by Equation (C.9). However, since the hydrogen generally does not diffuse out of the fuel tube, it is assumed to precipitate as solid hydride in the coldest region of the end cap. Such hydride deposits have, in fact, been found in the Zircaloy fuel tubes of WR-1 (an organic-cooled reactor at the Whiteshell Nuclear Research Establishment in Canada) and are identified in Figure C.5 as Hydride \#I. The hydride/alphaplus-hydride interface fell on an isotherm, as would be expected at or near equilibrium. As a result, Equation (C.9) has been used to determine the amount of hydrogen that may have diffused into the ends of the tube at any time and that may have been deposited as hydride.

The hydrogen redistribution to be expected after 90 years and the amount of hydrogen diffusing into the end caps have been predicted. The various constants used are given in Table C.2. The upper limit of the hydrogen distribution in Figure C.6 was used as the initial hydrogen distribution. A value of 20 for $w$ and a time interval of 0.1 year were used. These increments led to a difference of $<1.5 \%$ between the initial and final amounts of hydrogen.

Hydrogen distributions were computed for a burnup of $50 \mathrm{MWd} / \mathrm{kgU}$ for both helium and nitrogen cover gases. The temperature profiles, TSS, hydrogen distributions, and the amounts of hydrogen entering the end cap were calculated. Under helium, hydride was precipitated along the full length of the fuel tube in $<3$ years; under nitrogen, it took -5 years. The actual change in hydrogen concentration was small, $<1 \mathrm{ppm}$ for helium and $<10 \mathrm{ppm}$ for nitrogen. In both cases, there was little further change after 10 years.

The total amount of hydrogen diffused into the end cap region after 90 years is about $0.00043 \mathrm{mg} / \mathrm{cm}^{2}$ for helium cover gas and $0.029 \mathrm{mg} / \mathrm{cm}^{2}$ for nitrogen cover gas. Assuming that hydride is precipitated out, as shown as in Figure C.5,

$$
r=2.16(\bar{V})^{1 / 2}
$$

where $V$ is the volume of hydride per unit length of circumference of fuel tube. 


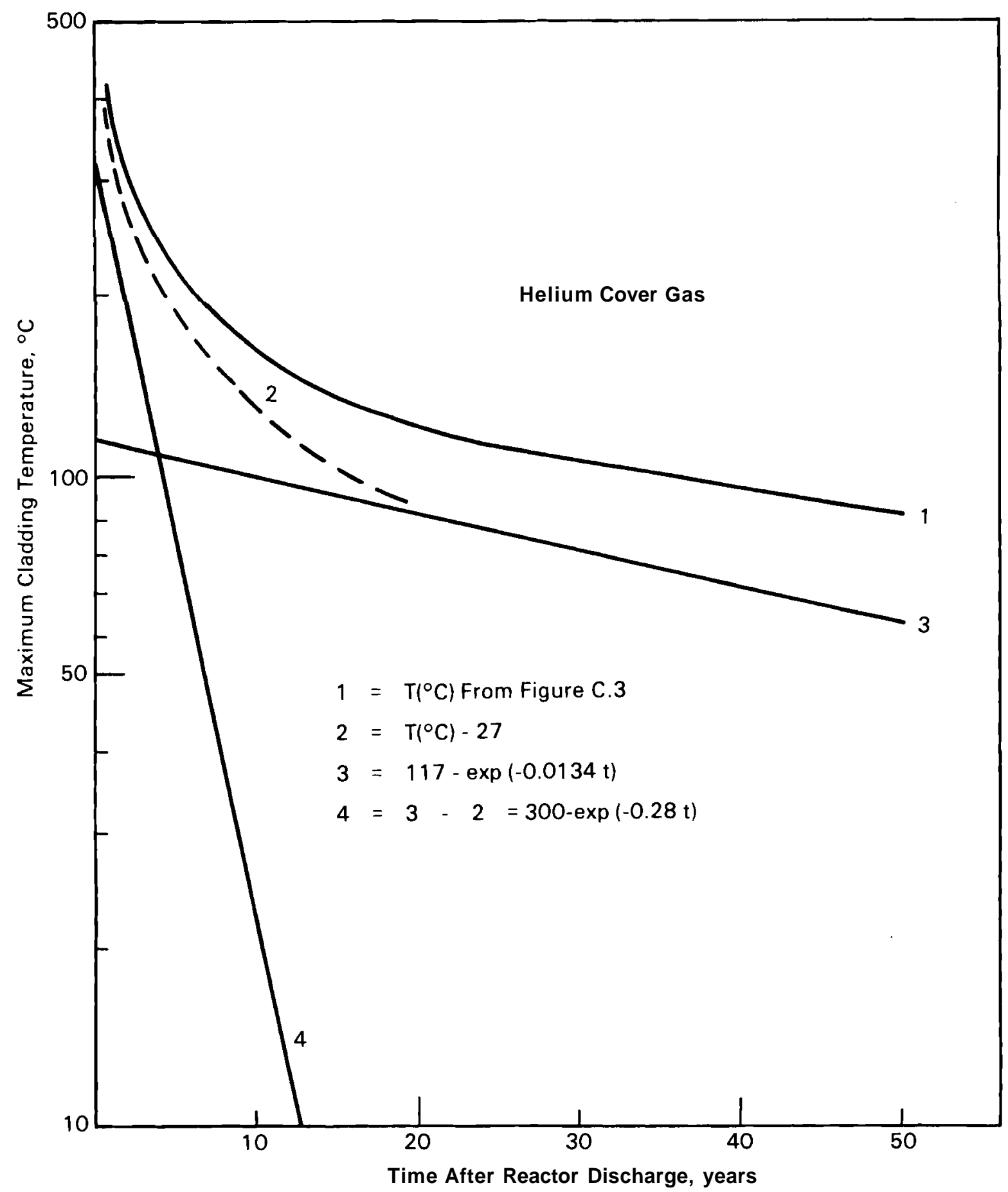

FIGURE C.4. Semi-Log Plot of Maximum Cladding Temperature as a Function of Time After Reactor Discharge 


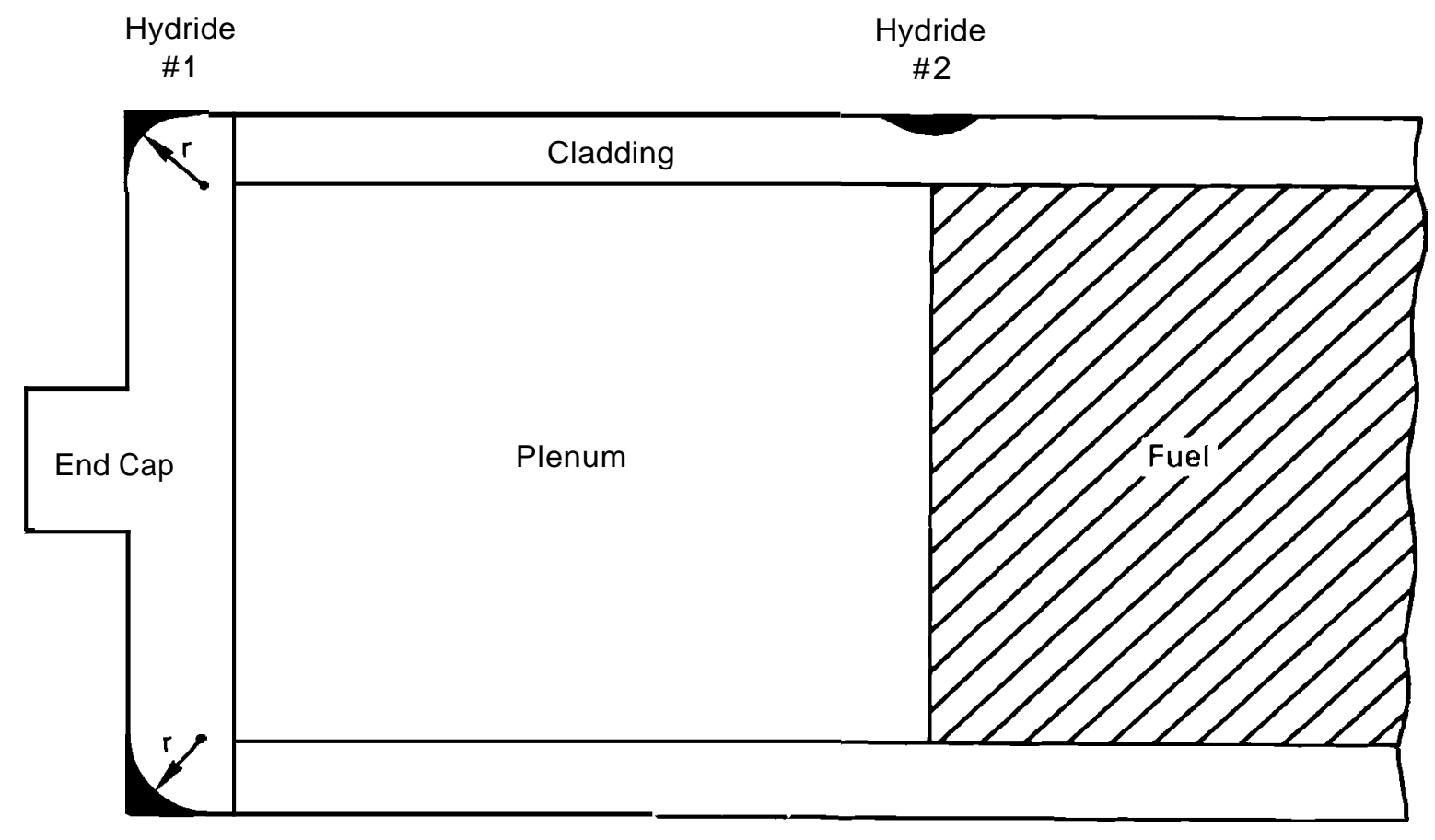

FIGURE C.5. Fuel Rod and Hydride Deposits

TABLE C.2. Constants Used in Hydrogen Redistribution Calculations

\begin{tabular}{|c|c|c|}
\hline Constant & Value & Reference \\
\hline$Q$ & $10,830 \mathrm{cal} / \mathrm{mol}$ & Kearns 1972 \\
\hline$Q^{*}$ & $6,000 \mathrm{cal} / \mathrm{mol}$ & Sawatzky 1960 \\
\hline H & $9,300 \mathrm{cal} / \mathrm{mol}$ & Sawatzky and Wilkins 1967 \\
\hline$D_{0}$ & $7.73 \times 10^{-3} \mathrm{~cm}^{2} / \mathrm{s}$ & Kearns 1972 \\
\hline$c_{0}$ & $1.99 \times 10^{5} \mathrm{ppm}$ & Sawatzky and Wilkins 1967 \\
\hline $\mathrm{R}$ & $1.987 \mathrm{cal} / \mathrm{mol}-\mathrm{K}$ & \\
\hline $\mathrm{L}$ & $490 \mathrm{~cm}$ & \\
\hline$\ell$ & $410 \mathrm{~cm}$ & \\
\hline$x_{0}$ & $40 \mathrm{~cm}$ & \\
\hline$t$ & $3.15 \times 10^{6} \mathrm{~s}$ & \\
\hline$T_{0}$ & $300 \mathrm{~K}$ & \\
\hline w & 20 & \\
\hline
\end{tabular}




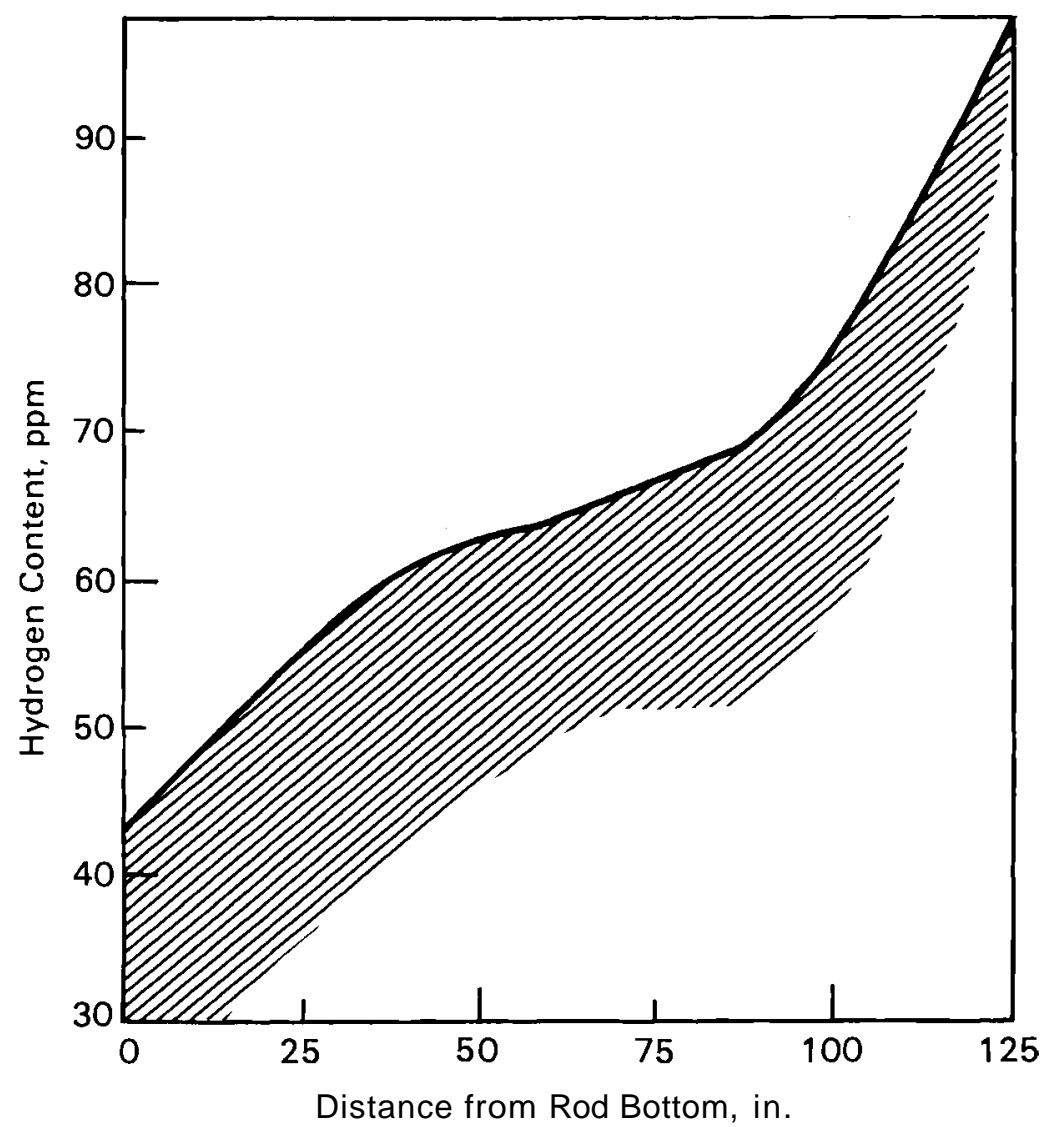

FIGURE C.6. Axial Hydrogen Distribution Observed in Fuel Rod Zircaloy Cladding from the Turkey Point Unit 3 Reactor (Atkin 1981)

The hydrogen concentration in solid hydride is about $110 \mathrm{mg} / \mathrm{cm}^{3}$. Therefore, in boiling water reactor fuel tubes (wall thickness $=0.89 \mathrm{~mm}$ )

$$
\begin{aligned}
& V=\frac{(0.00043) 60.089)}{110}=3.48 \times 10^{-7} \mathrm{~cm}^{3} / \mathrm{cm} \text { for helium } \\
& V=\frac{(0.029)(0.089)}{110}=2.35 \times 10^{-5} \mathrm{~cm}^{3} / \mathrm{cm} \text { for nitrogen }
\end{aligned}
$$

The corresponding $r$ values are

$$
\begin{aligned}
& r=2.16 \quad\left(3.48 \times 10^{-7}\right)^{1 / 2}=0.0013 \mathrm{~cm} \text { for helium } \\
& r=2.16 \quad\left(2.35 \times 10^{-5}\right)^{1 / 2}=0.010 \text { om for nitrogen. }
\end{aligned}
$$

The axial temperature profile has been taken to be sinusoidal for the hydrogen distribution calculations whereas, as indicated in Figure C.l, there 
may be a fairly sharp drop in temperature near the end of the fuel stack. This drop has little effect on hydrogen redistribution as long as the hydrogen is in solution. However, once TSS is exceeded, a higher hydrogen concentration might be expected in this region than would be predicted. In fact, bands of solid hydride extending halfway through the tube wall (as shown in Figure C.5, Hydride \#2) and leading to failure have been observed in experimental WR-1 fuel.

\section{C.3 REFERENCES}

Atkin, S D. 1981. Destructive Examination of 3-Cycle LWR Fuel Rods from Turkey Point Unit 3 for the Climax-Spent Fuel Test. HEDL-TME 80-89. Hanford Engineering Development Laboratory, Richland, Washington.

Creer, J. M., and D. $H$ Schoonen. 1986. "CASTOR-V/21 PRR Spent Fuel Storage Cask Performance Test." In Proceedings of Third International Spent Fuel Storage Technology Symposium/Workshop, CONF-860417, pp. S-20 to S-40.

Kearns, J. J. 1972. "Diffusion Coefficient of Hydrogen in Alpha Zirconium, Zircaloy-2 and Zircaloy-4." J. Nucl. Mat. 43: 330-338.

Sawatzky, A 1960. "Hydrogen in Zircaloy-2: Its Distribution and Heat of Transport." J. Nucl. Mat. 2(4):321-328.

Sawatzky, A 1986. Axial Hydrogen Diffusion. Contracted communication between Sawatzky Consultants, Pinawa, Manitoba, Canada, and Pacific Northwest Laboratory, Richland, Washington.

Sawatzky, A., and B.J.S. Wilkins. 1967. "Hydrogen Solubility in Zirconium Alloys Determined by Thermal Diffusion." J. Nucl. Mat. 22:304-310. 
APPENDIX D

CREEP RUPTURE MODELING 
APPENDIX D

\section{CREEP RUPTURE MODELING}

This appendix is a condensation of the creep rupture modeling performed by Chin, Khan, and Tarn (1986). Unless otherwise identified, the reference for the material in this appendix is Chin, Khan, and Tarn (1986). Deformation/ fracture maps for Zircaloy were developed because of the observed success of such maps for other metals, particularly 316 SS.

\section{D.I DEFORMATION MAP CONSTRUCTION}

An extensive survey of the literature was performed to identify possible mechanisms of deformation in the Zircaloy alloy system. Based on this survey, nine mechanisms were identified for investigation. These mechanisms were placed into four general categories: high-stress deformation, diffusioncontrolled dislocation creep, grain boundary sliding, and diffusional creep.

The high-stress deformation mechanisms category includes the theoretical strength of the material lattice that serves as an upper limit to deformation by dislocation motion. Below this upper limit, high-stress deformation will occur principally by conservative dislocation motion or glide. (a)

The diffusion-controlled dislocation creep processes are described by formulations for high-temperature climb, low-temperature climb, and a diffusional climb. All three formulations use a power law expression to describe the relationship between strain rate and stress.

With the use of quantified equations for each of the deformation mechanisms, a deformation map was produced by finding the portion of stress/ temperature space where a particular mechanism predicted the highest strain rate. Analytical solutions were derived for each of the boundaries between regions. The resulting deformation map is presented as Figure D.1.

(a) Constitutive equations describing deformation and failure mechanisms, along with their numerous references, are omitted here. Equations and reference notations are presented in Chin, Khan, and Tarn (1986). 


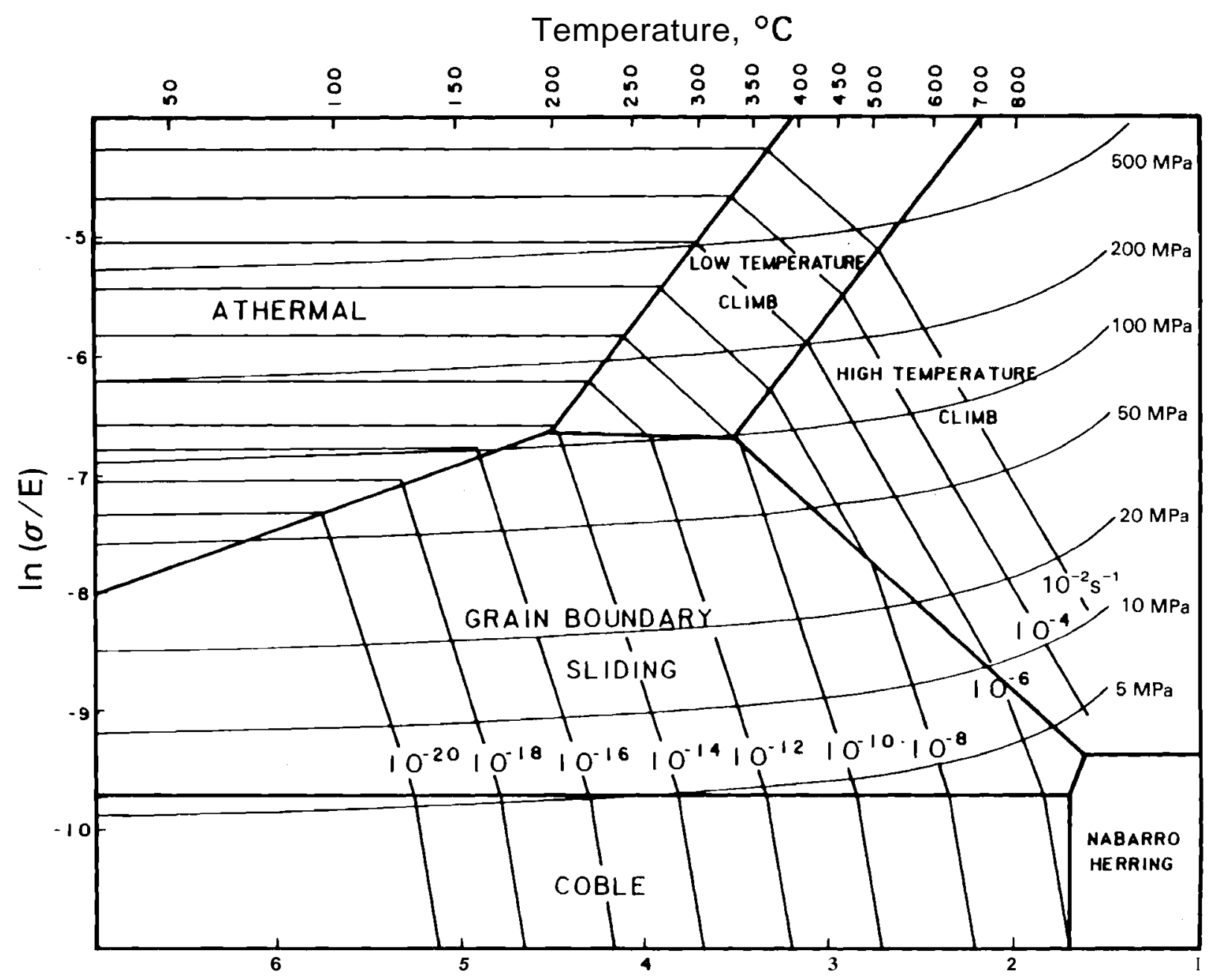

$\mathrm{Tm} / \mathrm{T}$, Absolute Melting Temperature/Absolute Temperature

FIGURE D.1. Deformation Map for Zircaloy (grain size $=5 \mu \mathrm{m}$ ) with Constant Stress and Strain Rate Contours

The map consists of regions dominated by the specific deformation mechanism listed in each region. Regions for theoretical strength and dislocation glide deformation do not show up on the plot because they occur at values of $\sigma / E$ (stress/Young's elastic modulus) greater than shown $[1 \mathrm{n}(\sigma / \mathrm{E})>\mathbf{- 3 . 7 3 ]}$. Harper-Dorn diffusional climb does not appear because Nabarro-Herring creep dominates for this grain size. Grain boundary sliding (lattice diffusion) is also narrowly eliminated by slightly higher high-temperature dislocation climb and Nabarro-Herring deformation rates. 
The methods for fracture map development, unfortunately, are not as advanced as those used in deformation map generation. There is much debate over the formulation of equations describing different fracture mechanisms. One transgranular and three intergranular processes of fracture were considered in this study for development of a fracture map.

Ductile transgranular fracture is at the higher end of the stress spectrum. In this mechanism, the presence of a "hard" inclusion disturbs the elastic and plastic displacement fields and thus leads to the buildup of local stresses at the inclusion-matrix interface. Once these local stresses reach a critical value, the inclusion either separates from the matrix or fractures and nucleates a hole. Once a void has nucleated further, plasticity makes it grow until it joins with other voids and a fracture path is created.

Transgranular creep-controlled fracture is found at somewhat lower stresses and at higher temperatures. This mechanism is very similar to ductile transgranular fracture. Here, also, voids nucleate at inclusions within the matrix and grow as the material creeps until coalescence occurs and the material fractures. Void nucleation in transgranular creep follows the steps described earlier for ductile fracture. In this case, however, if the temperature is high enough to allow diffusion, there is transport of matter from those areas on the inclusion surface that are in compression to those areas that are in tension. This transport tends to stabilize the plastic flow and thus postpone the coalescence of the voids.

Experimental observations of intergranular fracture have shown that there are two distinct characteristics of intergranular failure: wedge cracking and cavitation. One constitutive equation for wedge or triple-point cracking is presented; cavitation failure is described by two processes: power-law and diffusional growth.

Triple-point cracking occurs at low strain and relatively high stress. In this mechanism, the application of a tensile stress causes sliding of grains along the grain boundaries, giving rise to a stress concentration at triplepoints. This stress concentration can be relieved by the nucleation of a crack 
or change of the grain boundary orientation. Once the crack has been nucleated at the triple-point, it continues to grow by sliding of the grain boundaries.

Cavitation failure, on the other hand, has been experimentally observed under conditions of low stress and high temperatures. Here, cavities are nucleated and grow on the grain boundaries; the cavities continue linking up until fracture occurs. Diffusional growth models are based on the fact that vacancies diffuse along the grain boundaries, preferentially being absorbed into cavities. This movement of vacancies is equivalent to a reverse flow of atoms from the cavity between two adjacent grains. The cavities are separated by a bridge of material that must deform if the cavities are to grow. The growth of each cavity is thus controlled by the creep of the surrounding matrix of material, which is in turn controlled by a power-1aw-type behavior. A formulation describing this creep-controlled fracture behavior was adopted in this study. Mechanisms involving dynamic recrystallization and dynamic fracture were not included in this analysis because they require stress and temperatures greater than expected for normal inerted dry storage (IDS) conditions.

Using the fracture equations with the appropriate coefficients, analytical solutions for the boundaries between dominant fracture regions were developed. A fracture map was then generated using the strain rate predictions of the deformation map (see Figure D.2). Direct substitution of strain rates from the deformation map into the fracture equations results in a map that is totally dominated by triple-point cracking for stresses >150 MPa. This phenomenon results from the assumption that the contribution of grain boundary sliding to the total creep rate is a constant $20 \%$. To alleviate this problem, an upper limit stress of $200 \mathrm{MPa}$ was chosen for triple-point cracking. At this stress, the grain boundary sliding contribution was placed at zero. Hence, transgranular fracture becomes the dominant mechanism for higher stresses.

Because the fracture mechanisms depend on the rate at which deformation is accumulated, a change in the deformation map is usually reflected in the fracture map. Often, both the regions of dominance and the times to fracture are altered. 


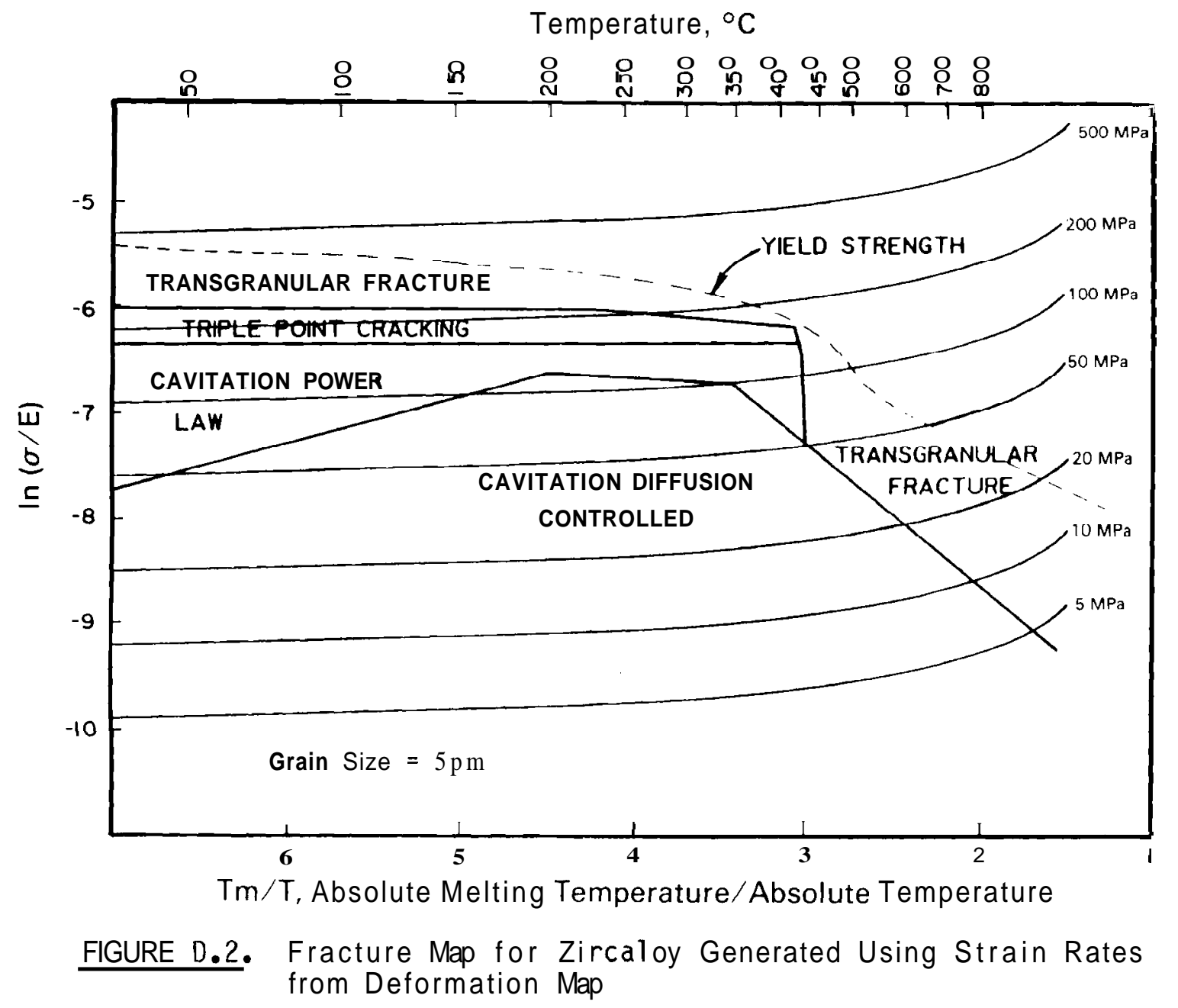

Expressions to describe the ductile transgranular fracture region were developed based on experimental yield stress and ultimate tensile strength data. This region was added by plotting the locus of the yield stresses, one from each temperature, onto the fracture map.

D.3 COMPARISON OF THE MODE WITH THE EXPERIMENTAL DATA

Experimental strain rate data were placed on a series of stress versus strain rate plots with each plot containing strain rate predictions for a specific temperature. The plot at $350^{\circ} \mathrm{C}$ is illustrated in Figure D.3. The data shown are for zirconium alloys used by each investigator. 


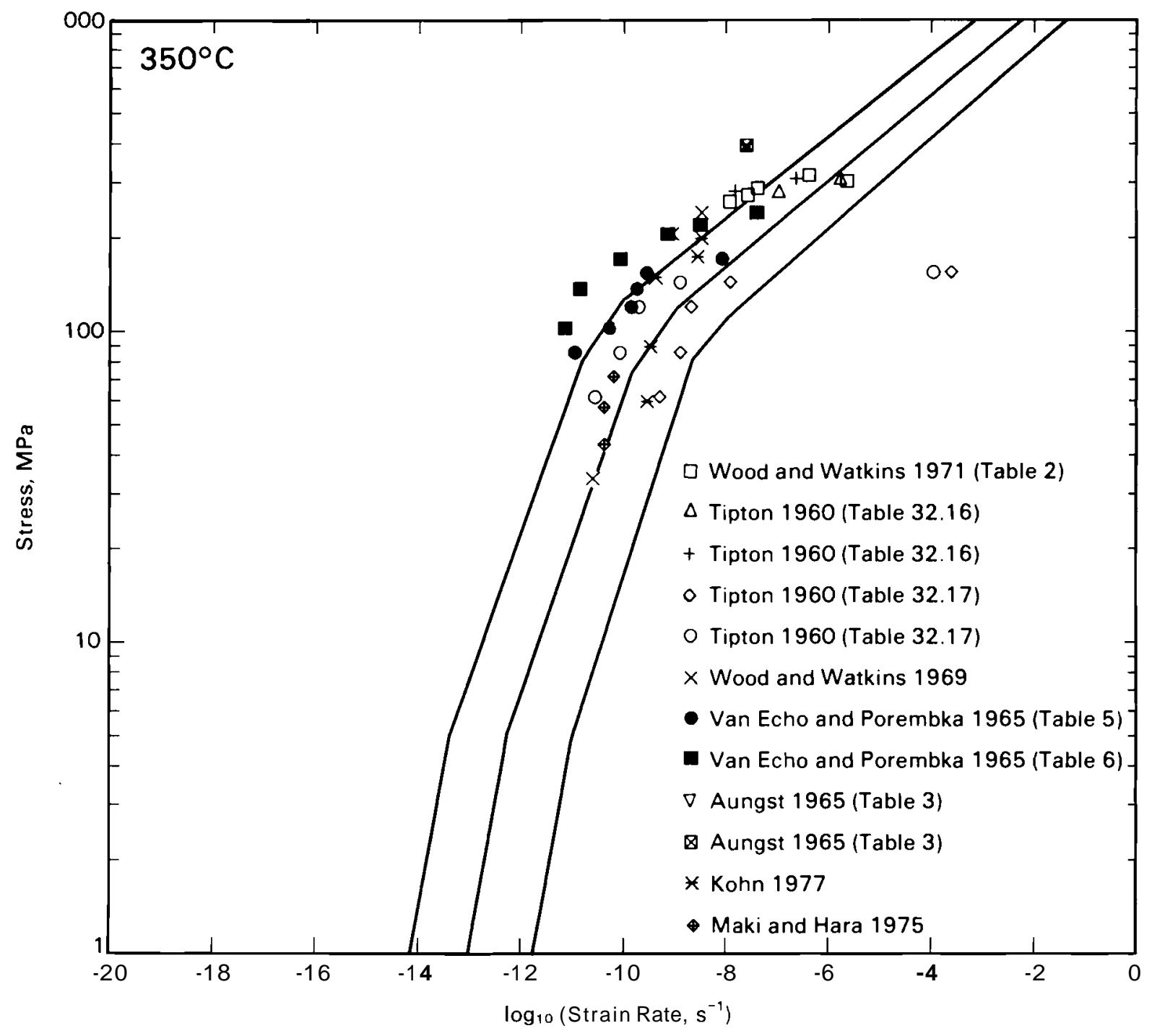

FIGURE D.3. Predicted Strain Rate Contours at $350^{\circ} \mathrm{C}$ Compared with Experimental Data. The middle curve is the prediction; the outer curves are order-of-magnitude shifts of the prediction.

Experimental fracture data were plotted on a series of stress versus time to fracture plots, with each plot containing predicted stress at fracture for a specific temperature. The plot for $350^{\circ} \mathrm{C}$ is presented as Figure D.4. The spread of the experimental data may be attributed to the variety of zirconium alloys used by the investigators. Additionally, much of the fracture data were 


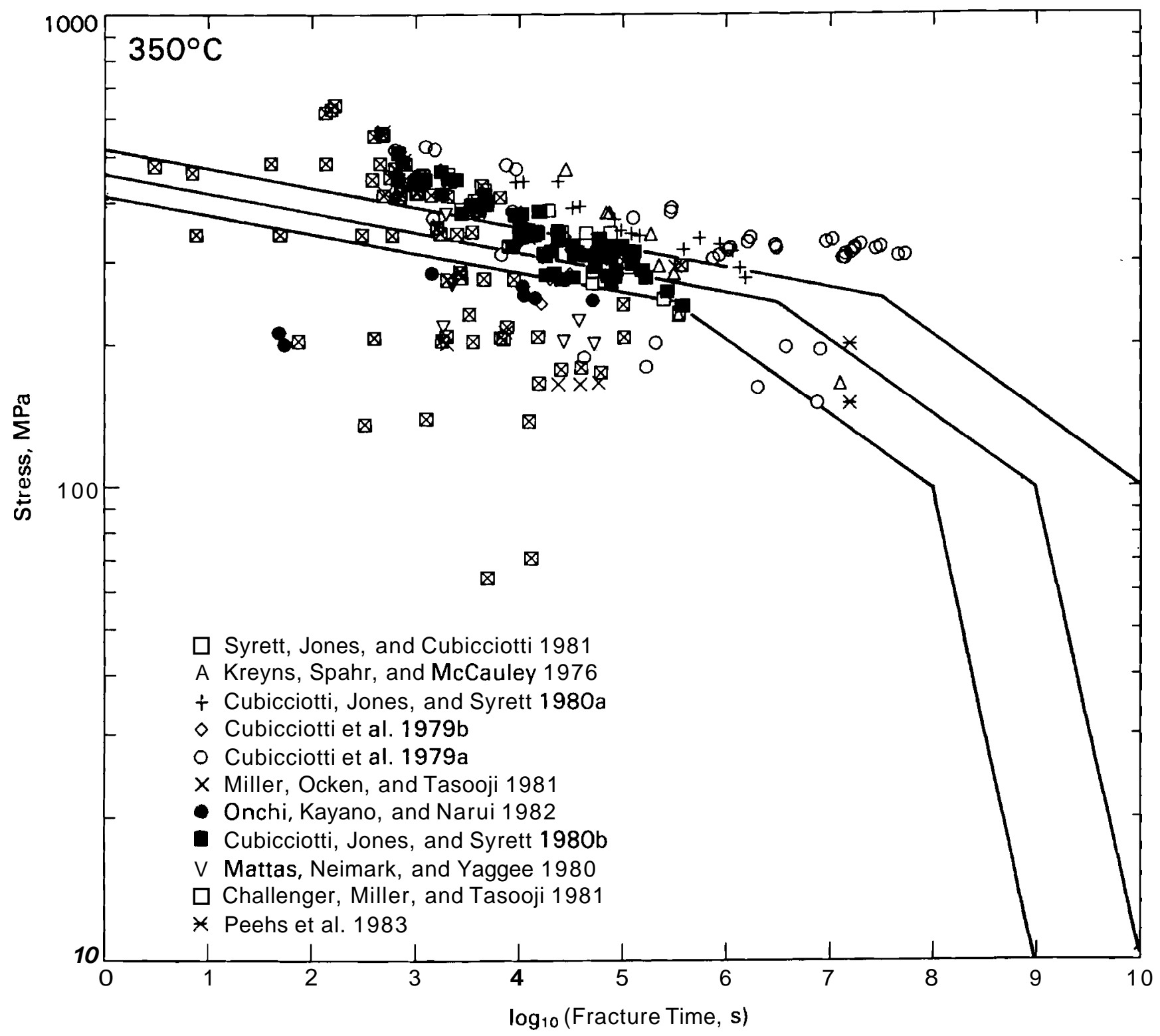

FIGURE D.4. Predicted Time to Fracture at $350^{\circ} \mathrm{C}$ Compared with Experimental Data. The middle curve is the prediction; the outer curves are order-of-magnitude shifts of the prediction. Prediction and order-of-magnitude curves in Figure 15 of Chin, Khan, and Tarn (1986) are in error and have been corrected here.

obtained from programs investigating stress corrosion cracking (SCC) rather than creep rupture; experimental conditions (high stresses) were such that SCC occurred more rapidly than creep rupture would have occurred. 
The best data prediction comparisons are for the temperature range of interest for IDS: 250 to $400^{\circ} \mathrm{C}$.

\section{D.4 ENVIRONMENTAL AND IRRADIATION EFFECTS}

Examination of three data sets generated at the Argonne National Laboratory (Yaggee, Mattas, and Neimark 1979), Kraftwerk Union (Peehs and Fleisch 1986), and the Chalk River site (Novak and Hastings 1983) revealed that the loss of ductility is one of the principal effects of irradiation. Postirradiation data showed fracture strains between $5 \%$ and $12 \%$ that correspond to reductions in ductility of $1 / 2$ to $1 / 10$.

For simplicity and because of the lack of additional postirradiation data, irradiation was assumed to reduce the ductility of the cladding by a factor of 10 in the stress/temperature region of interest for dry storage. Such an assumption is consistent with postirradiation behavior seen in 316 stainless steel. In a comparison of postirradiation, in-reactor, and laboratory pressurized tube specimens, only the onset of tertiary creep was found to be affected by irradiation. Because the steady-state creep rate is not affected by irradiation and because tertiary creep is theoretically associated with the onset of fracture of the material, it is consistent to assume that the primary effect of irradiation is a reduction in ductility that leads to a reduction by some constant factor in the fracture time. This assumption of a loss in ductility at fracture also leads to the enhancement of the triple-point cracking region to lower stresses because triple-point cracking is a relatively low strain (to fracture) mechanism. Irradiation also moves the boundary of the ductile transgranular fracture region upward by increasing the yield strength of the material.

In addition to stress and temperature changes that occur during dry storage of spent fuel, there will be Zircaloy microstructural adjustments that are anticipated to change material properties. These adjustments are the result of recovery of irradiation damage, including irradiation-enhanced dislocation density, point defect concentration, and other effects that are "annealed" out as a function of time in dry storage. This recovery is time and temperature dependent and is an important factor when storage temperatures 
exceed $350^{\circ} \mathrm{C}$. As the irradiation damage is annealed out, the material properties are anticipated to approach those of unirradiated material. The principal effect of annealing in the dry storage stress/temperature regime is a recovery of ductility. The time and temperature dependence of annealing, expressed as a recovery factor, is presented in Figure D.5. The relationship in Figure D.5 is based on data from nonirradiated, cold-worked Zircaloy; annealing of loop and cluster damage from irradiation may occur more quickly.

\section{D.5 LIFE-FRACTION RULE}

Of particular interest to cask designers is the maximum allowable initial storage temperature of the cask. All passive storage concepts to date project a decrease in storage temperature with time because of the decay in the heat generation rate of the fuel. To account for this anticipated decrease in storage temperature, a life-fraction rule was used to calculate accumulated damage for decreasing temperature conditions. The life-fraction rule can be expressed as the following equation:

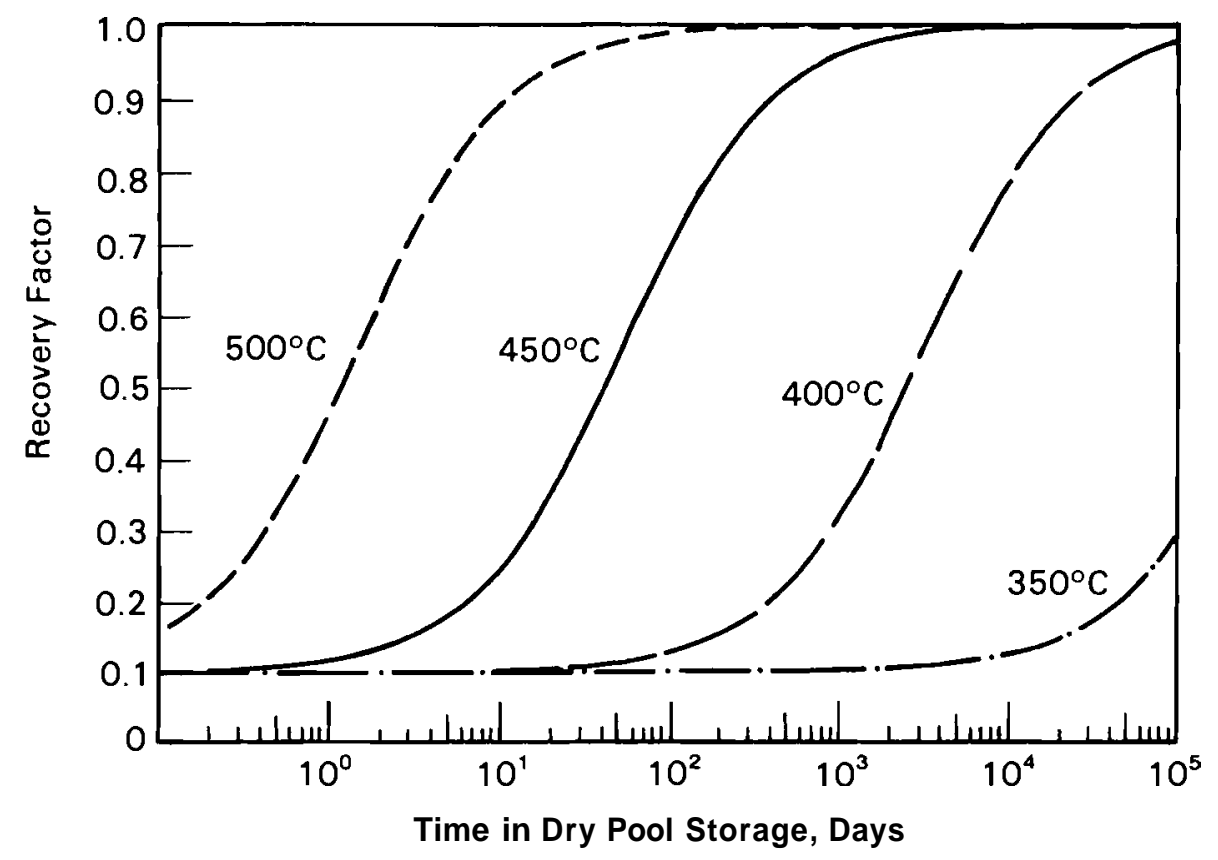

FIGURE D.5. Time and Temperature Dependence of Recovery Factor (annealing) in Zircaloy. Based on data reported by Steinberg, Weidinger, and Schaa (1984). 


$$
\sum_{i=1}^{N} \frac{\Delta t_{i}}{\tau_{i}}=1
$$

where $\Delta t_{i}$ is the time spent at the ith temperature and $\tau_{j}$ is the time required to fracture a specimen under isothermal, isostress testing conditions. When the cumulative damage fraction--the sum of the life fractions $\left(\Delta t_{j} / \tau_{j}\right)$--reaches 1 , the material is assumed to have failed.(a)

\section{D.6 ANALYSIS OF FEDERAL REPUBLIC OF GERMANY DATA}

Chin, Khan, and Tarn (1986) used the deformation and fracture map methodology to analyze data from four studies: 1) a study to simulate the dry storage of a pressurized water reactor (PWR) spent fuel assembly (Assembly B02 of the Turkey Point PWR) conducted at the Nevada Test Site in the Engine Maintenance and Disassembly (EMAD) shielded facility; 2) a study of abnormal dry storage events conducted at Pacific Northwest Laboratory (PNL); 3) a study performed by the Federal Republic of Germany (FRG) in support of its dry spent fuel storage effort; and 4) a study reported by Westinghouse Hanford Company in support of a dry spent fuel storage program. Only the analysis of the FRG data is discussed here to illustrate the utility of the deformation and fracture map methodology developed for Zircaloy-clad spent fuel.

A summary of both unirradiated and irradiated strain rate data from tests conducted by the $R G$ in support of its dry spent fuel storage effort is presented in Table D.I (Peehs et al. 1979). The data are superimposed on predictions of the deformation and fracture map methodology in Figure D.6. These plots represent temperatures of $300,325,350$, and $375^{\circ} \mathrm{C}$. Generally, good agreement is found between predictions and data. The data at these temperatures fall towards the lower limits of the data field (lower creep rates), but they are consistent with the data of other investigators. Because the $\mathrm{RRG}$ data

(a) Another application of the life-fraction rule, with additional discussion, is presented in Reid and Gilbert (1986). 
TABLE D.1. Strain Rate Data from the Federal Republic of Germany (Peehs et al. 1979)

\begin{tabular}{cccl} 
Temperature, ${ }^{\circ} \mathrm{C}$ & Stress, MPa & & Strain Rate, $\mathrm{s}^{-1}$ \\
\cline { 1 - 2 } 275 & 200 & & $4.215 \times 10^{-11}$ \\
300 & 150 & & $4.81 \times 10^{-11}$ \\
300 & 200 & $8.25 \times 10^{-11}$ \\
325 & 150 & $1.01 \times 10^{-10}$ \\
325 & 200 & $1.953 \times 10^{-10}$ \\
350 & 150 & & $2.65 \times 10^{-10}$ \\
350 & 200 & & $1.18 \times 10^{-9}$ \\
375 & 150 & $1.1185 \times 10^{-9}$ \\
375 & 70 & $6.09 \times 10^{-11(\mathrm{a})}$ \\
375 & 70 & $4.74 \times 10^{-11(\mathrm{a})}$ \\
400 & 150 & $9.4 \times 10^{-10}$ \\
400 & 112 & $3.61 \times 10^{-10}$ \\
400 & 75 & $2.81 \times 10^{-10}$ \\
400 & 70 & $1.74 \times 10^{-10}$ \\
400 & 70 & $1.625 \times 10^{-10}$ \\
400 & 70 & $1.44 \times 10^{-10}$ \\
400 & 70 & $1.323 \times 10^{-10}$ \\
400 & 70 & $1.87 \times 10^{-10}$ \\
400 & 70 & $1.92 \times 10^{-10}$ \\
400 & 70 & $1.48 \times 10^{-10}$ \\
400 & 70 & $1.63 \times 10^{-10}$ \\
400 & 70 & $1.0025 \times 10^{-9}(\mathrm{a})$ \\
400 & 70 & $9.485 \times 10^{-10}(\mathrm{a})$
\end{tabular}

(a) Out-of-reactor creep data.

fall towards the lower creep rate side of the data field, strain rates are best predicted by the lower-limit creep rate prediction of the deformation and fracture map models.

The $R$ R data are displayed on plots of stress versus fracture time predictions in Figure D.7. These maps represent temperatures of 300, 325, 350, and 

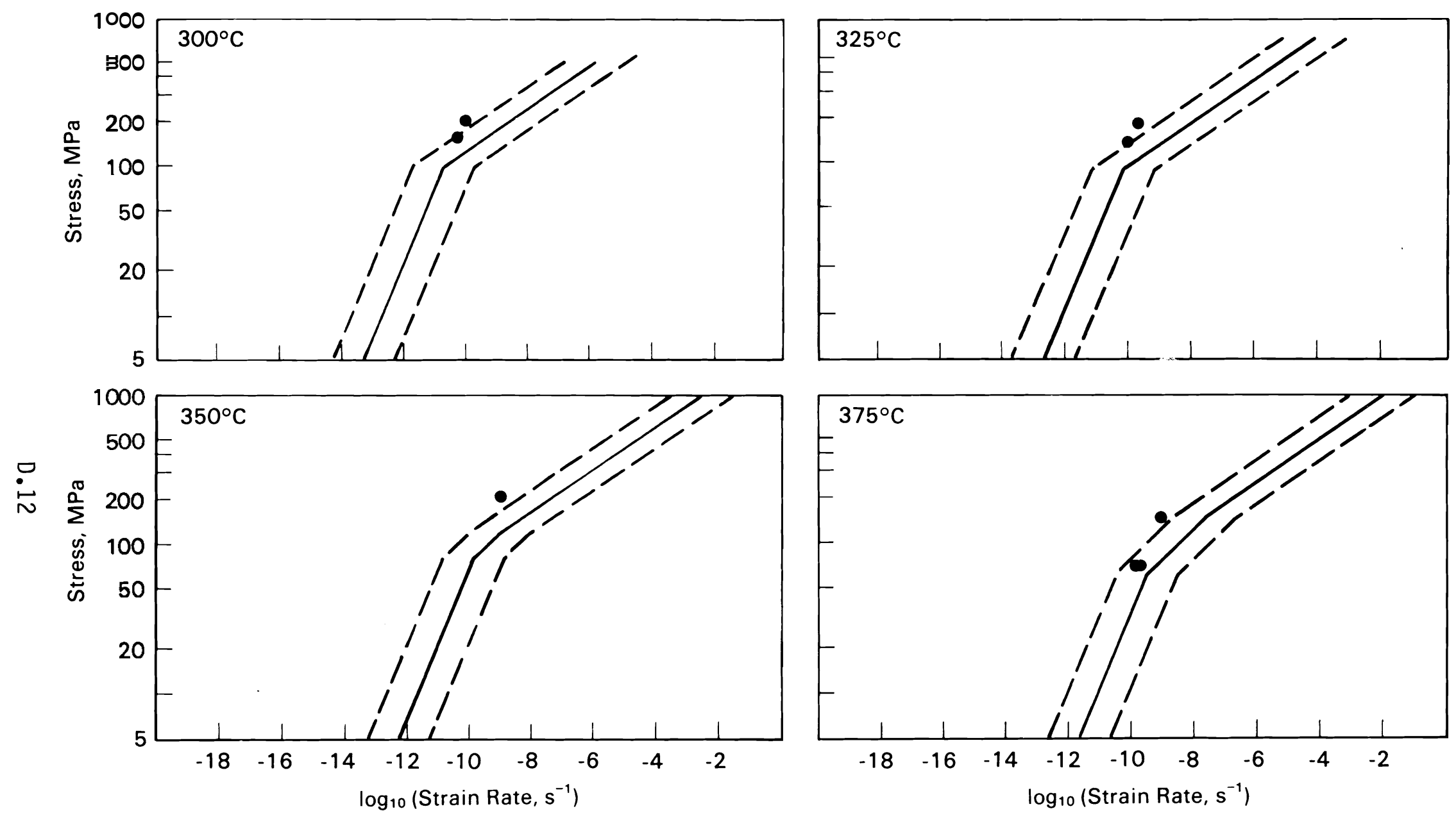

FIGURE D.6. Comparison of Predicted Strain Rates with FRG Experimental Data 

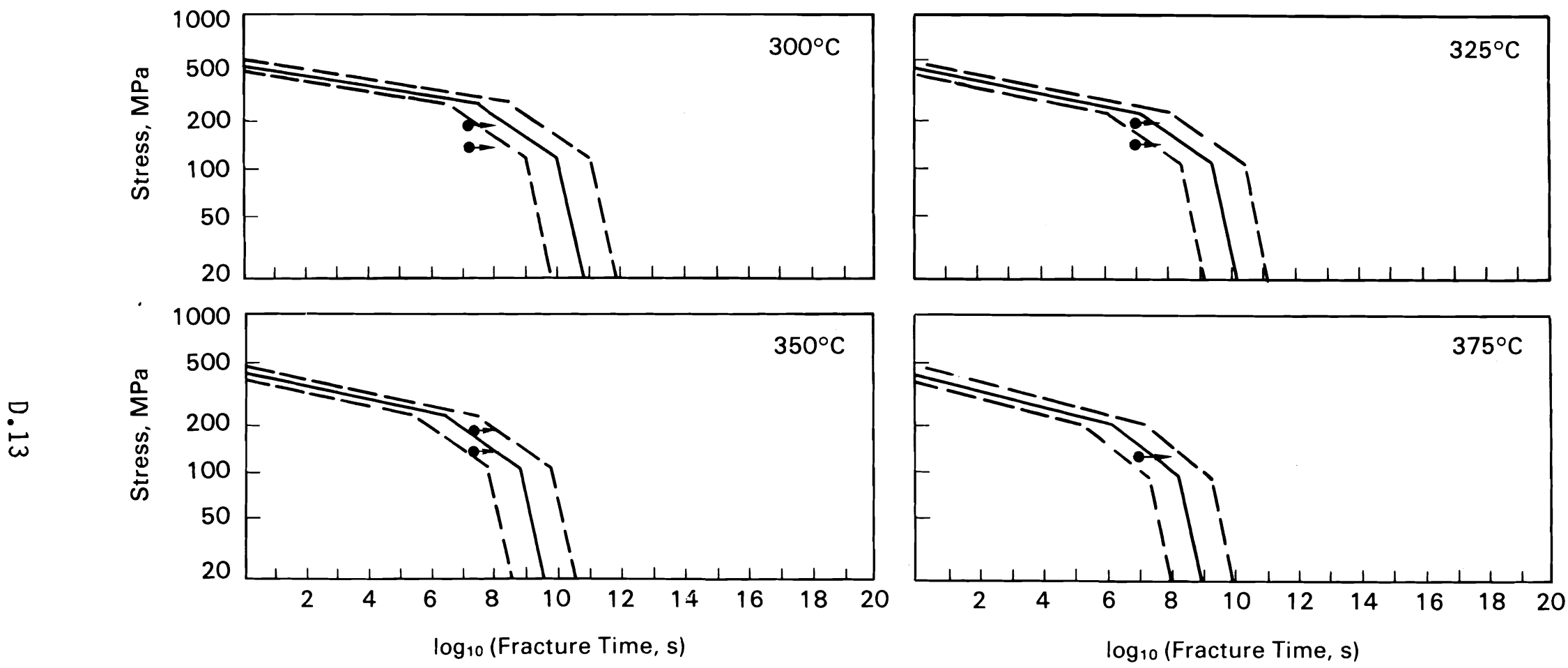

FIGURE D.7. Comparison of Predicted Fracture Times with FRG Experimental Data (Arrows indicate that specimens did not fracture.) 
$375^{\circ} \mathrm{C}$. None of the $\mathrm{RRG}$ specimens have actually fractured; therefore, the test data represent maximum time of exposure at temperature without fracture. This has been indicated by arrows pointing to longer times. Again the fracture maps appear to be conservative; no fractures are reported before predicted failure. At $350^{\circ} \mathrm{C}$ and $400^{\circ} \mathrm{C}$, some specimens have exceeded the predicted fracture time without indications of failure. However, since the accumulated strain on each of these specimens exceeds $1 \%$, they are all approaching failure. It is therefore concluded that the deformation and fracture maps provide good agreement with $\mathrm{FRG}$ data.

\section{D.7 REFERENCES}

Aungst, R. C. 1965. Stress Rupture Tests of Zircaloy-2 Pressure Tubes. BNWL-8, Pacific Northwest Laboratory, Richland, Washington.

Challenger, K. D., A K. Miller, and A. Tasooji. 1981. SSCIG: A Phenomenological Model for lodine Stress Corrosion Cracking of Zircaloy. EPRI NP-1798, Vol. 1, Electric Power Research Institute, Palo Alto, California.

Chin, B. A, M. A. Khan, and J. Tarn. 1986. Deformation and Fracture Map Methodology for Predicting Cladding Behavior During Dry Storage. PNL-5998, Pacific Northwest Laboratory, Richland, Washington.

Cubicciotti, D., et al. 1979a. "A Stress Corrosion Cracking Model for PelletCladding Interaction Failures in Light-Water Reactor Fuel Rods. In Zirconium in the Nuclear Industry: Proceedings of Fourth International Conference, ASTM STP 681, pp. 285-305.

Cubicciotti, D., et a1. 1979b. "Thresh01d Conditions for lodine-Induced Stress Corrosion Cracking of Unirradiated Zircaloy-4 Tubing Under Internal Pressurization." J. Nucl. Mat. 82:26-38.

Cubicciotti, D., R. L. Jones, and B. C. Syrett. 1980a. "Effects of Test Temperature, Alloy Composition and Heat Treatment on lodine-Induced Corrosion Cracking of Unirradiated Zircaloy Tubing." J. Nucl. Mat. 91:277-292.

Cubicciotti, D., R. L. Jones, and B. C. Syrett. 1980b. Stress Corrosion Cracking of Zircaloy. EPRI NP-1329, Electric Power Research Institute, Palo Atto, California.

Kohn, E. 1977. "In-Reactor Creep of Zr-2.5 Nb Fuel Cladding." In Zirconium in the Nuclear Industry: Proceedings of the Third International Conference, ASTM STP 633. 
Kreyns, P. H., G. L. Spahr, and J. E. McCauley. 1976. "An Analysis of lodine Stress Corrosion Cracking of Zircaloy-4 Tubing." J. Nucl. Mat. 61:203-212.

Maki, H., and T. Hara. 1975. "Out-of-Reactor Study on External Pressure Creep of Zircaloy-2 Fuel Cladding Tubes." J. Nucl. Sci. and Tech. 12:43-52.

Mattas, R. F., L. A. Neimark, and F. L. Yaggee. 1980. Characterization of Irradiated Zircaloy: Susceptibility to Stress Corrosion Cracking. EPRI NP-1557, Electric Power Research Institute, Palo Alto, California.

Miller, A. K. H. Ocken, and A. Tasooji. 1981. "lodine Stress Corrosion Cracking of Zircaloy: Laboratory Data, A Phenomenological Model and Predictions of In-Reactor Behavior.' J. Nucl. Mat. 99: 254-268.

Novak, J., and I - J. Hastings. 1983. "Post-Irradiation Behavior of Defected U0, Fuel Elements at $220^{\circ} \mathrm{C}$ to $250^{\circ} \mathrm{C}$ in Air." In Proceedings of Spent Fuêl/Cladding Reaction During Dry Storage, NUREG/CP-0049. Gaithersburg, Maryland.

Onchi, T., H. Kayano, and M. Narui. 1982. "Effects of Neutron Irradiation on lodine Stress Corrosion Cracking Susceptibility of Zircaloy-2 Tubing." لـ Nucl. Sci. and Tech. 19: 740-748.

Peehs, M, et al. 1979. "Out-of-Pile Testing of lodine Stress Corrosion Cracking in Zircaloy Tubing in Relation to the Pellet Cladding Interaction Phenomonen." ASTM STP 681, pp. 244-260.

Peehs, M., et al. 1983. "Zircaloy Post-Pile Creep Experimental Procedure, Test Samples and First Results." Paper presented at IAEA Seminar on Technical and Environmental Aspects of Spent Fuel Management, September 27-30, 1983, Madrid, Spain.

Peehs, M, and J. Fleisch. 1986. "LWR Spent Fuel Storage Behavior." $\underline{J}$. Nucl. Mat. 137:190-202.

Reid, C. R, and E. R. Gilbert. 1986. Methodology for Determining Criteria for Storing Spent Fuel in Air. PNL-6018, Pacific Northwest Laboratory, Richland, Washington.

Steinberg, E. H. G. Weidinger, and A Schaa. 1984. "Analytical Approaches and Experimental Verification to Describe the Influence of Cold Work and Heat Treatment on the Mechanical Properties of Zircaloy Cladding Tubes." In Zirconium in the Nuclear Industry: Sixth International Symposium, ASTM STP 824, pp. 106-122.

Syrett, B. C., R. L. Jones, and D. Cubicciotti. 1981. "The Effect of Axial Stress to Hoop Stress Ratio on the Susceptibility of Unirradiated Zircaloy-4 to lodine Stress Corrosion Cracking." J. of Nucl. Mat. 96:160-168.

Tipton, C. R. 1960. Reactor Handbook - Second Edition Materials. Vol. 1. Interscience, New York, pp. 715. 
Van Echo, J. A, and S. W. Porembka. 1965. Long-Term Creep Rupture of Sintered Aluminum Powder and Zircaloy-2 Alloys. BMl-X-10113, Battelle Memorial Institute, Columbus, Ohio.

Wood, D. S., and B. Watkins. 1969. "Applications Related Phenomena for Zirconium." Testing and Materials, pp. 236.

Wood, D. S, and B. Watkins. 1971. "A Creep Limit Approach to the Design of Zircaloy-2 Reactor Pressure Tubes at $275^{\circ} \mathrm{C} . "$ J. Nucl. Mat. 41:327-340.

Yaggee, F. L., R. F. Mattas, and L. A Neimark. 1979. Characterization of Irradiated Zircaloys: Susceptibility to Stress-Corrosion Cracking - An Interim Renort. EPRI NP-1155. Electric Power Research Institute. Palo Alto. California. 
APPENDIX E

STATUS OF INERTED DRY STORAGE TECHNOLOGY 
APPENDIX E

\section{STATUS OF INERTED DRY STORAGE TECHNOLOGY}

There has been a great deal of activity in inerted dry storage (IDS) since the 1983 report by Johnson and Gilbert. A number of storage casks have been designed, two storage facilities have been licensed in the United States, and considerable scientific work has been initiated and/or completed on dry storage. This appendix discusses the current need for IDS in the United States, IDS systems currently being promoted in the United States, and the status of IDS licensing. An overview of IDS experience is also provided.

\section{E.I EXPECTED SOOPE OF DRY STORAGE FOR U.S. SPENT FUEL}

Wet storage of spent fuel continues to be the principal interim spent fuel storage technology in use in the United States. All spent fuel will continue to be discharged to water pools and will remain in wet storage until decay heat levels decrease to levels consistent with maximum allowable cladding temperature limits during dry storage. Wet storage is a demonstrated, safe technology that has functioned effectively for years (IAEA 1982; DOE 1980; Johnson 1977). Most utilities will probably fully utilize their current or planned investments in wet storage facilities; dry storage will therefore be considered as a supplemental technology.

Beginning in 1987, some pressurized water reactors (PWRs) and boiling water reactors (BWRs) in the United States will begin to lose their full core reserve capability (a) (DOE 1986). The number of spent fuel assernblies expected to exceed the capacity of currently licensed storage facilities is presented in Figure E.1. This projection was based on utility estimates of spent fuel discharge rates and storage capacities, including currently licensed dry storage at the Surry and H. B. Robinson-2 plants. It assumes pool sharing between multiple plants at a common site when the plants share a common storage pool

(a) Full core reserve capability is the capability to remove the entire fuel load from the core and place it in the storage pool. 


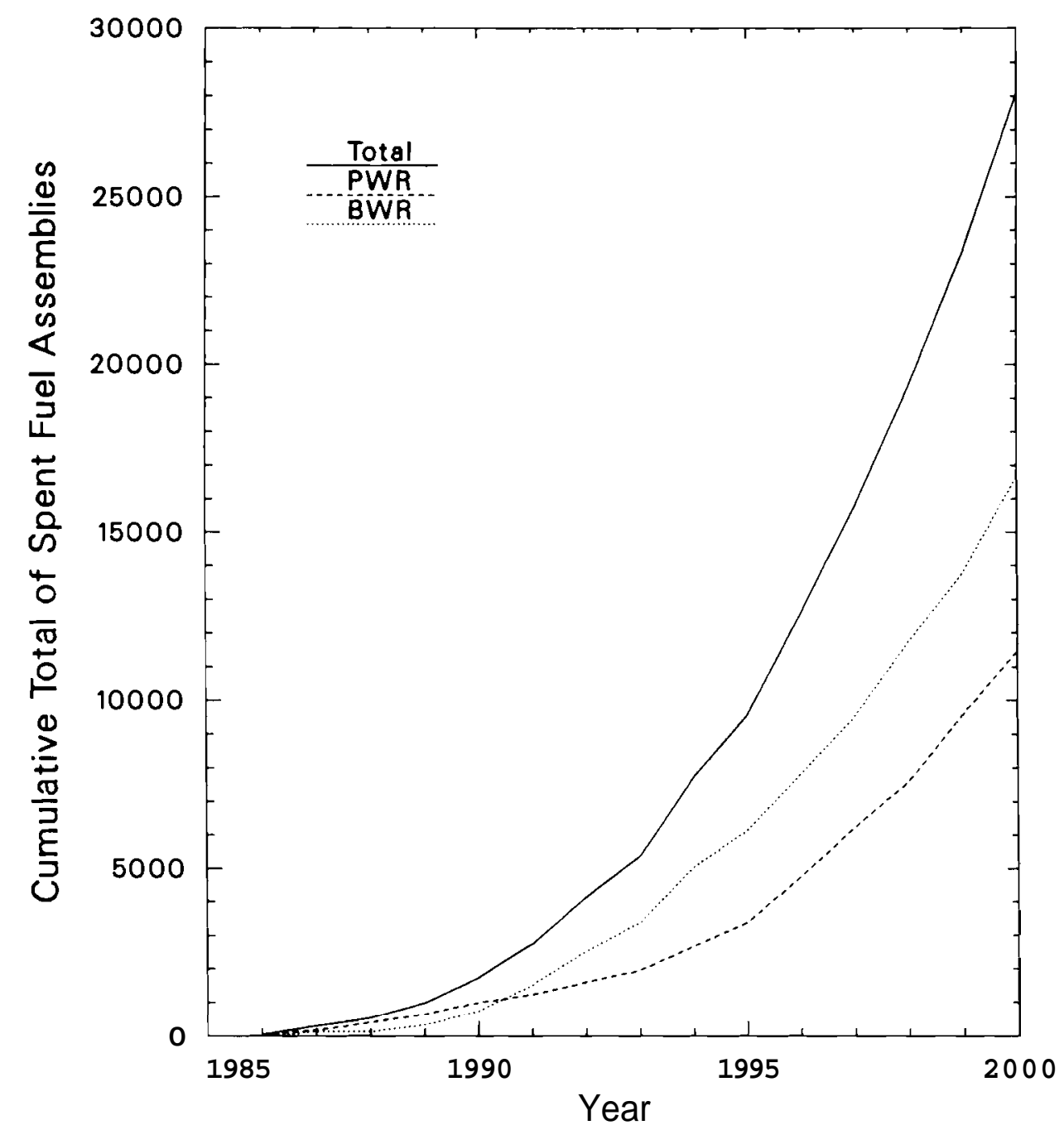

FIGURE E. 1. Projected Number of Spent Fuel Assembl ies (cumulative) in Excess of Available Onsite Storage Capacity

or when storage pools are linked by underwater connections for fuel transfers. The projected amount can probably be considered a maximum because it does not take into account increasing fuel utilization, planned (but not currently licensed) dry storage, or trans-shipments of spent fuel between plants of a utility.

To help alleviate the anticipated storage problem, the 1982 Nuclear Waste Policy Act specified that the federal government would begin to accept fuel from utilities in 1998 for storage in monitored retrievable storage (MRS) or final repository facilities, provided that utilities have not elected to 
reprocess the fuel. The United States has no current prospects for relieving the storage situation through reprocessing of spent fuel for recovery of uranium and plutonium and subsequent consolidation of waste. Until the MRS facility or the final repository has been implemented, IDS is expected to handle storage needs not met by wet storage.

No commercial fuel reprocessing has occurred in the United States since 1971; therefore, a substantial fraction of the stored spent fuel inventory consists of older fuel assemblies. The burnup distribution of discharged and stored fuel assemblies as of December 1985 is presented in Figure E.2 (Bailey and Wu 1986). A total of 29,174 BNR fuel assemblies and 18,518 RNR fuel assemblies were discharged in the United States by the end of 1985 (DOE 1986). Of the total, only 1,140 BNR and 577 PNR assemblies have been reprocessed at the West Valley facility.

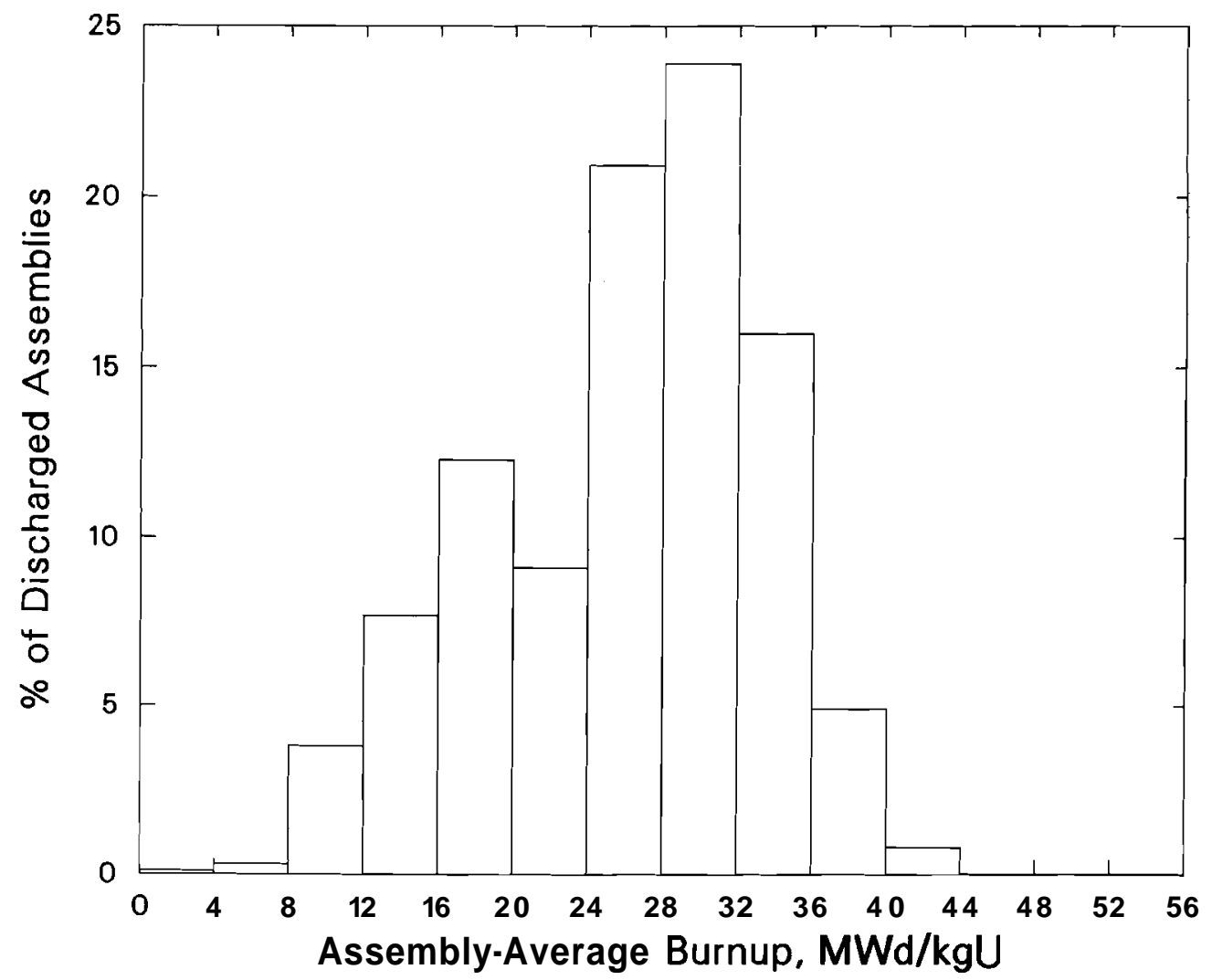

FIGURE E.2. Distribution of Stored Spent Fuel as a Function of Assembly-Average Burnup (as of December 1985; Bailey and W 1986) 


\section{E.2 PRINCIPAL STORAGE SYSTEMS}

The two principal dry storage systems currently being promoted in the United States are metal casks and concrete modules. Other systems under consideration include vaults and dry wells. The discussion that follows provides a brief but not necessarily complete overview of the principal designs that are currently being offered by various nianufacturers.

The CASTOR series of metal casks was initially designed and manufactured in the Federal Republic of Germany (FRG) by Deutsche Gessell schaft fur Wiederaufarbeitung von Kernbrennstoffen mbH (DWK). The CASTOR series casks are made of nodular cast iron and are designed to hold a varying number of spent fuel assemblies: Ia, 4 PNR assemblies; Ib, 4 PWR assemblies; Ic, 16 BNR assemblies; and V/21, 21 PWR assemblies (Spi 1ker and Fleisch 1986; Creer and Schoonen 1986; Fleisch and Peehs 1986). The V/21 cask is supplied by General Nuclear Systems, Inc. (GNSI), a joint-venture of Gessellschaft fur Nuclear Service (GNS) and Chem-Nuclear Systems, Inc. The CASTOR casks are filled with helium and passively cooled by air. The $V / 21$ cask has been used in a testing program conducted by Pacific Northwest Laboratory (PNL) at the Idaho National Engineering Laboratory (INEL) (Creer and Schoonen 1986) and has been 1icensed for dry storage at the Surry plant (Godlewski 1987; Smith, McKay, and Batalo 1986). A licensing action by the U.S. Nuclear Regulatory Commission (NRC) has set the cladding temperature limit for the CASTOR $V / 21$ cask at $370^{\circ} \mathrm{C}$ (Levy et al. 1987). The FRG has set a cladding temperature limit of $400^{\circ} \mathrm{C}$ for the Ic cask in use at the Gorleben facility (Muller 1986).

In the NUTECH Horizontal Modular Storage (NUHOMS) system, spent fuel assemblies are placed in a helium-filled stainless steel canister, which is then horizontally stored in a passively air-cooled concrete module. Each canister and module is designed to store seven PWR assemblies (Massey et al. 1986). This system has been licensed for dry storage at the $H$. B. Robinson plant (Godlewski 1987; Roberts and Sturz 1986). The NRC-licensed maximum cladding temperature is $380^{\circ} \mathrm{C}$ (Massey et al. 1986).

Additional metal casks designs that have been announced but not yet licensed include the following: 
- The TN-24 cask, a forged steel cask, is manufactured by Transnuclear, Inc. (TN) and has several variations. The basic TN-24 cask is designed for 24 PWR assemblies or 52 BNR assemblies; the TN-24P cask is specifically designed for 24 PWR assembles; the TN-BRP cask was designed for transport and storage of 85 Big Rock Point BNR spent fuel assemblies; and the TN-REG cask was designed for transport and storage of 40 R. E. Ginna PRR spent fuel assemblies (Williams and Goldman 1986). Specified cladding temperature limits are $375^{\circ} \mathrm{C}$ for the TN-REG cask and $336^{\circ} \mathrm{C}$ for the TN-BRP cask (Pennington and Teer 1986). An additional $\mathbb{T N}$ cask, the $\mathbb{T N} 1300$, is designed to hold 12 PWR assemblies (Spilker and Fleisch 1986).

- The MSF-IV cask (originally REA 2023) uses a stainless steel outer skin, a lead/stainless steel gamma shield, and a water/glycol neutron shield (Mckinnon et al. 1986a). This cask was originally developed by Ridihalgh, Eggers \& Associates (REA), but the rights to the cask now belong to Mitsubishi Heavy Industries (Godlewski 1987). The cask is designed to hold 52 BWR spent fuel assemblies.

- Westinghouse Electric Corporation has designed a cask designated the MC-10 that will hold 24 PWR assemblies (Godlewski 1987). The primary cask material is forged steel.

- Nuclear Assurance Corporation (NAC) has designed a combination transport/storage cask designated the NAC S100 (Roberts and Sturz 1986). This cask has a capacity of 24 RNR or 60 BNR spent fuel assembli es.

- Combustion Engineering (CE) is proposing two carbon steel casks: the Dry-Cap-P24 to hold 24 PWR assemblies and the Dry-Cap-B60 to hold 60 BNR assemblies (Godlewski 1987; Roberts and Sturz 1986).

- Robatel SLPI of France has designed the RS-24 metal cask (Robatel and Bochard 1986) to handle 24 PNR assemblies with a maximum cladding temperature of $300^{\circ} \mathrm{C}$. The RS-24.1 cask is for transport and storage of spent fuel after 4 years of cooling, and the RS-24.2 cask is for storage of spent fuel after 10 years of cooling. 
Two other dry storage systems have been proposed. One is a modular dry vault system being proposed by the Foster-Wheeler Company and General Electric Company of the United Kingdom (Godlewski 1987; Roberts and Sturz 1986). In this concept, the fuel is placed in metal canisters and stored in concrete vaults. The other system is a nontransportable concrete cask storage system being proposed by Nuclear Packaging (NuPac). The NuPac CP-9 cask will hold 9 RNR assemblies, and the NuPac CB-25 cask will hold 25 BNR assemblies. Variations of each concrete cask will allow either dry or wet transfer (Godlewski 1987). This cask system is based on the Canadian system of storing CANDU fuel.

\section{E.3 STATUS OF LICENSING FOR DRY STORAGE OF LIGHT-WATER REACTOR (LWR) FUEL}

Dry storage facilities are now licensed in both the United States and other countries.

\section{E.3.1 United States}

In 1986, two facilities at commercial U.S. reactor sites were licensed for dry storage of spent fuel in an inert gas atmosphere. These two facilities are at the Surry plant, operated by Virginia Power and Electric Company, and the H. B. Robinson-2 plant, operated by Carolina Power and Light.

The licensed facility at Surry is storing spent fuel in CASTOR-V/21 casks placed vertically on concrete pads (Smith, McKay, and Batalo 1986). The facility was licensed on July 2, 1986, for a period of 20 years (Godlewski 1987). The license allows for three concrete pads with a capacity of 28 casks per pad (84 casks total). The CASTOR-V/21 cask (Creer and Schoonen 1986) has a capacity of 21 RNR assemblies that have been aged (a) for 5 years and has been licensed with a maximum cladding temperature of $370^{\circ} \mathrm{C}$ (Levy et al. 1987). As of December 1986, two casks had been loaded and the first cask was in place on a concrete pad (Godlewski 1987).

The licensed facility at the H. B. Robinson plant uses the NUHOMS concept: a metal spent fuel canister that is stored horizontally within a concrete module. Each metal canister with its concrete module is designed to hold seven

(a) Fuel age refers to the time after the fuel was removed from the reactor. 
RNR assemblies with a maximum cladding temperature of $380^{\circ} \mathrm{C}$ (Massey et al. 1986). The facility was issued a 20-year license on August 13, 1986, for a total of eight modules; three of the modules have been constructed (Godlewski 1987). The fuel to be stored in the facility will have been cooled for 5 years and have a maximum burnup of $35 \mathrm{MWd} / \mathrm{kgU}$.

The CASTOR-V/21 and NUOMS dry storage systems are the only ones that have been issued letters of approval and safety evaluation reports by the NRC (Roberts and Sturz 1986). Other casks under review by the NC include the f ollowing:

- CASTOR-Ic - topical report submitted in 1984 and approved in 1985

- TN-24 (plus variations TN-24P, TN-REG, TN-BRP) - topical report has been submitted on TN-24P

- MSF-IV (REA 2023) - topical report submitted in 1984 by REA; a new topical report submittal by Mitsubishi is expected

- MC-10 - topical report submitted by Westinghouse in 1985; the NRC returned comments to Westinghouse in December 1985

- NAC S100 - topical report submitted by NAC in 1985; NAC returned comments to NAC in October 1985

a Dry-Cap-P24 and Dry-Cap-B60 - topical report submitted by CE in December 1985.

\section{E.3.2 Foreign}

Four foreign facilities have been licensed for dry storage of spent fuel. These facilities are at Gorleben, FRG; Whiteshell Nuclear Research Establishment (WNRE) and the Gentilly-1 reactor site, Canada; and the Swiss Federal Institute for Reactor Research, Switzerland.

The away-from-reactor (AFR) facility at Gorleben wi11 use CASTOR series casks for intermediate storage of spent fuel for a period of 40 years (Einfeld and Popp 1986). This facility has a capacity of 1500 MTU (420 casks) and was licensed by the Physikalisch-Technische Bundesanstalt (Muller 1986). The casks are to be stored inside a building; the building facilitates natural air convection cooling and provides radiation shielding for the surrounding 
environment but does not function as a barrier against the escape of radioactive materials. Spent fuel may be stored after 1 year of aging and with a maximum burnup of $35 \mathrm{MWd} / \mathrm{kgU}$ for $\mathrm{RNR}$ fuel and $33 \mathrm{MWd} / \mathrm{kgU}$ for BAR fuel. A maximum cladding temperature of $400^{\circ} \mathrm{C}$ has been specified (Mu1le r 1986). A second AR facility is planned at nearby Ahaus.

Dry storage of WR-1 spent fuel at WWE began in 1975. In 1985, a WNE canister design was licensed by the Atomic Energy Control Board for the storage of Gentilly-1 spent fuel at the Gentilly-1 site (Patterson and Hoye 1986). The WWE storage concept is based on storage of fuel elements in metal baskets, which are then placed in vertical concrete canisters. The Gentilly-1 fuel that is being stored has a maximum burnup of $4.7 \mathrm{MWd} / \mathrm{kgU}$ and was cooled for 7 years prior to IDS.

Spent fuel from the DIORIT reactor in Switzerland has been licensed for dry storage onsite at the Swiss Federal Institute for Reactor Research (Ospina 1986). The fuel storage cask is a variation of the CASTOR design. Prior to being placed in IDS, the spent fuel, with a maximum burnup of $17.7 \mathrm{MWd} / \mathrm{kgU}$, was cooled for 10 years.

\section{E.4 DRY STORAGE RESEARCH PROGRANS}

The research being performed in support of dry storage of spent fuel may be grouped into the following two general areas:

- behavior of spent fuel during dry storage, with emphasis on demonstrating the acceptability of dry storage - A major objective is specifying the maximum allowable cladding temperature during storage.

This work includes single-rod experiments, fuel assembly experiments, and specialized tests for obtaining data on, for example, creep behavior and resistance to iodine stress corrosion cracking. A summary of experience and a description of the overall status of research targeted for licensing IDS are presented in Section E.4.1. A summary of specified maximum allowable cladding temperatures is presented in Section E.4.2. Comments related to storing spent fuel in air are provided in Section E.4.3. 
- performance analysis of dry storage systems, with the emphasis on evaluating thermal and radioactive shielding performance - A major objective of this work is to provide data for computer code modeling. A principal example of this type of test is provided by Creer and Schoonen (1986), and this type of work was discussed in Section 4.2 .

\section{E.4.1 Summary of Dry Storage Testing Experience}

Experimental programs and long-term storage demonstrations are summarized in Tables E.I and E.2; the data in these two tables are based on Tables 5 and 6 from Johnson and Gilbert (1983). Demonstration tests conducted in the United States on dry storage casks are summarized in Table E.3. In the period since the summaries were originally prepared, a number of the identified programs have continued while a few new programs have been initiated. To date, more than 30,000 fuel rods have been exposed to IDS for periods ranging from days to more than 10 years. Cladding temperatures have ranged from less than $100^{\circ} \mathrm{C}$ to greater than $450^{\circ} \mathrm{C}$. A general summary of the dry storage experience is presented below:

- Work performed in the $\mathrm{RG}$ has been summarized in Peehs and Fleisch (1986); Peehs, Bokelmann, and Fleisch (1986); and Fleisch and Peehs (1986). More than 3000 LWR fuel rods have been used in dry storage tests with cladding temperatures ranging up to $450^{\circ} \mathrm{C}$ and test periods to 30 months; no rod failures have been reported.

- Canadian experience with WR-1 and pressurized heavy water reactor spent fuel placed in dry storage using concrete silos has been summarized by Patterson and Hoye (1986). More than 9000 fuel rods have been stored dry in inert gas. No rod failures have been reported.

- Considerable experience in dry storage of advanced gas reactor (AGR) spent fuel in the United Kingdom has been obtained at the Wylfa magnox power station (Cundi11, Wheeler, and Barrett 1986). Three storage modules containing $2.49 \times 10^{5} \mathrm{kgU}$ spent fuel cooled by $\mathrm{CO}_{2}$ have been operating since 1973 . The maximum operating cladding 
TABLE E1. Laboratory/Hot Cell Tests Involving Zircaloy-Clad Spent Fuel(a)

\begin{tabular}{|c|c|c|c|c|c|}
\hline Country & Site ${ }^{(b)}$ & Cladding & $\begin{array}{c}\text { Temperature, } \\
{ }^{\circ} \mathrm{C}\end{array}$ & №. Rods & Time, days \\
\hline USA & $\mathrm{BCL} / \mathrm{HEDL}$ & Zircaloy-4 & 480 to 570 & 14 & 30 to 320 \\
\hline USA & $\mathrm{BCL} / \mathrm{HEDL}$ & Zircaloy-4 & 325 & 6 & 87 \\
\hline USA & $\mathrm{BCL} / \mathrm{PNL}$ & Zircaloy-4 & 325 & 2 & 87 \\
\hline USA & PNL & Zircaloy-4 & 800 & 3 & 1 to 2 \\
\hline USA & $\begin{array}{l}\text { PR I/ TVA/ } \\
\text { HEDL/ ANL }\end{array}$ & Zircaloy-4 & 250 to 350 & 48 & \\
\hline USA & $\begin{array}{l}\text { NRC/HEDL/ } \\
\text { INEL }\end{array}$ & $\begin{array}{l}\text { Zircaloy-2 } \\
\text { Zircaloy-4 }\end{array}$ & $\begin{array}{l}230 \\
230\end{array}$ & $\begin{array}{l}4 \\
4\end{array}$ & $\begin{array}{l}248 \\
248\end{array}$ \\
\hline Canada & $\mathrm{AECL} / \mathrm{OH}$ & Zircaloy-4 & 220 to 250 & 13 & 30 \\
\hline Canada & $\mathrm{AECL} / \mathrm{OH}$ & Zircaloy-4 & 150 & 16 & 1300 \\
\hline $\mathrm{RRG}$ & HNO & Zircaloy-4 & 100 to 300 & & 550 \\
\hline RG & KNU & Zircaloy-4 & 350 t o 450 & 20 & 40 to 170 \\
\hline $\mathrm{FRG} / \mathrm{Ita} \mid \mathrm{y}$ & Ispra/NUKEM & $\begin{array}{l}\text { Zircaloy-2 } \\
\text { Zircaloy-4 }\end{array}$ & $\begin{aligned} & 400 \\
430 \text { to } & 450\end{aligned}$ & $\begin{array}{l}25 \\
50\end{array}$ & $\begin{array}{r}18 \\
150\end{array}$ \\
\hline FRG & HWU & Zircaloy-4 & 400 & 6 & 180 \\
\hline
\end{tabular}

\footnotetext{
(a) This table was abstracted from Table 5 of Johnson and Gilbert (1983). All tests except the Canadian tests at $150^{\circ} \mathrm{C}$ had some type of surveillance monitoring.

(b) See acronym list for definitions (p. vii).
}

temperature has been $150^{\circ} \mathrm{C}$, though $600^{\circ} \mathrm{C}$ is specified as the limiting temperature. Two additional modules using air as the cooling medium were added in 1980; more than $7.0 \times 10^{5} \mathrm{kgU}$ of spent fuel have been cooled in air with maximum cladding temperatures of $150^{\circ} \mathrm{C}$ since 1983. No fuel rod failures have been reported.

- The IDS experience in the United States has not been fully summarized recently; general overviews are presented in Godlewski (1987) and Roberts and Sturz (1986). Approximately 18,700 LWR fuel rods have 
TABLE E.2. Dry Storage $p^{e m o n s t r a t i o n s ~ I n v o l v i n g ~ Z i r c a l o y-C l a d ~}$ Spent Fuel(a)

\begin{tabular}{|c|c|c|c|c|}
\hline Country & Site ${ }^{(b)}$ & Cladding & No. of Rods & $\begin{array}{c}\text { Temperature, } \\
{ }^{o} \mathrm{C}\end{array}$ \\
\hline USA & EMAD/NTS & Zircaloy-4 & 816 & 170 \\
\hline USA & EMAD/NTS & Zircaloy -4 & 204 & 150 \\
\hline USA & EMAD/NTS & Zircaloy-4 & 2448 & 220 \\
\hline USA & CIimax/NTS & Zircaloy-4 & 2244 & 230 \\
\hline USA & EMAD/NTS & Zircaloy-4 & 202 & 275 \\
\hline Canada & WNE & $\begin{array}{l}\text { Zircaloy/ } \\
2.5 \% \mathrm{Nb}\end{array}$ & $>2484$ & 120 \\
\hline Canada & WNE & Zircaloy-4 & 7921 & 120 \\
\hline FRG & KDO & Zircaloy-4 & 180 & 300 \\
\hline PRG & WDO & Zircaloy -4 & 180 & 400 \\
\hline $\mathrm{FRG}$ & KWW & Zircaloy-2 & 896 & 385 \\
\hline RG & $\begin{array}{l}\text { KKS/ } \\
\text { Karlsruhe }\end{array}$ & Zircaloy -4 & 816 & 430 \\
\hline Sui & EIR & Zircaloy-2 & & 180 \\
\hline
\end{tabular}

(a) This table was abstracted from Table 6 of Johnson and Gilbert (1983). All tests except the Canadian Zircaloy-4 tests had some type of surveillance monitoring. The Swiss test monitored only the cask exterior temperature.

(b) See acronym list for definitions (p. vii).

been used for dry storage testing and demonstrations; in addition, 9450 PNR rods are stored in the first two casks at the Surry independent spent fuel storage installation (ISFSI), and 106 canisters of non-LWR fuel rods have been stored at the Idaho Chemical Processing Plant (Christensen et al. 1986). In general, recent U.S. IDS efforts have concentrated on fuel behavior modeling (Chin, Khan, and Tarn, 1986; Levy et al. 1987) and evaluation of metal cask operating conditions (e.g., Creer and Schoonen 1986). 
Only two fuel rod failures (cladding breach) have been reported during dry storage testing of spent fuel. The first fuel rod failure occurred in Assembly B02 from the Turkey Point reactor during testing at the EMAD facility. (a) This spent fuel assembly was stored in helium at $\angle 150^{\circ} \mathrm{C}$ for 4 years at the EMAD facility. The rod failure occurred during a fuel temperature test at $270^{\circ} \mathrm{C}$ with air as the cover gas (Johnson et al. 1985; 1987). The cause of the rod failure has not been determined; 17 Turkey Point fuel assemblies containing -3500 fuel rods were involved in the EMAD program.

The second fuel rod failure occurred during performance testing of a TN-24P cask (McKinnon et al. 1986b). Based on cask cover gas analysis, one rod apparently developed a small leak during the fourth test series with the fuel in the cask. This horizontal test used helium as the cover gas and followed three vertical tests using varying cover gases. The cask held 24 assemblies containing 4896 fuel rods. The cause of the rod failure is not known, and post-test examination has not yet been performed.

Therefore, as of early 1987, there have been only two known fuel rod failures during dry storage testing and demonstration of $>30,000$ Zircaloy-clad spent fuel rods ( $>18,000$ LWR rods plus spent fuel from CANDU, AGR, and other reactor designs). One of the rods failed during testing in air, so only one rod has failed during dry storage using an inert cover gas.

\section{E.4.2 Specified Maximum Cladding Temperatures}

The major emphasis in many research programs has been the determination of acceptable storage conditions, principally cladding temperature, for dry storage of spent fuel. Cladding temperature during dry storage is of major concern because temperature directly affects internal gas pressure in rods and thus cladding stress. Cladding stress, in turn, is the primary driving force for cladding failure, e.g., creep rupture, stress corrosion cracking, delayed hydride cracking. Though cladding stress is the parameter promoting failure,

(a) Engine Maintenance and Disassembly facility, Nevada Test Site; used for a dry storage demonstration of spent fuel in dry wells. 
temperature is the variable that can be directly controlled. Listed below are the limiting conditions for LWR spent fuel in IDS that have been specified to date:

- a maximum allowable cladding temperature of $380^{\circ} \mathrm{C}$, recommended by Blackburn et al. (1978). This limit was based on an analysis of stress rupture while accounting for a decay temperature history.

- a maximum cladding surface temperature $1 \mathrm{imit}$ of $380^{\circ} \mathrm{C}$, recommended by Johnson and Gilbert (1983). This limit was derived based on research information available at that time.

- a maximum cladding temperature limit of $370^{\circ} \mathrm{C}$ for the CASTOR $\mathrm{V} / 21$ cask, specified by the NRC for the Surry dry storage license (Levy et al. 1987). The $V / 21$ cask is currently licensed for fuel cooled for 5 years, with a maximum initial enrichment of 2.2 wt\% ${ }^{235} U$. The CASTOR Ic cask was assigned a maximum cladding temperature limit of $400^{\circ} \mathrm{C}$ by the NRC (Levy et al. 1987) and RG licensing authorities (Mu1ler 1986).

- a maximum cladding temperature lim it of $380^{\circ} \mathrm{C}$, specified by NUTECH, and licensed by NRC, for the NUHOMS system (Massey et al. 1986). Fuel is to have a maximum burnup of $35 \mathrm{MWd} / \mathrm{kgU}$ and to have been cooled for 5 years.

a a maximum cladding temperature limit of $300^{\circ} \mathrm{C}$, specified by the manufacturer for the RS-24 (Robatel and Bochard 1986)

- manufacturer-specified limits on the TN-24 cask and its derivatives, as follows: $\mathrm{TN}-24,375^{\circ} \mathrm{C}, 35 \mathrm{MWd} / \mathrm{kgU}, 5$ years cooling, $3.7 \% 235 \mathrm{U}$ : TN-REG, $375^{\circ} \mathrm{C}$; and TN-BRP, $336^{\circ} \mathrm{C}$ (Pennington and Teer 1986). Note that the TN-REG and TN-BRP are special design variations of the standard cask (Williams and Goldman 1986).

- a cladding temperature limit of $375^{\circ} \mathrm{C}$ for the proposed U.S. MRS facility (Woods and Unterzuber 1986).

- a variable temperature limit based on the temperature-time history during storage of the spent fuel, internal gas pressures (and 
resulting cladding stress) in the spent fuel, and modeling of failure mechanisms (Levy et a 1. 1987). This model is based on deformation and fracture maps (presented in Section 3.2 and Appendix D) and is presented in more detail in Section 4.

\section{E.4.3 Dry Storage of Spent Fuel Using Air as a Cover Gas}

Though not the topic of this report, dry storage of spent fuel in air is of interest from the standpoint of increased convenience and reduced storage costs. The convenience and cost benefits arise principally from the reduced cask atmosphere monitoring requirements and being able to use a freely available resource for cooling. Monitoring requirements are reduced because the integrity of an inert gas atmosphere does not have to be assured if acceptable conditions for air cooling are defined.

The main issue of concern with dry storage in air is the possible access of the air to the $\mathrm{UO}_{2}$ fuel through a cladding defect and the subsequent oxidation of the fuel. Oxidation of the fuel can lead to swelling, splitting, and possible breakup of the cladding, as well as to the formation of respirable size particles. Cladding degradation and respirable particle formation would result in handling difficulties and risk of radiological exposure. Several studies are under way to define acceptable conditions for storing spent fuel in air (Gilbert and Einziger 1986).

TABLE E.3. Dry Storage Cask Demonstration Tests in the U.S. (Johnson, Gilbert, and Bailey 1987)

\begin{tabular}{lccc}
\multicolumn{1}{c}{ Cask } & \multicolumn{2}{c}{$\begin{array}{c}\text { Maximum C ladding } \\
\text { Temperature, }{ }^{\circ} \mathrm{C}\end{array}$} & Test Period, d \\
\cline { 1 - 1 } MSF-IV (REA-2023) & 250 & & 125 \\
CASTOR V/21 & 350 & 100 \\
TN-24P & 290 & 250 \\
MC-10 & 210 & 125
\end{tabular}




\section{E.5 REFERENCES}

Bailey, W. J., and S. Wu 1986. Fuel Performance Annual Report for 1985. NUREG/CR-3950, Vol. 3, PNL-5210, Pacific Northwest Laboratory, Richland, Washington.

Blackburn, L D, et al. 1978. Maximum Allowable Temperature for Storage of Spent Nuclear Reactor Fuel; An Interim Report. HEDL-TME 78-37. Hanford Engineering Development Laboratory, Richland, Washington.

Chin, B. A, M A Khan, and J. Tarn. 1986. Deformation and Fracture Map Methodology for Predicting Cladding Behavior During Dry Storage. PNL-5998, Pacific Northwest Laboratory, Richland, Washington.

Christensen, A B., et al. 1986. "Lessons Learned During Start-Up of a Facility for Storing Spent LWBR in Dry Wells at the Idaho Chemical Processing Plant." In Proceedings of Third International Spent Fuel Storage Technology Symposium/Workshop, CONF-860417, pp. S-156 to S-174.

Creer, J. M, and D. H Schoonen. 1986. "CASTOR-V/21 RNR Spent Fuel Storage Cask Performance Test." In Proceedings of Third International Spent Fuel Storage Technology Symposi um/Workshop, CONF-860417, pp. S-20 to S-42.

Cundill, B R, D. J. Wheeler, and R. 0. Barrett. 1986. "The Addition of AirCooled Dry Vault Storage Facilities to Operating Nuclear Plants." In Pror ceedings of Third International Spent Fuel Storage Technology Symposium/ Workshop, CONF-860417, pp. P-16 to P-26.

DOE 1980. Proposed Rulemakina on the Storaage and Disposal of Nuclear Waste:; Statement of Position of the United States Department of Energy. DOE/NE-0007, Apri 7 1980, and D0E/NE-0007, Supplement 1, September 1980.

DOE 1986. Spent Fuel Storage Requirements. DOE/RL-86-5, U.S. Department of Energy, Richland Operations Office, Richland, Washington.

Einfeld, K, and F. W. Popp. 1986. "Dry Storage Systems Using Casks for Long Term Storage in an AFR and Repository." In proceedings of Third International Spent Fuel Storage Technology Symposium/Workshop, CONF-860417, pp. S-99 to S-116.

Fleisch, J., and M. Peehs. 1986. "Analysis of Spent Fuel Behavior in Dry Storage Cask Demonstrations in the FRG." In Proceedings of Third International Spent Fuel Storage Technology Symposi um/Workshop, CONF-860417, pp. S-253 to S-262.

Gilbert, E R, and R. E. Einziger. 1986. "Fuel Integrity Morning Workshop Summary on $\mathrm{UO}_{2}$ Oxidation." In Proceedings of Third international Spent Fuel Storage Technology Symposium/Workshop, CONF-860417, pp. W-1 to W-5.

Godlewski, N Z 1987. "Spent-Fuel Storage - An Update." Nuclear News $30(3): 47-52$. 
IAEA. 1982. Storage of Water Reactor Fuel in Water Pools, Survey of World Experience. TRS No. 218, International Atomic Energy Agency, Vienna, Austria.

Johnson, A B, Jr. September 1977. Behavior of Spent Nuclear Fuel in Water Pool Storage. BNWL-2256, Pacific Northwest Laboratory, Richland, Washington.

Johnson, A B, Jr., et al. 1985. "Simulated Dry Storage of a Spent PNR Nuclear Fuel Assembly in Air." In Proceedings of Waste Management '85, Vol. 1, pp. 513-519.

Johnson, A B, Jr., et al. 1987. Assessment of the Integrity of Spent Fuel Assemblies Used in Dry Storage Demonstrations at the Nevada Test Site.

PNL-6207, Pacific Northwest Laboratory, Richland, Washington.

Johnson, A B., Jr., and E R. Gilbert. 1983. Technical Basis for Storage of Zircaloy-Clad Spent Fuel in Inert Gases. PNL-4835, Pacific Northwest Laboratory, Richland, Washington.

Johnson, A B, Jr., E R. Gilbert, and W. J. Bailey. 1987. "Status of Spent Fuel Integrity Studies." PNL-SA-14601, presented at the IMM Spent Fuel Storage Seminar IV, Washington, D.C, January 21 to 23, 1987.

Levy, I- S, et al. 1987. Recommended Temperature Limits for Dry Storage of Spent Light Water Reactor Zircaloy-Clad Fuel Rods in Inert Gas. PNL-6189, Pacific Northwest Laboratory, Richland, Washington.

Massey, J. V., et al. 1986. "Design of a Horizontal Concrete Module and a Dry Shielded Canister for Use in an Irradiated Fuel Storaze System." In Proceedings of Third International Spent Fuel Storage Technology Symposium/ Workshop, CONF-860417, pp. P-99 to P-120.

Mckinnon, M A, et al. 1986a. "REA-2023 BAR Cask Performance Test." In Proceedings of Third International Spent Fuel Storage Technology Symposium/ Workshop, CONF-860417, pp. S-45 to S-60.

Mckinnon, M A et al. 1986b. TN-24P PNR Spent Fuel Storage Cask Performance Testing and Analyses. EPRI NP-5128, Electric Power Research Institute, Pa10 Alto, Calitornia

Muller, A 1986. "Safety-Related Aspects of Interim Dry Storage in the Scope of Atomic Licensing Procedures." In Proceedings of Third International Spent Fuel Storage Technology Symposi um/Workshop, CONF-860417, pp. S-118 to S-135.

Ospina, C. 1986. "Dry Storage Cask - DIORIT - Swiss Experience." In Proceedings of Third International Spent Fuel Storage Technology Symposium/ Workshop, CONF-860417, pp. P-128 to P-134. 
Patterson, D. W, and D. S Hoye. 1986. "Canadian Experience Storing Irradiated CANDU Fuel in Concrete Canisters." In Proceedings of Third International Spent Fuel Storage Technol ogy Symposium/Workshop, CONF-860417, pp. S-136 to S-155.

Peehs, M., and J. Fleisch. 1986. "LWR Spent Fuel Storage Behavior." J. Nucl. Mat. $137: 190-202$.

Peehs, M., R. Bokelmann, and J. Fleisch. 1986. "Spent Fuel Dry Storage Performance in Inert Atmosphere." In Proceedings of Third International Spent Fuel Storage Technol ogy Symposi um/Workshop, CONF-860417, pp. S-215 to S-229.

Pennington, C. W., and B. R. Teer. 1986. "Dry Storage Technology from Transnuclear." In Proceedings of Third International Spent Fuel Storage Technol ogy Symposi um/Workshop, CONF-860417, pp. P-91 to P-98.

Robatel, M., and C. Bochard. 1986. "Robatel RS 24 packaging.". in Proceeaings of Third International Spent Fuel Storage Technol ogy Symposi um/Workshop, CONF-860417, pp. P-121 to P-127.

Roberts, J. P, and F. C. Sturz. 1986. "Progress in Dry Spent Fuel Storage Licensing and Rulemaking." In Proceedings of Third International Spent Fuel Storage Technology Symposi um/Workshop, CONF-860417, pp. S-204 to S-212.

Smith, M. L, H. S McKay, and D. P. Batalo. 1986. "Spent Fuel Storage Activities at the Surry Power Station." In Proceedings of Third International Spent Fuel Storage Technology Symposium/Workshop, CoNF-860417, pp. S-175 to S-184.

Spilker, H., and J. Fleisch. 1986. "Dry Storage Demonstrations of CASTOR I and TN-1300 Casks." In Proceedings of Third International Spent Fuel Storage Technol ogy Symposi um/Workshop, CONF-860417, pp. S-1 to S-18.

Williams, F. J., Jr., and K. Goldman. 1986. "Transport/Storage of NFS Spent Fuel in TN-BRP and TN-REG Casks." In Proceedings of Third International Spent Fuel Storage Technology Symposium/Workshop, CONF-860417, pp. S-61 to S-75.

Woods, W. D., and R. Unterzuber. 1986. "Monitored Retrievable Storage (MRS) Facility Surge Storage Systems." In Proceedings of Third International Spent Fuel Storage Technology Symposium/Workshop, CONF-860417, pp. S-185 to S-202. 


\section{DISTRIBUTION}

No. of

Copies

\section{OFFSITE}

30

DOE Technical Information Center

H. J. Hale

Office of Civilian Radioactive Waste Management

U.S. Department of Energy

RW-30

Washington, D 20545

\section{J. Epstein}

Office of Civilian Radioactive Waste Management

U.S. Department of Energy

Washington, DC 20545

K. A Klein

Office of Civilian Radioactive Waste Management

U.S. Department of Energy

RW-30

Washington, 20545

D. E. Shelor

Office of Civilian Radioactive Waste Management

U.S. Department of Energy

RW-32

Washington, DC 20545

W. Stringfield

Office of Civilian Radioactive Waste Management

U.S. Department of Energy

RW-32

Washington, $\mathbb{C} 20545$

L. Barrett

Office of Civilian Radioactive Waste Management

U.S. Department of Energy

RW-33

Washington, $\mathbb{C} 20545$
No. of

Copies

C. W. Conner

Office of Civilian Radioactive

Waste Management

U.S. Department of Energy

RW-33

Washington, \& 20545

J. S. Finucane

Energy Information Administration

U.S. Department of Energy

EI-53

Washington, $\mathbb{C} 20545$

C. J. Dankowski

U.S. Department of Energy Defense Programs

San Francisco Operations Office

1333 Broadway

Oakland, CA 94612

M. Fisher

U.S. Department of Energy Idaho Operations Office 550 Second Street

Idaho Falls, ID 83401

K. G. Golliher

U.S. Department of Energy

P.O. Box 5400

Albuquerque Operations Office

Albuquerque, NM 87115

H. Steinberg

U.S. Department of Energy

Office of Storage and

Transportation Systems

RW-33

1000 Independence

Washington, C 20585 
No. of

Copies

S Mann

U.S. Department of Energy

Chicago Operations Office

Argonne, IL 60439

M Kunich

U.S. Department of Energy

P.O. Box 14100

Nevada Operations Office

Las Vegas, N 89114.

C. Matthews

U.S. Department of Energy

Oak Ridge Operations Office

P.O. Box E

Oak Ridge, TN 37830

B A Chin

Auburn University

Mechanical Engineering Dept.

247 Wilmore Laboratories

Auburn, AL 36830

L. A Walton

Babcock \& Wilcox Co.

P.O. Box 10935

Lynchburg, VA 24506-0935

P. A File

Baltimore Gas and Electric Co.

Calvert Cliffs Nuclear Power Plant

Lusby, MO 20657

J. A Carr

Battel le Project Management Division

Office of Nuclear

Waste Isolation

505 King Avenue

Columbus, OH 43201

R. Kohli

Battelle Columbus Division

505 King Avenue

Columbus, 아 43201
No. of

Copies

V. Pasupathi

Battell e Columbus Division

505 King Avenue

Columbus, $\mathrm{OH} 43201$

5 T. W. Wood

Battelle Memorial Institute

Washington Operations

2030 M Street-NW

Suite 800

Washington, D 20036

G A Townes

BE Inc.

P.O. Box 145

New El lenton, SC 29809

R. L Hails

Bechtel Power Corporation

15740 Shady Grove Rd.

Gaithersburg, MD 20760

D. R. Olander

University of Cal ifornia

647 San Fernando Avenue

Berkeley, CA 94707

R. Kunita

Carolina Power \& Light Co.

411 Fayetteville St.

P.O. Box 1551

Raleigh, NC 27602

L. Martin

Carolina Power \& Light Co.

411 Fayetteville St.

P.O. Box 1551

Raleigh, NC 27602

G. C. Jobson

Chem-Nucl ear Systems, Inc.

One Greystone West Building

240 Stoneridge Drive, Suite 100

Columbia, SC 29210 
No. of

Copies

C. K. Anderson

Combustion Engineering, Inc.

GE Power Systems

1000 Prospect Hill Road

Windsor, CT 06095

N. Fuhrman

Combustion Engineering, Inc.

C-E Power Systems

1000 Prospect Hill Road

Windsor, CT 06095

R. L. Moscardini

Combustion Engineering, Inc.

1000 Prospect Hill Road

Windsor, CT 06095

G. P. Wagner

Commonwealth Edison

Nuclear Stations Division

P.O. Box 767

Chicago, IL 60690

T. J. Marz

Consumers Power Company

1945 W. Parnall Road

Jackson, MI 49201

S. J. Raffety

Dai ryland Power Coop.

2615 E. Ave. S.

Lacrosse, WI 54601

R. W. Rasmussen

Duke Power Company

P.O. Box 33189

Charlotte, N 28242

Ebasco Services, Inc.

Two World Trade Center

New York, NY 10098

R. Stanford

Edison Electric Institute

1111 19th St., NW

Washington, DC 20036
No. of

Copies

M. J. Jènsen

EG\&G Idaho, Inc.

P.O. Box 1625

Idaho Falls, ID 83415

R. F. Williams

Electric Power Research Institute

P.O. Box 10412

Palo Alto, CA 94304

R. W. Lambert

Electric Power Research Institute

P.O. Box 10412

Palo Alto, CA 94304

G. T. Zamry

Florida Power \& Light Co.

9250 W. Flagler St.

Miami, FL 33174

FLUOR Engineers, Inc.

Advanced Technology Division P.O. Box C-11944

Santa Ana, CA 92711-1944

B. K. Agarwal

FN Energy Applications, Inc.

110 Orange Avenue

Livingston, NJ 07039

E. E. Voiland

General Electric Co.

Morris Operation

Morris, IL 60450

W. L. Dobson

Gilbert Associates, Inc.

P.O. Box 1498

Reading, PA 19603

V. J. Barnhart

GNSI

135 Darling Dr.

Avon, CT 06001 
No. of

Copies

B. Handly

Houston Lighting \& Power Co.

Nuclear Fuels-SPII

12301 Kurland Dr.

Houston, TX 77034

E. R. Johnson

11702 Bowman Green Drive

Reston, VA 22090

J. A. McBride

E. R. Johnson Associates, Inc.

11702 Bowman Green Drive

Reston, VA 22090

L. M. Trosten

LeBoeuf, Lamb, Leiby, \& MacRae 1333 New Hampshire Ave. NW

Washington, XC 20036

L. D. Ramspott

Lawrence Livermore National Laboratory

P.O. Box 808

Mail Stop L404

Livermore, CA 94550

V. M. Oversby

Waste Package Task, NNWSI

Lawrence Livermore National Laboratory

P.O. Box 808

L206

Livermore, CA 94550

H. Shaw

Waste Package Task, NNWSI

Lawrence Livermore National Laboratory

P.O. Box 808

L206

Livermore, CA 94550
No. of

Copies

M. Schwartz

Lawrence Livermore National Laboratory

P.O. Box 808

Mai 1stop L197

Livermore, CA 94550

L. B. Ballou

Lawrence Livermore National Laboratory

P.O. Box 808

Livermore, CA 94550

C. F. Smith

Lawrence Livermore National Laboratory

P.O. Box 808

Livermore, CA 94550

J. H. Garrity

Maine Yankee Atomic Power Co.

Edison Drive

August, ME 04336

G. D. Whittier

Maine Yankee Atomic Power Co.

Edison Drive

Augusta, ME 04336

R. Whale

Michigan Public Service

Commis sion

6545 Mercantile Way

Lansing, M I 48909

R. Calabro

Northeast Utilities Service Co.

P.O. Box 270

Hartford, CT 06101

R. Isakson

Northeast Utilities Service Co.

P.O. Box 270

Hartford, CT 06101 
No. of

Copies

E. Krinick

Northeast Utilities Service Co.

P.O. Box 270

Hartford, CT 06101

J. Houston

Nuclear Assurance Corp.

5720 Peach Tree Parkway

Norcross, GA 30092

J. M. Viebrock

Nuclear Assurance Corp.

5720 Peachtree Parkway

Norcross, GA 30092

J. Clark

Nuclear Fuel Services

6000 Executive Blvd.

Rockville, MD 20852

R. T. Haelsig

Nuclear Packaging Inc.

1010 S. 336th St.

Federal Way, 98003

B. Lehnert

NUTECH Engineers

145 Martinvale Lane

San Jose, CA 95119

G. J. Antonucci

NUS Corporation

910 Clopper Rd.

Gathersburg, MD 20878

J. V. Massey

Reedy \& Associates

103 Albright Way

Los Gatos, CA 95030

J. Van Cleve

Oak Ridge National Laboratory

P.O. Box $X$

Oak Ridge, $\mathbb{T N} 37831$
No. of

Copies

M. Litterman

Portland General Electric, Trojan Fuel

121 S.W. Salmon St.

Portland, OR 97204

D. Woods

Ralph M. Parsons Co.

700 West Walnut Street

Pasadena, CA 91124

G. C. Allen

Sandia National Laboratory

Division 6323

Transportation Technology Center

P.O. Box 5800

Albuquerque, NM 87185

J. F. Ney

Sandia National Laboratory

Division 6323

Transportation Technology Center

P.O. Box 5800

Albuquerque, M 87185

T. L. Sanders

Sandia National Laboratory

P.O. Box 5800

Albuquerque, M 87185

E. Kuhns

Stone and Webster Engineering Corp.

1 Penn Plaza

250 W. 34th St.

New York, NY 10119

L. J. Jardine

Bechtel National Inc.

P.O. Box 3965

San Francisco, CA 94119

E. Gordon

Transnuclear, Inc.

507 Newmark Esplanade

Rockville, MD 20850 
No. of

Copies

J. Mangusi

Transuclear, Inc.

$1 \mathrm{~N}$. Broadway

White Plains, NY 10601

B. R. Teer

Transnuclear, Inc.

$1 \mathrm{~N}$. Broadway

White Plain, NY 10601

C. E. King

Uranium Mgt. Corp.

175 Curtner Avenue

MC620

San Jose, CA 92525

N. H. Davison

U.S. Nuclear Regulatory Commission

Office of Nuclear Materials Safety and Safeguards

Washington, \& 20555

TRW, Exploration/Pro

P.O. Box 441807

Houston, TX 77244-1807

R. J. Mullin

Tennessee Valley Authority

1101 Market St.

BR6N Space 40A

Chattanooga, TN 37402

C. Feldman

U.S. Nuclear Regulatory Commission

Office of Nuclear Regulatory Research

Washington, DC 20555

J. Roberts

U.S. Nuclear Regulatory Commission

Office of Nuclear Materials Safety and Safeguards

Washington, D 20555
No. of

Copies

L. C. Rouse

U.S. Nuclear Regulatory Commission

Spent Fuel Storage Installation

Division of Fuel Cycle and Materia1 Safety

Washington, $\mathbb{C} 20555$

C. H. Peterson

U.S. Nuclear Regulatory Commission

Office of Nuclear Materials

Safety and Safeguards

Mai 1stop 623-SS

Washington, $\mathbb{C} 20555$

S. P. Turel

U.S. Nuclear Regulatory Commission

Office of Nuclear Regulatory Research

Washington, $\mathbb{C} 20555$

W. J. Wachter

U.S. Tool and Die, Inc.

4030 Route 8

Allison Park, PA 15101

G. E. Lucas

University of California

Dept. of Chemical and Nuclear Engineering

Santa Barbara, CA 93106

J. A. Nevshema 1

Toledo Edison Co.

2155 Kathy Lane

Genoa, OH 43430

E. S. Bassler

Westinghouse Electric Corp.

Box 2728

Pittsburgh, PA 15230 
No. of

Copies

A. R. Hakl

Westinghouse Electric Corp.

Waste Technology Services Div.

P.O. Box 10864

Pittsburgh, PA 15236

C. F. Davis

Westinghouse Electric Corp.

Waste Technology Services Div.

P.O. Box 10864

Pittsburgh, PA 15236

A. Sawatzky

Sawatzky Consultants

Box 137

Pinawa, Manitoba

Canada ROE 1 LO

N. Dayem

R. F. Weston Co.

955 L Enfant Plaza \$V 8th Floor

Washington, DC 20024-2119

E. Benz

R. F. Weston Co.

955 L Enfant Plaza \$V 8th Floor

Washington, $\mathbb{C}$ 20024-2119

ONSITE

5 DOE Richland Operations Office
J. P. Collins
D. E. Crouter
M. S. Karol
0. L. Olson
J. J. Sutey

3 Westinghouse Hanford Company
M. B. Arndt
C. L. Brown
G. T. Harper

No. of

$\underline{\text { Copies }}$

68 Pacific Northwest Laboratory

R. T. Allemann

M. J. Apted

W. J. Bailey

J. 0. Barner

G. H Beeman

C. E. Beyer

D. J. Bradley

J. L. Braitman

T. K Campbell

T. D. Chikalla

J. M. Creer (5)

M. E. Cunningham

D. G. Doran

S. K Edler

R. E. Einziger

M. D. Freshley

E. R. Gilbert (20)

R. J. Guenther

R. F. Hazelton

C. M. Heeb

R. E. Heineman

A. B. Johnson, Jr.

R. W. Knoll

M. R. Kreiter

L. T. Lakey

D. D. Lanning

I - S. Levy

J. L. McElroy

M. A. McKinnon

G. L. McVay

L. G. Morgan

L. J. Parchen

J.T.A. Roberts

E P. Simonen

R. I - Smith

J. L. Straalsund

C. A. Thornhill

B. J. Wrona

Publishing Coordination (2)

Technical Report Files (5) 